Florida International University FIU Digital Commons

$11-10-2016$

\title{
Risk-Based Decision Making Support for Construction Corporate Resource Management
}

\author{
Reza Sheykhi \\ Florida International University, rsheykhi@gmail.com
}

DOI: $10.25148 /$ etd.FIDC001258

Follow this and additional works at: https:// digitalcommons.fiu.edu/etd

Part of the Civil Engineering Commons, and the Construction Engineering and Management Commons

\section{Recommended Citation}

Sheykhi, Reza, "Risk-Based Decision Making Support for Construction Corporate Resource Management" (2016). FIU Electronic Theses and Dissertations. 3039.

https://digitalcommons.fiu.edu/etd/3039 


\section{FLORIDA INTERNATIONAL UNIVERSITY}

Miami, Florida

\section{RISK-BASED DECISION MAKING SUPPORT FOR CONSTRUCTION CORPORATE RESOURCE MANAGEMENT}

A dissertation submitted in partial fulfillment of

the requirements for the degree of

DOCTOR OF PHILOSOPHY

in

CIVIL ENGINEERING

by

Reza Sheykhi

2016 
To: $\quad$ Interim Dean Ranu Jung

College of Engineering and Computing

This dissertation, written by Reza Sheykhi, and entitled Risk-Based Decision Making Support for Construction Corporate Resource Management, having been approved in respect to style and intellectual content, is referred to you for judgment.

We have read this dissertation and recommend that it be approved.

$\begin{array}{r}\hline \text { Arindam G. Chowdhury } \\ \hline \text { Michael Bienvenu } \\ \hline \text { Xia Jin, Co-Major Professor } \\ \hline \text { Wallied Orabi, Co-Major Professor }\end{array}$

Date of Defense: November 10, 2016

The dissertation of Reza Sheykhi is approved.

Interim Dean Ranu Jung College of Engineering and Computing

Andrés G. Gil

Vice President for Research and Economic Development

And Dean of the University Graduate School

Florida International University, 2016 
(C) Copyright 2016 by Reza Sheykhi

All rights reserved. 


\section{DEDICATION}

To my mother, Tayyebeh, and my father, Mohammad, who are my greatest lifelong teachers and supporters. Without doubt, their unconditional love was the most important key to all my achievements.

To my beloved brother, Amin, who has been my closest friend since he was born. I am blessed to have him in my life, and truly grateful for his support and friendship. 


\section{ACKNOWLEDGMENTS}

I want to thank the members of my committee for their support through my studies. I would like to extend my most sincere thanks to my major professor, Dr. Wallied Orabi, who has been my adviser, mentor, and older brother since I started my doctoral studies. Dr. Orabi has been always encouraging and supporting during development of this research, and I believe that I have become a more knowledgeable researcher and more dependable individual working with him. I want to thank all my friends for their support, motivation, and patience through all these years. I would also like to thank all faculty and staff of FIU Department of Civil and Environmental Engineering and FIU School of Construction for providing me with this great opportunity. 


\author{
ABSTRACT OF THE DISSERTATION \\ RISK-BASED DECISION MAKING SUPPORT FOR \\ CONSTRUCTION CORPORATE RESOURCE MANAGEMENT \\ by \\ Reza Sheykhi
}

Florida International University, 2016

Miami, Florida

\title{
Professor Wallied Orabi, Co-Major Professor \\ Professor Xia Jin, Co-Major Professor
}

Competitive bidding typically challenges contractors to stay in business by reducing contingency and limiting profit margin, which imposes more prudent resource utilization and allocation decisions during both planning and construction phases of projects. Many of these decisions must be made considering uncertainties that affect resource production and construction performance through several factors such as weather, managerial practices, job-type, and market conditions, etc. Construction decision makers will therefore have varied approaches to deal with these uncertainties based on their risk utility or perception. This research presents the development of a model for investigating the impact of risk-based approaches on construction network outcomes. The current study contributes to development of a model that enables corporate managers to understand the impact of different resource utilization and sharing policies on the overall outcome of their 
project and to select among optimum planning solutions that satisfy their profit margin and capital limitations. This research also enables corporate decision makers to have more realistic estimates for the profitability of their company, and understand consequences of their decisions in short and long term. Findings of this research provide decision makers with different solutions for profitability of their corporation based on non-dominated optimal time-cost tradeoffs, and also broader perspective on how overall time and budget limitations, as well as risk perceptions, can affect the decision-making process. The model is verified and the results are validated through acquiring data from actual large scale construction projects in South Florida. 


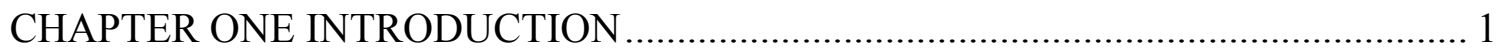

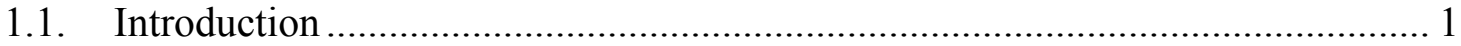

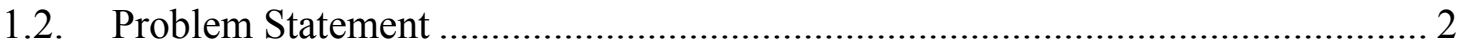

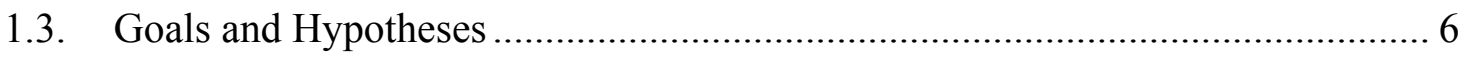

1.4. Method and Design ............................................................................... 9

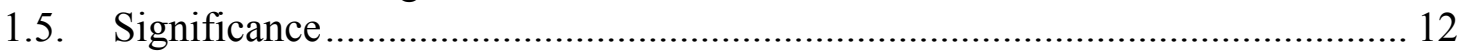

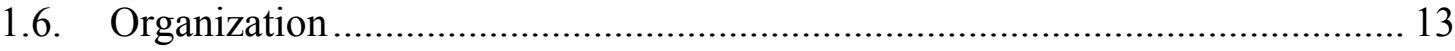

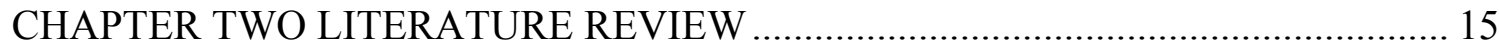

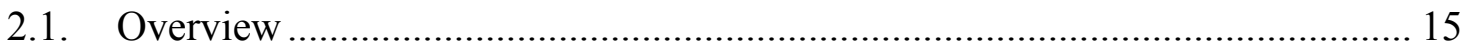

2.2. Resource Utilization Under Uncertainty .................................................... 15

2.3. Multi-Project Resource Planning Under Uncertainty ....................................... 17

2.4. Corporate Level Resource and Profitability Management................................. 20

CHAPTER THREE RESOURCE UTILIZATION AND UNCERTAINTY ................... 23

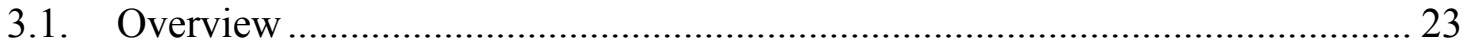

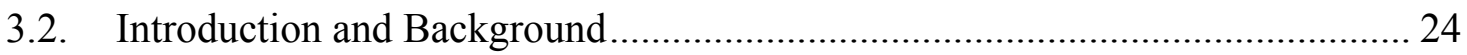

3.3. Methodology: Productivity Simulation Model (PSM) ………………............. 26

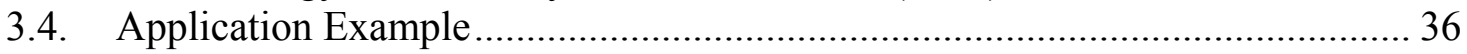

3.5. Conclusions and Recommendations for Future Research................................. 38

CHAPTER THREE RISK-BASED RESOURCE PLANNING TOWARD

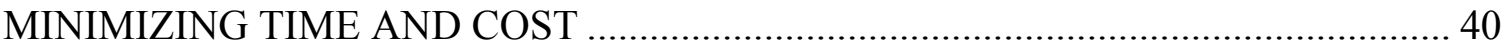

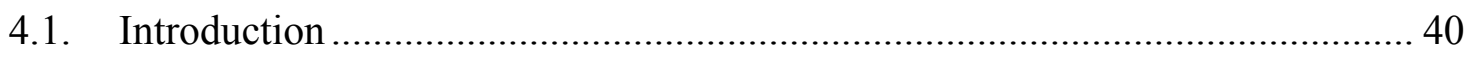

4.2. Stochastic Simulation of the Portfolio Network ............................................. 44

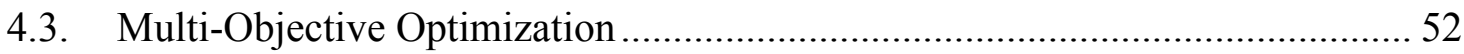

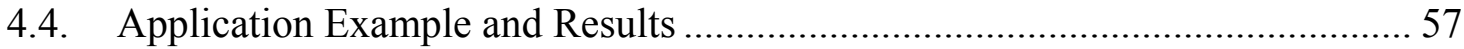

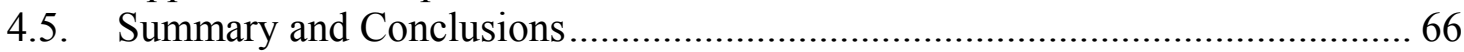


CHAPTER FIVE RISK-BASED DECISION MAKING ON CORPORATE

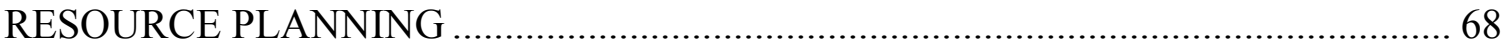

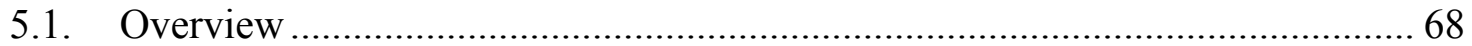

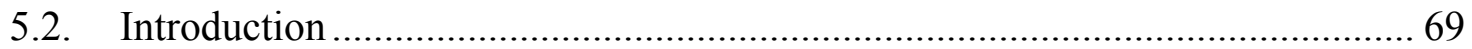

5.3. Stochastic Simulation Module …................................................................. 71

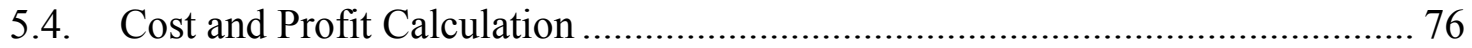

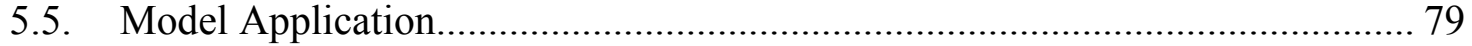

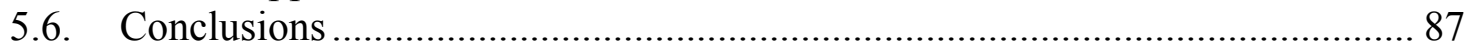

CHAPTER SIX CONCLUSIONS AND FUTURE RESEARCH................................ 89

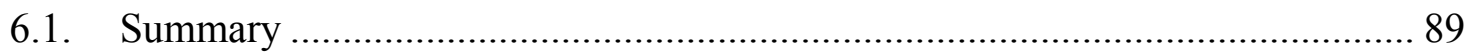

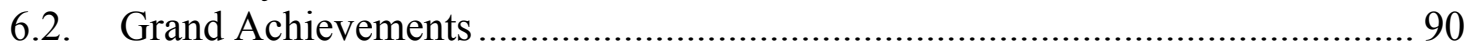

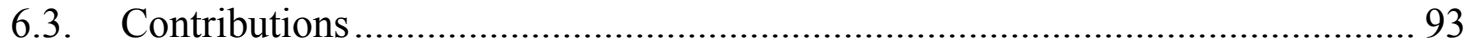

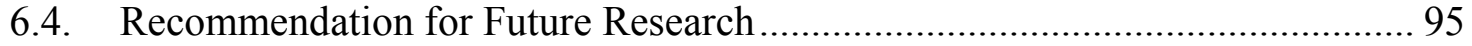

REFERENCES AND FURTHER READINGS ...................................................... 98

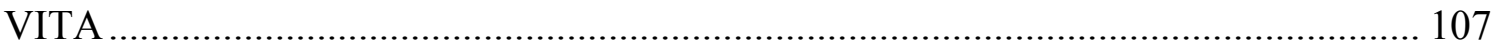




\section{TABLE OF TABLES}

TABLE

PAGE

Table 3.1 Application example project and resource data 36

Table 4.1 Risk attitudes and corresponding probabilities 56

Table 4.2 Crew productivity distributions, cost and availability data 58

Table 4.3 Project scheduling, resource requirements and indirect cost data 59

$\begin{array}{lll}\text { Table } 4.4 & \text { Overtime policy alternatives } & 60\end{array}$

Table 4.5 Resource planning sample clusters and solutions 64

$\begin{array}{lll}\text { Table 5.1 Overtime policy alternatives } & 73\end{array}$

$\begin{array}{lll}\text { Table 5.2 Risk utilities and corresponding probabilities } & 78\end{array}$ 


\section{TABLE OF FIGURES}

FIGURE

PAGE

Figure 3.1 Productivity Simulation Model (PSM)

Figure 3.2 Flowchart for the Monte Carlo simulation procedure

Figure 3.3 Construction cost calculation at different resource utilization levels

Figure 3.4 Duration and cost distribution curves at project and portfolio levels

Figure 4.1 General components and overall flow of the model

Figure 4.2 Analysis levels and general flow of the simulation module

Figure 4.3 Activity level analysis from the simulation module

Figure 4.4 Optimization module general flow and components

Figure 4.5 Extracting portfolio duration and cost from stochastic simulation outputs (distributions) based on pre-defined confidence levels

Figure 4.6 Portfolio Time-Cost tradeoff

Figure 4.7 Optimal resource planning clusters with sample solutions from risk-averse attitude

Figure 4.8 Portfolio time-cost tradeoff in sample clusters

Figure 4.9 Portfolio time-cost tradeoff in sample clusters 
$\begin{array}{lll}\text { Figure 5.1 Flowchart of the simulation module } & 74\end{array}$

$\begin{array}{lll}\text { Figure 5.2 Multi-Objective optimization module } & 77\end{array}$

$\begin{array}{lll}\text { Figure 5.3 Explanation of risk utility } & 79\end{array}$

$\begin{array}{lll}\text { Figure 5.4 Application example results } & 81\end{array}$

Figure 5.5 Time-Cost under different resource utilization plans $\quad 81$

Figure 5.6 Time-Cost under different resource utilization plans and risk $\quad 82$ perceptions

Figure 5.7 Time-Cost under different resource sharing priorities and risk $\quad 83$ perceptions considering regular working hours

Figure 5.8 Time-Cost under different resource sharing priorities and risk $\quad 83$ perceptions considering extra working hours

Figure 5.9 Time-Cost under different resource sharing priorities and risk $\quad 84$ perceptions considering added night shifts

Figure 5.10 Resource management solutions and their profit-cash tradeoff $\quad 85$

Figure 5.11 Resource management solutions and their profit-cash tradeoff for 85 6,12 and 18 month periods

Figure 5.12 Resource management solutions and their profit-cash tradeoff for various resource sharing priorities

Figure 5.13 Resource management solutions and their profit-cash tradeoff in case of expanding network with a new project 


\section{CHAPTER ONE}

\section{INTRODUCTION}

\subsection{Introduction}

Project objectives, as the most appropriate criteria for success (De Wit 1988), may be achieved as effective as possible through continuous replanning and rescheduling of projects (Castro-Lacouture et al. 2009); Therefore, success is, a fortiori, dependent on decisions made during both planning and construction phases of projects. There is a rich body of literature that addresses construction decision making for resource planning, yet the industry is reported to face a consistent challenge with failure in achieving project goals, especially planned time and cost (Shrestha et al. 2013). Globally, large construction projects resulted in an average cost overrun of $\% 28$ without reduction in the last 70 years (Flyvbjerg et al. 2002; Flyvbjerg et al. 2003). In the recent years, 10\% of infrastructure project are shown to end up with over 10\% cost overrun (Queensland DMR 2005), and as reported, only $5 \%$ of large industrial projects meet both their authorized cost and schedule within an acceptable margin (Construction Industry Institute (CII) 2012).

To address this issue, various studies have been conducted in order to improve construction planning toward avoiding overruns and maintaining profitability (Elazouni and Abido 
2014), as well as wining new projects and staying competitive (Han et al. 2005; Aziz 2013). Many of these efforts focused on analyzing alternative resource utilization decisions due to the significant impact on construction operations (Ozcan-Deniz et al. 2011). However, uncertainties as well as imprecision, still highly affect construction decision-making practices, regardless of managers experience and knowledge in planning and execution (Castro-Lacouture et al. 2009). To cope with the impact of uncertainties on planning outcomes probabilistic aspects of construction operations has been frequently considered, and the use of risk-based approaches in projects is reported to be increasing (Touran 2009). In this context, making decision under uncertainty is noted to require contractors to raise awareness regarding their own tendency toward risk (i.e. risk utility) (Kim and Reinschmidt 2010), since for instance, highly unrealistic expectations in planning decisions have been found to affect performance and efficiency of construction (Park et al. 2010).

As a result, new research in the area of supporting risk-based decision making for planning and management of construction projects becomes of paramount importance. The proposed study, therefore, aims to improve construction planning through addressing significance of incorporating managerial risk utilities in to decision making for resource planning under uncertainty.

\subsection{Problem Statement}

To properly investigate the impact of risk utilities, it is required to first understand how uncertainties affect construction performance. Applying uncertainties to resource utilization plan has been proved to affect project completion outcomes (e.g. duration and cost). As an example, modeling the efficiency and/or continuousness of resource 
utilization for weather-sensitive activities has shown to output a wide range of project durations, when repeated in presence of stochastic weather conditions (Shahin et al. 2010; Lee et al. 2009). Similarly, many studies suggested major cost variations in construction when efficiency and performance are probabilistically modeled (Heravi and Faeghi 2012). On the other hand, understanding impact of contingencies on different levels of construction seems inevitable in order to accurately investigate the impact of managerial risk utilities on planning decisions.

To this end, existing literature have modeled uncertainties in different resource planning levels. Limited number of researches studied impact of uncertainties on daily-level basis (Orabi et al. 2013; Chen et al. 2012), while most of the studies in this area have focused on activity/process level. Among those are various models considering parameters such as activity duration (Ökmen and Öztaş 2008; Lee 2005; Hong et al. 2011; Lee and Arditi 2006), activity cost (Taghaddos et al. 2011) or both (Isidore and Back 2002; Feng et al. 2000). Some others modeled uncertainties at project level, where for instance, project cost is studied as a probabilistic parameter (Gabriel et al. 2006). Few researchers have also developed models to analyze allocation and sharing of limited resources at the portfolio level (Barraza 2010). To address the importance of portfolio-level planning and analysis, it should be noted that more than $80 \%$ of firms operate multiple parallel projects (Lova and Tormos 2001), and over $90 \%$ of all construction projects are accomplished in a multiproject environment, worldwide (Payne 1995). Therefore, planners need to obtain a broad perspective on applicable and potential planning solutions that may lead to higher chance of achieving corporate-level objectives. This would be possible through decision making 
toward reducing contingency and limiting profit margin, which imposes more prudent resource utilization and allocation decisions.

In many cases, contractors sacrifice profit in order to ensure staying in the market (Love et al. 2010), where, for instance, nearly $40 \%$ of industrial EPC projects struggle to even generate profit (Construction Industry Institute (CII) 2014). To support proper decisions, many efforts have been made in the area of planning a group of project and decision making for maximizing profit (Aziz 2013; Ahn et al. 2012; Liu and Wang 2010; Senouci and ElRayes 2009). In this context, it is required to investigate the impact of risk-based resources planning under uncertainty for both ongoing and new projects in a group of concurrent projects, and support construction decision makers on corporate-level resource planning according to their risk utility.

Three main research gaps can be identified within the existing literature. Uncertainties are claimed to frequently affect resource on a daily basis. However, there is lack of research studies that accurately model contingencies affecting outcome of the resource utilization planning of construction under uncertainties. In addition, consideration of resource planning for a group of projects seems required for an improved and realistic decision making regarding properly prioritizing projects for sharing resources under uncertainty. Finally, there is a need for new research to investigate impact of risk perceptions on decision making for resource management at corporate level. Accordingly, new research studies in the area of risk-based decision making on resource planning are needed, especially regarding concurrent construction projects. The proposed research, therefore, presents the development of a new simulation-optimization model to cover the identified 
research gaps and consequently facilitate the investigation of risk utility on planning objectives.

There are three levels of decision making in construction environment. First, decisions with regards to resource utilization planning under uncertainty which are made by project managers. Second, decisions with regards to resource sharing priorities throughout the network of projects, which are made by corporate managers. Finally, decisions regarding general direction of the company and whether or not expanding their network by going for new bids, which is made by corporate managers based on provided information from above mentioned situations. Making decisions at each level requires supporting decision materials specifically prepared for that level.

At resource utilization planning level, improper perspective of construction managers leads to failure in making reasonable decisions regarding execution of work task and activities. Improving decision at this level will be through consideration of impact of risk factors and uncertainties on performance and efficiency of resources and eventually performance and efficiency of executed work. At resource allocation level, projects managers are supposed to make decision about properly sharing their resources among network in order to maintain project time and cost within acceptable margin. This decision is often affected by their perspective and awareness about resource limits and stage of projects, types of uncertainties that impact their project, and their confidence on performance of project resources (crew, equipment, etc.) under uncertainty. At resource sharing (corporate) level, decisions are mainly about how to efficiently share resources among portfolio of projects. Mentioned resources at this level include crew/equipment as well as financial resources 
(cash, credit, bonds, etc.). Making proper decisions at this level requires broad perspective on outcome of every and each project in the network, as well as reliability of the planned outcomes under uncertainties that affect construction. At the following section, objectives of this research regarding supporting mentioned decisions at each level are explained.

\subsection{Goals and Hypotheses}

The main goal of this research is to improve decision making process in different construction management levels under uncertainties and risk related factors. Eventually all these decisions will contribute to a higher performance in execution, better project outcomes and finally improved leadership decision making at enterprise level in order to bring company to a higher profitability and competitiveness in the industry market. This research has three main objectives:

\subsubsection{First Objective and Hypothesis}

\section{Objective 1.}

The first objective of the current research is to understand how to improve decision making on resource utilization planning for construction projects in order to maintain project time and cost as planned under uncertainty.

\section{Question 1.}

How do different risk perceptions affect outcome of resource utilization plans under uncertainty (time and cost) in project? 


\section{Hypothesis 1.}

Considering different risk perceptions of construction resource productivity, planning for higher number of working hours in a week results in less uncertain time and cost outcome for the project.

\section{Specific Questions:}

Question 1.1. How do performance-related risk factors affect short-term processes in construction projects?

Question 1.2. How does sharing of constrained resources over a project under uncertainty affect time and cost.

to investigate the impact of mentioned uncertainties in construction network?

Question 1.3. How to incorporate planers' confidence level towards performance of their resources into time and cost analysis.

\subsubsection{Second Objective and Hypothesis}

\section{Objective 2.}

The second objective of the current research is to understand how to improve decision making on resource sharing priorities for construction projects in order to maintain project time and cost as planned under uncertainty. 


\section{Question 2.}

How does taking different risk perceptions affect project outcomes in case of change in sharing priorities?

Hypothesis 2. Considering different risk perceptions of construction resource productivity, giving the priority of sharing to projects at early stage (in oppose to projects which are in their mid-stage) results in higher uncertainty in time and cost outcome for the project.

\section{Specific Questions:}

Question 2.1. What factors mainly affect profit estimation of new and ongoing projects?

Question 2.2. How identified factors of particular projects affect profit of the entire group of projects?

Question 2.3. How to investigate impact of manager's risk utility in single or multiple projects on profit margin in presence of uncertainties?

\subsubsection{Third Objective and Hypothesis}

\section{Objective 3.}

The third objective of the current research is to understand how to improve decision making on resource management for construction companies in order to maintain profitability and required cash in hand as planned under uncertainty. 


\section{Question 3.}

How does taking different risk perceptions on resource productivity affect corporate resource management outcomes such as profitability?

Hypothesis 3. Taking lower risk regarding productivity of resources results in less profitability for the company, however, requires higher amount of cash to fund ongoing and new projects in short term.

\section{Specific Questions:}

Question 3.1. How to model a network of construction projects in order to search for optimum resource planning solutions that maximize corporate-level profit?

Question 3.2. How to develop reliability indicator that in order to help decision makers decide about selecting optimal planning solutions?

Question 3.3. How to improve decision making on corporate-level profit maximization by consideration of developed indicator.

\subsection{Method and Design}

The proposed research methodology to achieve the abovementioned objectives is classified into the following tasks, the details of these tasks are:

\subsubsection{Design for Hypothesis One}

Task 1.Develop a stochastic simulation model that produces construction time and cost distributions considering performance-related risks inherent in daily construction work, in 
order to facilitate investigation of relationship between planners' risk utility and time-cost tradeoff of projects.

This task will be accomplished by conducting the following subtasks:

Task 1.1. Identify the impact of uncertainties that affect short-term performance of construction and investigate their impact on resource consumption and/or schedule of processes.

Task 1.2. Develop a module that estimates time and cost of different construction levels considering identified uncertainties.

Task 1.3. Develop a stochastic model to simulate the construction network under identified uncertainties and produce time and cost distributions.

Task 1.4. Investigate the developed distributions and understand the impact of identified uncertainties on construction processes and consequently time and cost.

Task 1.5. Investigate the relationship between planners' risk utilities and time-cost tradeoff of construction under uncertainty.

\subsubsection{Design for Hypothesis Two}

Task 2. Develop a module to estimate profit of a group of new and ongoing projects in order to facilitate investigation of relationship between risk utilities and corporate-level profit.

This task will be accomplished by conducting the following subtasks: 
Task 2.1. Identify factors that mainly affect profit within different construction levels.

Task 2.2. Develop a module to estimate project-level and corporate-level profit of construction.

Task 2.3. Estimate expected corporate-level profit based on both most likely performance of resources and prespecified risk setting of the portfolio (risk scenario based of risk utility of managers in particular projects).

\subsubsection{Design for Hypothesis Three}

Task 3. Develop an optimization model that considers corporate-level resource planning policies in order to support decision-making on maximizing profit and improve decision making by introducing reliability indicators for different optimal solutions.

This task will be accomplished by conducting the following subtasks:

Task 3.1. Develop an optimization model to search for optimal resource utilization plans for projects and maximizes corporate-level profit as the objective.

Task 3.2. Develop reliability indicator for each planning solution based on expected deviation between planned and most-likely corporate-level profits.

Task 3.3. Develop a decision support model in order to help planers maintain maximum corporate-level profit considering different resource and schedule scenarios and through investigating the reliability of solutions. 


\subsection{Significance}

This research is conducted with the main objective of improving decision making process at different construction levels. Results of this research will lead to the following benefits for construction researchers and contractors.

\subsubsection{Theoretical Significance}

Benefits to Construction Researchers

1. Understanding impact of short term risk factors on performance and efficiency of construction processes.

2. Understanding impact of risk utility (i.e. risk tendency) of project managers of outcomes and objectives of construction at project and corporate level.

3. Understanding how to improve risk-based decision making regarding profitability estimation at project and corporate level of construction.

\subsubsection{Practical Significance}

Benefits to Construction Contractors

1. Obtaining more realistic support on decision making with regards to choosing resource utilization plans under uncertainty and being enabled to select different potential outcomes of performance and efficiency based on limited resource criteria as well as personal risk utility. 
2. Improved decision making regarding allocating resources over each project as well as sharing resources among corporate network. This research enables managers to be aware of their realistic choices of resource planning, choose among optimum solutions that satisfy their time, cost and profit margin, obtain what if scenarios regarding their different sets of decisions and finally understand reliability of decisions based on their risk attitude.

3. Making more reliable decisions on whether to expand their network of projects (to go or not to go for a bid). This research enables corporate decision makers to make more realistic estimates and make more reliable decision for profitability of their company, and understand consequences of their decisions in short and long term based on what if scenarios.

\subsection{Organization}

This research is conducted in format of three technical chapters, one introduction chapter (current chapter) and one conclusion chapter.

Chapter two contributes to development of a research in context of capturing uncertainties in construction processes, developing a model to examine construction performance and efficiency under risk factors, and providing decision making support for managers to enable choosing proper resource utilization plans via stochastic simulation of project execution.

Chapter three is about development of stochastic simulation-optimization model to provide decision makers and project managers with time-cost tradeoff of their projects under 
uncertainty, and enable them to understand how uncertainties affect construction overall outcomes and be aware of the potential optimum resource utilization plans that satisfy their time and cost requirement. It also enables project managers to understand reliability of their decisions based on most likely out comes of the construction and their personal confidence level on performance of available resources throughout the project.

Chapter four contributes to development of model to use outcomes of the previously developed models in second and third chapters in order to create tradeoffs for profitability and liquidity (short available cashable assets) under uncertainty. This model enables corporate managers to understand impact of different resource utilization and sharing policies on overall outcome of their project and to choose among optimum planning solutions that satisfy their profit margin and capital limitations. This research enables corporate decision makers to make more realistic estimates and make more reliable decision for profitability of their company, and understand consequences of their decisions in short and long term based on what if scenarios.

Chapter five is about concluding remarks of this doctorate research, connects findings of the developed models and papers, and explains contributions and benefits of this conducted research for decision makers at different levels of construction works, as well as academic construction researchers. 


\section{CHAPTER TWO}

\section{LITERATURE REVIEW}

\subsection{Overview}

There is a rich body of literature in the area of decision making on resource management in construction industry. This chapter presents a review on previous literature that have addressed main areas of the current research.

\subsection{Resource Utilization Under Uncertainty}

Several research studies focused on planning and scheduling construction projects under uncertainties considering different objectives and using different simulation methods. Most of these studies focused on stochastic scheduling of construction projects assuming unlimited resources (Hong et al. 2011, Lee 2005, Lee and Arditi 2006, Lee et al. 2009, Ökmen and Öztaş 2008); or under resource constraints (Sadeghi et al. 2011, Taghaddos et al. 2012, Vaziri et al. 2007, Zhang and Li 2004). Other research studies focused on investigating the tradeoff between time and cost for stochastic planning of construction projects (Feng et al. 2000, Isidore and Back 2001, Isidore and Back 2002, Khamooshi and Cioffi 2012). In addition, other research studies on stochastic planning of construction projects focused on: allocating a project contingency for time to the different activities 
(Barraza 2011); overcoming the challenge of extensive data requirements (Ökmen and Öztaş 2008); balancing strategic and operational perspectives (Peña-Mora et al. 2008); and integrating space constraints and crew options in the planning process (Chen et al. 2012).

Most of the aforementioned research studies simulated activity and/or project durations, using different methods and processes, in order to account for the time-related risk factors and their associated uncertainties. Therefore, despite the original contributions of these research studies, no reported research considered the dynamic nature of utilizing construction resources on a day-to-day basis and its impact on crew production rate. In addition, no reported research studies considered the impact of time-related risk factors and their uncertainties on planning a portfolio of projects competing for a limited pool of construction resources. Accordingly, there is a pressing need for a new model that covers these two important research gaps.

This this paper therefore presents the development of a new Productivity Simulation Model (PSM) that is capable of considering the impact of time-related risk factors that can affect crew production rate on a day-to-day or shift-to-shift basis. This is done by simulating crew production rate instead of project or activity durations. In addition, PSM is designed to provide resource utilization capabilities at three different levels, namely the activity-, project-, and portfolio-levels in order to facilitate sharing a limited pool of resources among a portfolio of competing construction projects. Furthermore, PSM takes into consideration the impact of extended working hours and/or additional working shifts on crew production rate and therefore on construction time and cost. The following sections of the paper present the development of the new Productivity Simulation Model, an application 
example designed to illustrate the use of PSM and demonstrate its capabilities, and discuss the conclusions of this research and provide recommendations for future research.

\subsection{Multi-Project Resource Planning Under Uncertainty}

Applying uncertainties to resource utilization plan has been proved to affect project completion outcomes (e.g. duration and cost). As an example, modeling the efficiency and/or continuousness of resource utilization for weather-sensitive activities has shown to output a wide range of project durations, when repeated in presence of stochastic weather conditions (Lee et al. 2009; Shahin et al. 2010). To model resource utilization under uncertainty, planners should be aware of parameters that are impacted by stochastic nature of uncertainties (e.g. crew production rate, material cost, etc.). To this end, it is necessary to identify the level of construction at which uncertainties are being modeled. Most of the studies in this area have focused on modeling of uncertainties at activity/process level. It means they have planned activity parameters to probabilistically change every time that activity or process is scheduled. These studies considered parameters such as activity duration (Puri and Martinez 2012; Ökmen and Öztaş 2008; Sadeghi et al. 2012; Shahin et al. 2010; Barraza 2010; Hong et al. 2011; Lee 2005; Lee and Arditi 2006), cost (Taghaddos et al. 2011) or both (Heravi and Faeghi 2012; Khamooshi and Cioffi 2012; Isidore and Back 2001; Isidore and Back 2002; Feng et al. 2000) in their models. Some others modeled uncertainties at project level, where for instance, project cost is studied as a probabilistic parameter (Gabriel et al. 2006). Limited number of researches, however, studied impact of uncertainties on a daily-level basis. These studies have contributed to development of stochastic models in order to estimate either performance of crews each day (Orabi et al. 
2013) or number of daily assigned crews (Chen et al. 2012). For effective consideration of resource sharing in different construction levels, some researchers have used resource constraints (Orabi et al. 2013; Sadeghi et al. 2012; Vaziri et al. 2007) to examine outcomes of their stochastic models regarding resource limitations. Few researchers have also developed models to analyze allocation and sharing of limited resources at their project level (Khamooshi and Cioffi 2012; Barraza 2010) or portfolio level (Orabi et al. 2013; Gabriel et al. 2006) scheduling. There are also certain studies that attempted to find optimal resource allocation solutions (at project level) through various stochastic optimization methods (Heravi and Faeghi 2012; Vaziri et al. 2007; Zhang and Li 2004).

It is shown in the recent studies that results of stochastic simulation can provide decision makers with statistical outcomes of projects at certain confidence levels (Orabi et al. 2013). Many researchers have used simulation methods to model impact of uncertainties on indicated parameters. Depending on the nature of the construction work and the level of uncertainty modeling, different simulation methods have been implemented in existing models. Monte Carlo Simulation (Orabi et al. 2013; Heravi and Faeghi 2012; Ökmen and Öztaş 2008) and Discrete-Event Simulation (Puri and Martinez 2012; Taghaddos et al. 2011; Lee et al. 2010; Zhang and Li 2004) are among the most-used simulation methods. Some researchers have employed other methods, such as Chance-Constrained Programming (Gabriel et al. 2006), SIMPHONY simulation (Chen et al. 2012), CYCLONE simulation (Hong et al. 2011), or combined methodologies (Sadeghi et al. 2012; Shahin et al. 2010; Peña-Mora et al. 2008). However, the important issue in this area of study is using results of mentioned stochastic models to obtain a more realistic plan for 
resource utilization. Two main research gaps can be identified within the studies on resource utilization planning under uncertainty in construction. First, there is lack of research studies that properly model day-to-day change of productivity under uncertainties, since uncertainties such as weather condition can frequently affect crew productivity on a daily basis (Shahin et al. 2010). In addition, resource utilization planning of a group of projects competing for a limited pool of resources requires planners to examine different resource sharing policies to find optimal solutions. However, no reported research considered stochastic optimization of resource sharing at portfolio level. Accordingly, there is a need for a new model that covers these two important research gaps.

This paper therefore presents the development of a new simulation-optimization model, which simulates crew production rate instead of project or activity durations and in fact, considers the impact of uncertainties on the daily production rate of the resource. The developed model is capable of utilizing resources at three construction levels: activity, project and portfolio. This provides the model with ability of sharing a limited pool of resources among a portfolio of competing projects considering resource utilization, allocation and sharing policies. Furthermore, the multi-objective optimization model simultaneously minimizes completion time and cost of the portfolio, while taking into consideration the impact of alternative resource utilization scenarios. The results of the model provides decision makers with a comprehensive perspective on construction performance of the portfolio under uncertainty. Figure 1 shows general components and overall flow of the proposed model. In the simulation module, uncertainties and their impact on daily resource production rate contribute to estimation of resource consumption 
and construction performance estimates. Then, having duration and cost of the portfolio (i.e. result of network scheduling simulation for certain number of iterations) aside to preassumed alternative scenarios (i.e. decision variables), the model finds the optimum solutions for resource planning through multi-objective optimization process. The following sections of the paper present the development of the proposed model, an illustrative application example to demonstrate and discuss its capabilities, and eventually, conclusions and recommendations for future research.

\subsection{Corporate Level Resource and Profitability Management}

It is mentioned in the literature that when deciding on resource utilization and allocation practices under uncertainty, decision makers need to have a proper perspective of their own approaches toward risk (Kim and Reinschmidt 2010). To better investigate the impact of risk utilities, it is required to first understand how uncertainties affect projects. Applying uncertainties to resource utilization plan has been proved to affect project completion outcomes (e.g. duration and cost). As an example, modeling the efficiency and/or continuousness of resource utilization for weather-sensitive activities has shown to output a wide range of project durations, when repeated in presence of stochastic weather conditions (Shahin et al. 2010; Lee et al. 2009). Similarly, many studies suggested major cost variations in construction when efficiency and performance are probabilistically modeled (Heravi and Faeghi 2012). Existing literature have modeled uncertainties in

different resource planning levels. Limited number of researches studied impact of uncertainties on daily-level basis (Orabi et al. 2013; Chen et al. 2012), while most of the studies in this area have focused on activity/process level. Among those there are various 
models considering parameters such as activity duration (Ökmen and Öztaş 2008; Lee 2005; Hong et al. 2011; Lee and Arditi 2006), activity cost (Taghaddos et al. 2011) or both (Isidore and Back 2002; Feng et al. 2000). Some others modeled uncertainties at project level, where for instance, project cost is studied as a probabilistic parameter (Gabriel et al. 2006). Few researchers have also developed models to analyze allocation and sharing of limited resources at the portfolio level (Barraza 2010).

On the other hand, investigating risk utilities requires to note that managers' level of confidence on performance of resources under uncertainty affects the amount of risk they are willing to take regarding planning decisions. It is shown in the recent studies that results of stochastic simulation can provide decision makers with statistical outcomes of projects at certain confidence levels (Orabi et al. 2013). Many studies developed stochastic simulation models to capture uncertainty in construction (Puri and Martinez 2012; Gabriel et al. 2006; Chen et al. 2012; Peña-Mora et al. 2008). There are also certain studies that attempted to find optimal resource allocation solutions (at project level) through various stochastic optimization methods (Heravi and Faeghi 2012; Vaziri et al. 2007; Zhang and Li 2004). However, three main research gaps can be identified within the existing literature. Uncertainties are claimed to frequently affect resource performance on a daily basis. However, there is lack of research studies that accurately model contingencies affecting daily performance of construction under uncertainties. In addition, consideration of resource planning for a group of projects consuming limited resources seems required for an improved and realistic decision making. However, no reported research considered stochastic optimization of resource sharing at portfolio level. In addition, there is a need 
for new research to investigate impact of risk utilities on decision making in planning phase.

Finally, decision makers at corporate level need to have a broad perspective on their network, resources possibilities and risk utility of their project managers in order to improve their decisions with regards to reliability of potential outcomes. This paper therefore, presents the development of a new simulation-optimization model to cover the identified research gaps and consequently facilitate the investigation of risk utility on reliability of corporate level construction outcomes. The developed model consists of simulation and optimization modules, as well as decision support material which are introduced in next sections of the paper. 


\section{CHAPTER THREE}

\section{RESOURCE UTILIZATION AND UNCERTAINTY}

\subsection{Overview}

Risks are inherent in construction and therefore needs to be incorporated in construction project planning. To this end, existing stochastic planning models use historical activity duration data to model time uncertainties and simulate project durations. This approach does not take into consideration the impact of day-to-day changes on time-related risk factors (e.g. weather, labor availability, and trade coordination) and their associated uncertainties. Therefore, simulation of crew production rate can provide a more accurate representation of these time-related uncertainties. This paper therefore presents the development of a new stochastic planning model that uses historical crew production rate data to simulate both activity and project durations. The model uses Monte Carlo simulation with beta distributions to capture day-to-day and shift-to-shift changes in crew production rate. In addition, the model also considers the impact of sharing a limited pool of resources on the construction duration of a portfolio of projects rather than single projects. An application example is analyzed to evaluate the performance of the new model and demonstrate its capabilities. 


\subsection{Introduction and Background}

Construction planners and schedulers need to consider the impact of several variable factors while scheduling construction projects. These factors include jobsite management conditions, weather, resource availability among others. Each of these factors can have a significant impact on production rate and therefore the time needed to complete construction activities and processes. Furthermore, many of these factors can change from day-to-day and even from shift-to-shift resulting in unpredictable crew production rate rates. This uncertainty makes estimating activity and project durations a complex and challenging task. In addition, the need to consider limited availability of resources and/or sharing a limited pool of resources among a portfolio of construction projects adds to the complexity of this problem.

Several research studies focused on planning and scheduling construction projects under uncertainties considering different objectives and using different simulation methods. Most of these studies focused on stochastic scheduling of construction projects assuming unlimited resources (Hong et al. 2011, Lee 2005, Lee and Arditi 2006, Lee et al. 2009, Ökmen and Öztaş 2008); or under resource constraints (Sadeghi et al. 2011, Taghaddos et al. 2012, Vaziri et al. 2007, Zhang and Li 2004). Other research studies focused on investigating the tradeoff between time and cost for stochastic planning of construction projects (Feng et al. 2000, Isidore and Back 2001, Isidore and Back 2002, Khamooshi and Cioffi 2012). In addition, other research studies on stochastic planning of construction projects focused on: allocating a project contingency for time to the different activities 
(Barraza 2011); overcoming the challenge of extensive data requirements (Ökmen and Öztaş 2008); balancing strategic and operational perspectives (Peña-Mora et al. 2008); and integrating space constraints and crew options in the planning process (Chen et al. 2012).

Most of the aforementioned research studies simulated activity and/or project durations, using different methods and processes, in order to account for the time-related risk factors and their associated uncertainties. Therefore, despite the original contributions of these research studies, no reported research considered the dynamic nature of utilizing construction resources on a day-to-day basis and its impact on crew production rate. In addition, no reported research studies considered the impact of time-related risk factors and their uncertainties on planning a portfolio of projects competing for a limited pool of construction resources. Accordingly, there is a pressing need for a new model that covers these two important research gaps.

This this paper therefore presents the development of a new Productivity Simulation Model (PSM) that is capable of considering the impact of time-related risk factors that can affect crew production rate on a day-to-day or shift-to-shift basis. This is done by simulating crew production rate instead of project or activity durations. In addition, PSM is designed to provide resource utilization capabilities at three different levels, namely the activity-, project-, and portfolio-levels in order to facilitate sharing a limited pool of resources among a portfolio of competing construction projects. Furthermore, PSM takes into consideration the impact of extended working hours and/or additional working shifts on crew production rate and therefore on construction time and cost. The following sections of the paper present the development of the new Productivity Simulation Model, an application 
example designed to illustrate the use of PSM and demonstrate its capabilities, and discuss the conclusions of this research and provide recommendations for future research.

\subsection{Methodology: Productivity Simulation Model (PSM)}

The main purpose of the new Productivity Simulation Model (PSM) is to evaluate and measure the impact of day-to-day time-related risks and their associated uncertainties on construction projects schedule and cost. To this end, PSM simulates the production rate of construction crews on a shift-to-shift basis. In order to achieve this objective, the model is developed in three main phases: input phase, simulation phase, and output phase. The following subsections describe the development of each of these phases. It should be mentioned that the simulation model has been coded in $\mathrm{C}++$ programing language and organized in four main modules for input data initialization, Monte Carlo simulation, project structure and duration calculation.

\subsubsection{Input Phase}

The main purpose of this phase is to collect and prepare the data needed for simulating production rate and scheduling a portfolio of projects competing for a limited pool of construction resources. The model uses five different types of data: resource availability, crew production rate, project scheduling, cost, and portfolio scheduling data, as shown in Figure 1. First, the user needs to provide data on the availability of resources in the contractor's pool, including the types of resources used by the contractor, the number of available crews of each resource type, the availability dates of each crew, and the production rate adjustment factor for crews working overtime or night shifts. Second, for each of the resource types used by this contractor, the user also needs to input crew 
production rate data that is representative of the historical performance of each resource type. These data include selecting a suitable frequency distribution for crew production rate (i.e. beta, triangular, normal ... etc.) and providing the statistical data required to describe the selected distribution (e.g. most likely, optimistic, and pessimistic production rate rates in the case of the beta distribution). The selected frequency distribution should be representative of the time-related risk factors that can significantly change crew production rate on shift-to-shift or day-to-day basis. Third, project schedule data include the planned activities for each project of the portfolio, scope of work (i.e. quantity) of each activity, resource requirements, and activity precedence information. Fourth, the user is required to provide data on direct and indirect costs. Direct costs include cost rates of each resource type and a lumpsum material cost for each activity. The indirect cost input data include one fixed daily rate for each project of the portfolio to cover site and main office overheads. Finally, the portfolio schedule data include projects prioritization (i.e. order of project execution), and working schedule and overtime policy for each project. 


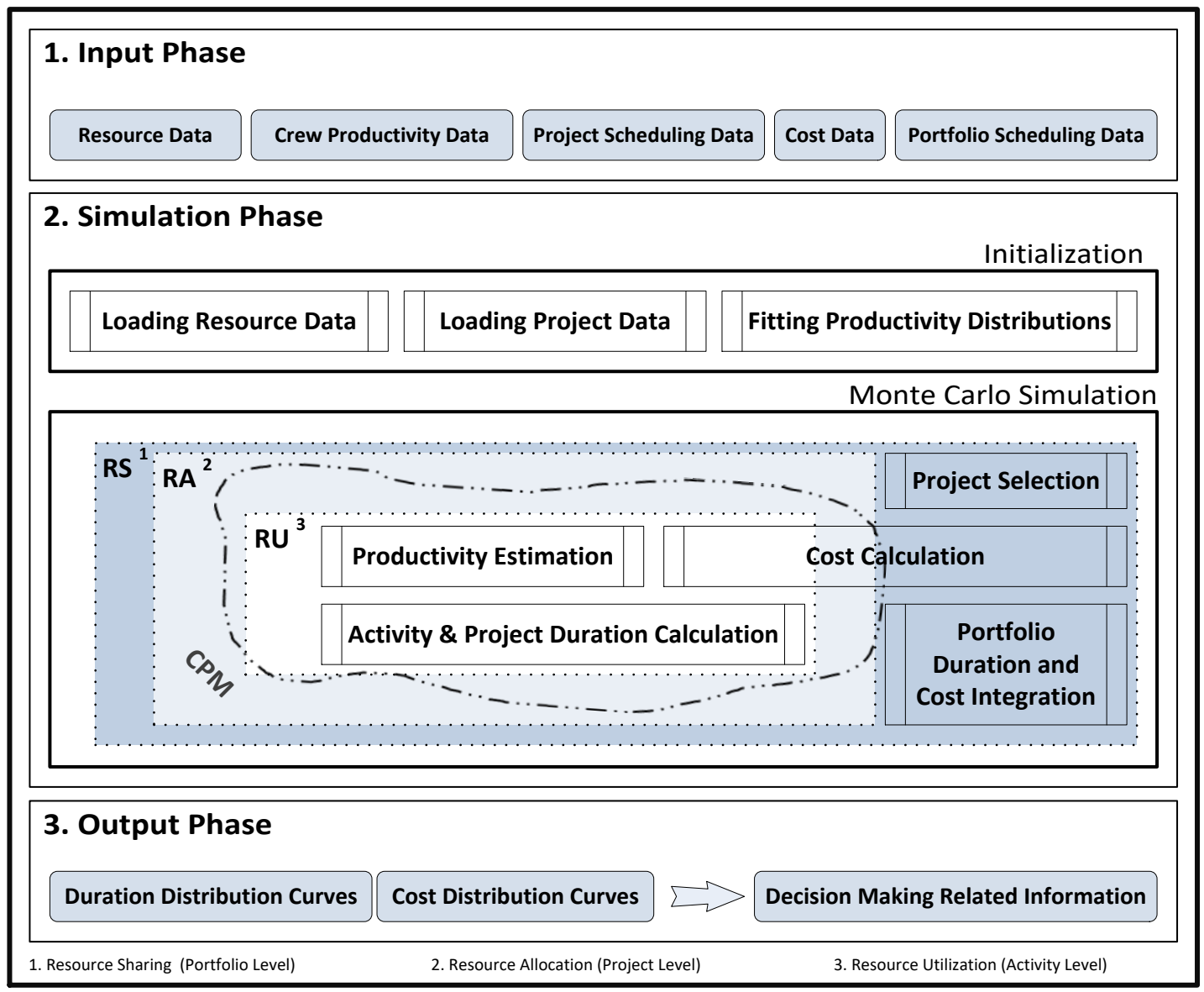

Figure 3.1. Productivity Simulation Model (PSM)

\subsubsection{Simulation Phase}

The main purpose of this phase of PSM is to simulate the production rate of the contractor's crews and analyze its impact on construction duration and cost at both the project and portfolio levels. This phase of PSM has two main procedures: initialization and Monte Carlo simulation. 
Initialization Procedure is executed only once at the onset of running PSM and is aimed at loading the resource and project data collected in the previous phase and storing it in efficient data structures. These data structures are designed to provide swift access and seamless sharing of data among the different PSM processes in order to reduce the PSM computational overhead. Furthermore, the initialization procedure also includes fitting frequency distribution curves for crew production rate based on the crew data collected in the previous phase. This curve fitting process is completed for each crew in the contractor's resource pool based on the distribution curve selected by the user and the descriptive statistical production rate data provided in the input phase. Currently, PSM only considers beta distribution; therefore, any simulated instances of a crew's production rate should be generated using a Beta Probability Density Function (PDF). To this end, PSM generates the simulated crew production rate instances using the widely accepted Program Evaluation and Review Technique (PERT). Therefore, the mean and standard deviation of crew production rate can be estimated as follows:

[1]. $\mu_{\mathrm{n}}=\frac{\left(P_{o p t}\right)_{n}+4 \times\left(\mathrm{P}_{\mathrm{ml}}\right)_{n}+\left(\mathrm{P}_{\mathrm{pes}}\right)_{n}}{6}$

[2]. $\sigma_{n}=\frac{\left(P_{o p t}\right)_{n}-\left(\mathrm{P}_{\mathrm{pes}}\right)_{n}}{6}$

Where, $\left(\mu_{\mathrm{n}}\right)$ and $\left(\sigma_{\mathrm{n}}\right)$ are the mean and standard deviation of crew $(n)$ production rate, respectively. $\left(\mathrm{P}_{\mathrm{opt}}\right)_{\mathrm{n}},\left(\mathrm{P}_{\mathrm{ml}}\right)_{\mathrm{n}}$, and $\left(\mathrm{P}_{\mathrm{pes}}\right)_{\mathrm{n}}$ are the optimistic, most likely, and pessimistic productivities of crew $(n)$, respectively; as collected from the user in the input phase. The estimated production rate mean and standard deviation are then used with an inverse beta 
function to generate the simulated instances of production rate that follows the beta probability density function. This process ensures generating crew productivities that are representative of the impact of time-related risk factors and their associated uncertainties.

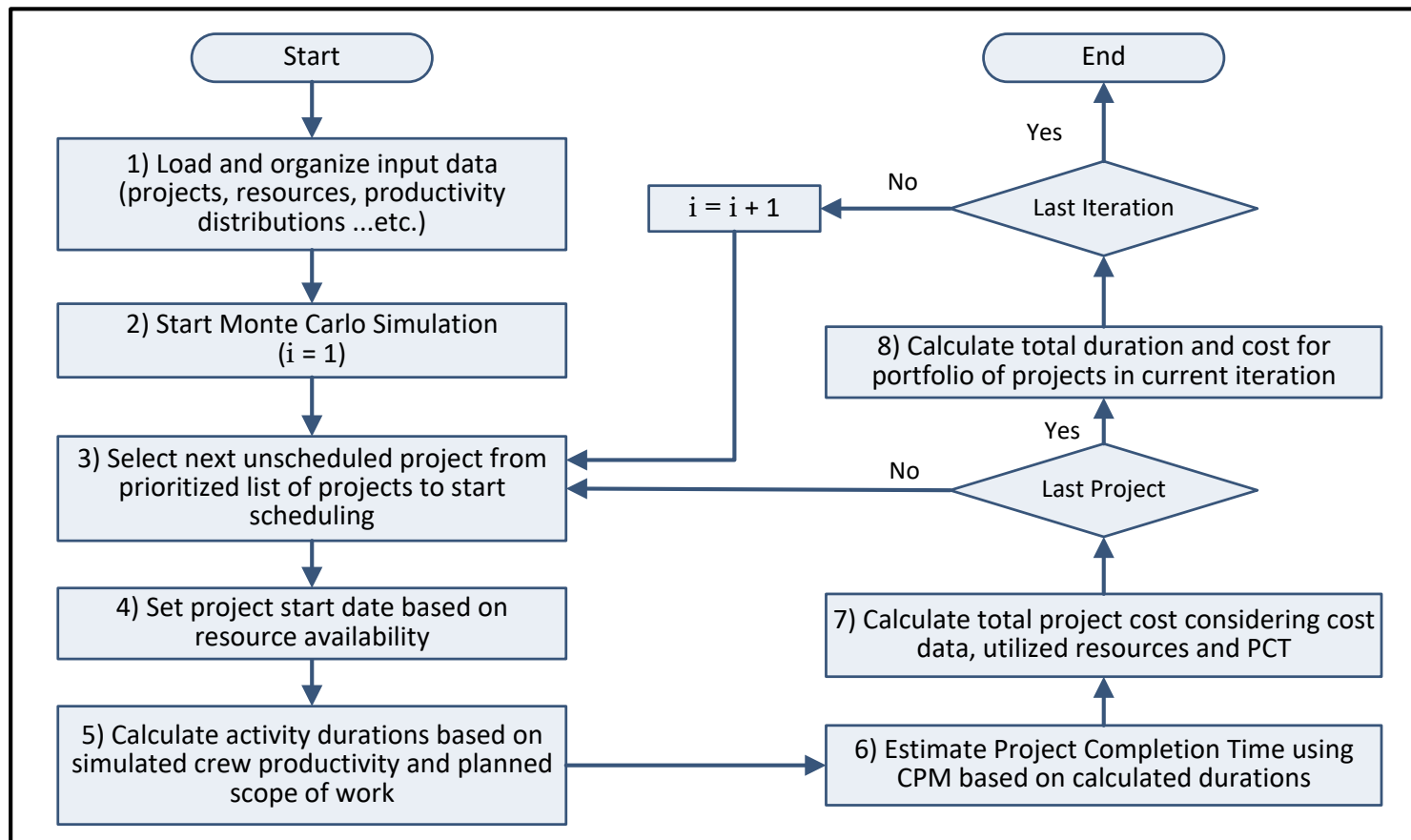

Figure 3.2. Flowchart for the Monte Carlo simulation procedure

Monte Carlo Simulation Procedure is the core of PSM and is comprised of several processes and methods that are designed to analyze and measure the impact of the aforementioned risk factors and their associated uncertainties on construction duration and cost at the project and portfolio levels. This is achieved by analyzing construction resource utilization and management practices based on the simulated crew production rate instances. To this end, PSM analyzes resource management at three main levels: resource utilization at the activity level; resource allocation at the project level; and resource sharing at the portfolio level, as shown in Figure 1. At the activity level, PSM analyzes the impact 
of the simulated production rate instances on activity durations and therefore costs, which accounts for the risk factors that can result in changing production rate on a day-to-day basis. At the project level, the estimated activity durations are used to allocate the limited construction resources available to different activities based on the resource requirements of these activities and the project logic. At the portfolio level, PSM analyzes the impact of sharing the limited resources among competing projects on the duration and cost of these projects according to the prioritization specified by the user. This procedure is executed for a number of iterations predefined by the user and involves two nested loops, as described in the following steps (see Figure 2):

1. Load project, resources and production rate data and store them in appropriate data structures, which allow swift and efficient access in the following steps.

2. Start the Monte Carlo simulation procedure and repeat it for a predefined number of iterations (i) set by the user. Therefore, the following steps 3 through 8 are repeated iteratively for $(i)$ times.

3. Select the next unscheduled project $(p)$ of the portfolio according to the project prioritization identified by the user. This is at the portfolio level resource management (i.e. resource sharing) and is designed to give projects with higher priority access to the contractor's limited resource pool before other projects that have lower priority.

4. Set the start date of the current project $(p)$ based on the availability of resources. This data depends on having enough resources available and free to work on this 
project. Resources become free once they complete all work required on projects of higher priority and are released to the contractor's pool for use in other projects. The start date of the first activity of project $(p)$, and accordingly the project start date, is therefore set to the early finish of the last activity using the same resource type in the immediately preceding project in terms of priority. PSM uses a resource-tracking database that is updated every time a crew is deployed to or from the resource pool to facilitate sharing construction crews at both the project and portfolio levels. This database can provide the number and types of resources available at any point in time. It is noteworthy that PSM allows activities to start with fewer crews than its requirements and can adjust the production rate as more crews become available.

5. Calculate the duration of all activities in the current project $(p)$ based on the simulated instances of crew production rate. As mentioned in step 4, an activity can start with a fewer number of crews than required and its production rate gradually increases as more crews become available according to the resourcetracking database. The production rate of construction resources is therefore not constant over the duration of activity (a). Actually, two main factors contribute to the variability in production rate of construction resources over an activity's duration: the varying number of crews available; and the individual production rate of these crews that can change from one shift to the other due to time-related risk factors and the project overtime policy implemented, if any. PSM therefore uses a process to calculate project duration that takes into consideration this variable crew 
production rate. This process monitors the amount of work that can be completed during each shift and estimates how many time units (e.g. days) are needed to complete the entire work and hence the activity duration. This activity duration calculation process includes the following equations:

[3]. $q_{x}=\sum_{s=1}^{n} p_{x}^{s}$

[4]. $Q_{r}=Q_{\text {total }}-q_{x}$

Where, $\left(q_{x}\right)$ is the quantity of work that can be completed in day $(x),\left(p_{x}^{S}\right)$ is the crew production rate in shift $(s)$ of day $(x),(n)$ is the number of working shifts according to the implemented overtime policy, $\left(Q_{r}\right)$ is the remaining quantity of work at the end of each day, and $\left(Q_{\text {total }}\right)$ is the total quantity of work required for activity $(a)$. It is noteworthy that $\left(p_{x}^{s}\right)$ takes into consideration adjusting the production rate for crew working for extended hours or second shifts due to the expected fatigue. Equations (3) and (4) are repeated iteratively until $\left(Q_{r}\right)$ is equal to or less than zero. The minimum number of days needed to have $\left(Q_{r}\right)$ equal to or less than zero is the duration of activity (a). As described above, crew production rate $\left(p_{x}^{S}\right)$ is simulated to fit the beta probability density function using a random number that is generated individually for each single crew of each working shift $(s)$.

6. Estimate the completion time of project $(p)$ based on the activity durations calculated in the previous step and according to the planning project logic using the Critical Path Method (CPM). To this end, the start date of any activity (a) will 
depend on the completion of the immediately preceding activities and availability of resources similar to setting project start date in step 4. This step is performed concurrently with step 5 by setting the start date of activity $(a)$, calculating its duration, and setting its finish date before moving on to the following activity until all activities are scheduled and the project completion time (PCT) is set to be the earliest finish of the last activity.

7. Calculate the total cost of project $(p)$, which is comprised of two main types of cost: direct (DC) and indirect (IC), as shown in Figure 3. In PSM, the direct cost includes the lumpsum cost of material required for completing the planned work, and the construction crew cost. The crew cost is estimated as the product of each activity's duration and the crew cost rate. Activity crew costs are then added up to calculate the total crew cost for the entire project. The indirect cost is estimated as the product of the project duration and the indirect cost rate that represents site and main office overheads. Steps 3 through 7 are repeated iteratively until all the projects of the portfolio are scheduled and their duration and total costs are known.

Portfolio or Resource Sharing (RS) Level

Project or Resource Allocation (RA) Level

Activity or Resource Utilization (RU) Level

Cost Calculation Process

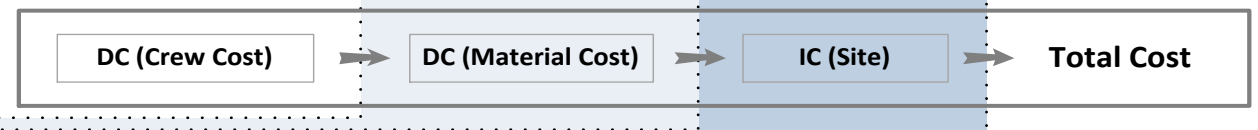

Figure 3.3. Construction cost calculation at different resource utilization levels 
Calculate the duration and total cost for completing the portfolio based on the duration and cost of the individual projects as per steps 3 through 7. The portfolio duration is estimated as the difference between the latest early finish and earliest early start of all projects. The total portfolio cost however is the summation of all project costs. The estimated portfolio duration and cost in this step are associated only with the current iteration $(i)$ and are dependent on the simulated crew production rate of the same iteration. Therefore, in order to account for the aforementioned time-related risk factors and their associated uncertainties, steps 3 through 8 are repeated for a predefined number of iterations, and storing the pairs of portfolio duration and cost of each iteration for further analysis.

\subsubsection{Output Phase}

The main purpose of this phase of PSM is to use the results of the simulation in order to help planners identify an estimate for portfolio duration and cost according to their risk tolerance. To this end, the pairs of portfolio duration and cost generated for each iteration of the simulation phase is used to develop frequency distribution curves for both portfolio duration and cost. These distribution curves depict the frequency of occurrence of each portfolio duration and each portfolio cost according to the simulated crew production rate. Similarly, each project can have distribution curves for its duration and cost that can be used for decision making at the project-level. Planners can therefore identify, at any of the portfolio or project levels, the duration and cost for a given confidence level, which is representative of their risk tolerance. Furthermore, these distribution curves can be used in further analyses, e.g. what-if scenarios, in order to identify an optimal utilization plan of 
the limited resource pool. The following section demonstrates an example of how to use PSM to plan and schedule construction projects.

\subsection{Application Example}

An application example for planning a portfolio of constructing three identical prefabricated metal buildings is analyzed to illustrate the use of PSM and demonstrate its capabilities. The activities in these three projects are similar and are adopted from Ahuja et al. (1995). Each project consists of five activities and requires five different types of construction resources. Table 1 shows the five activities of each project, activity precedence information, activity quantity of work, required resources, crew daily production rate (i.e. optimistic, most likely, and pessimistic daily production rate rates), material and crew cost rates, and the number of crews available of each resource type. The daily indirect costs are $\$ 800, \$ 850$ and $\$ 1000$ for projects 1,2 and 3, respectively. In addition, the projects are numbered based on their priority. All three projects are assumed to work for two shifts per working day.

\section{Table 3.1. Application example project and resource data}

\begin{tabular}{|c|c|c|c|c|c|c|c|c|c|c|c|}
\hline \multicolumn{5}{|c|}{ Sample Project Data } & \multicolumn{7}{|c|}{ Available Resources Pool of the Portfolio } \\
\hline \multirow[b]{2}{*}{ Activity } & \multirow[b]{2}{*}{ Description } & \multirow[b]{2}{*}{ Predecessors } & \multirow[b]{2}{*}{ Quantity } & \multirow[b]{2}{*}{ Unit } & \multirow{2}{*}{$\begin{array}{c}\text { Required } \\
\text { Crew } \\
\text { Type }\end{array}$} & \multicolumn{3}{|c|}{ Crew Daily Productivity } & \multirow{2}{*}{$\begin{array}{l}\text { Material } \\
\text { Unit Cost }\end{array}$} & \multirow{2}{*}{$\begin{array}{l}\text { Crew } \\
\text { Daily } \\
\text { Cost }\end{array}$} & \multirow{2}{*}{$\begin{array}{c}\text { Available } \\
\text { Number of } \\
\text { Crews }\end{array}$} \\
\hline & & & & & & Optimistic & $\begin{array}{l}\text { Most } \\
\text { Likely }\end{array}$ & Pessimistic & & & \\
\hline 1 & Prefab metal building & none & 60 & Ton & $\mathrm{A}$ & 0.30 & 0.27 & 0.24 & 185 & 850 & 3 \\
\hline 2 & Clear site & none & 25,000 & S.F. & $\mathrm{B}$ & 500.00 & 208.33 & 166.67 & 0 & 1050 & 3 \\
\hline 3 & Underground and foundations & 2 & 900 & C.Y. & $\mathrm{C}$ & 18.00 & 7.50 & 6.00 & 70 & 970 & 3 \\
\hline 4 & Erect prefab building & 1,3 & 60 & Ton & $\mathrm{D}$ & 0.75 & 0.53 & 0.30 & 0 & 300 & 3 \\
\hline 5 & Finish interior & 4 & 6,000 & S.F. & $E$ & 66.67 & 59.70 & 54.55 & 100 & 740 & 3 \\
\hline
\end{tabular}

This portfolio of projects was analyzed using the new PSM for a total number of 500 iterations. Figure 4 shows the resulting duration and cost distribution curves for each of 
the three projects and for the entire portfolio. Since the scope and resource requirements for all three projects are similar, their duration distribution curves are almost identical and ranges from 155 to 162 days for each project. The project cost distribution curves however, have similar shapes but different mean values due to the different indirect cost rates used for each project. At the portfolio level, the cost distribution curve shows total portfolio cost ranging from approximately $\$ 4,040,000$ to over $\$ 4,080,000$. Similarly, the portfolio duration distribution curve shows a total portfolio duration ranging between 315 and 323 days. Planners and decision makers can use these distribution curves to make informed bidding and resource utilization decisions that fit their needs and in accordance with their risk tolerance.

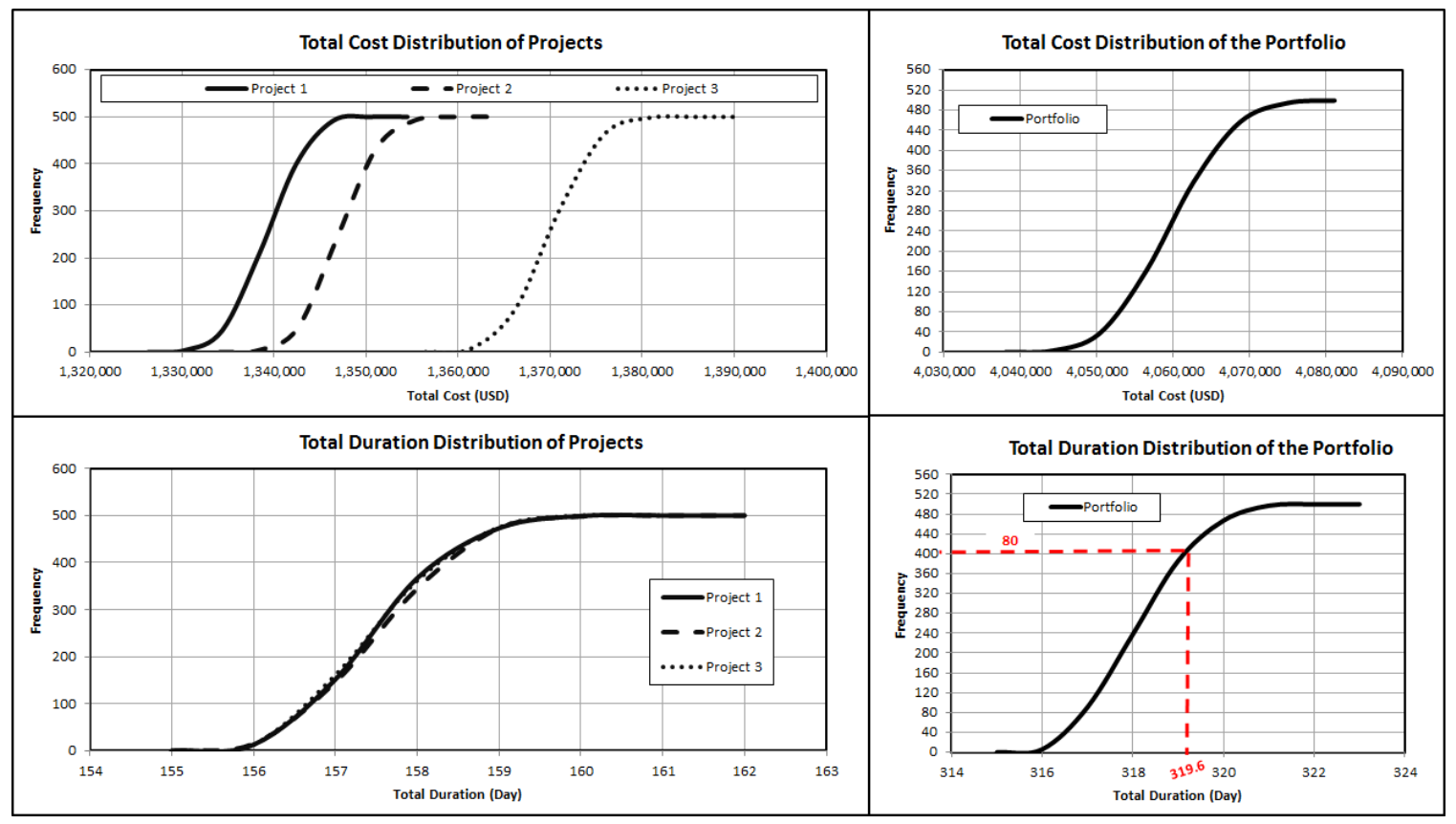

Figure 3.4. Duration and cost distribution curves at project and portfolio levels 
For example, for a contractor bidding on a similar three- project portfolio, the estimator can safely assume that the portfolio is expected to complete after 320 days at probability of $80 \%$. For other contractors who are more risk averse, they can use a higher confidence level, which will result in a higher duration, and vice versa for risk loving contractors who are willing to bear more risks and can choose a lower confidence level.

\subsection{Conclusions and Recommendations for Future Research}

Construction projects are prone to myriad time-related risk factors (e.g. weather, labor availability, and trade coordination) that can result in significant changes in crew production rate on a day-to-day basis. This scheduling uncertainty problem makes it challenging for planners and decision makers to plan these projects and select optimal resource utilization plans. Existing stochastic planning models are insufficient to solve this problem since they depend on simulating activity and/or project duration, which does not address the problem of daily changes in crew production rate. Therefore, this paper presented the development of new Productivity Simulation Model (PSM) that estimates activity, and hence project, durations based on simulated crew production rate. In addition, PSM is also capable of planning a portfolio of projects competing for a limited pool of resources and considers the impact of working for extended hours of multiple working shifts. The model is comprised of three main phases. First, the input phase collects project and resource data that are readily available for users. Second, the simulation phase uses Monte Carlo simulation to capture the variation in crew production rate and its impact on construction duration and cost at both the project and portfolio levels. Finally, the output phase provides the user with distribution curves for construction duration and cost, which 
allows planners to make informed decisions. PSM also uses three levels of resource management to facilitate effective and efficient resource utilization at the activity, project, and portfolio levels.

Further research is needed in order to improve the capabilities of PSM and provide more accurate depiction of construction risks and their impacts on different planning objectives. For example, the model could be expanded to consider the impact of risk factors on material costs and crew cost rates. In addition, resource utilization decisions can be optimized in order to select the project prioritization and overtime policy options that can simultaneously minimize portfolio construction duration and cost. 


\section{CHAPTER THREE}

\section{RISK-BASED RESOURCE PLANNING TOWARD MINIMIZING TIME AND COST}

\subsection{Introduction}

Due to the importance of understanding and capturing risks in construction planning, numerous research studies have focused on planning of resource utilization under uncertainty as main source of unexpected changes during construction projects. Applying uncertainties to resource utilization plan has been proved to affect project completion outcomes (e.g. duration and cost). As an example, modeling the efficiency and/or continuousness of resource utilization for weather-sensitive activities has shown to output a wide range of project durations, when repeated in presence of stochastic weather conditions (Lee et al. 2009; Shahin et al. 2010). To model resource utilization under uncertainty, planners should be aware of parameters that are impacted by stochastic nature of uncertainties (e.g. crew production rate, material cost, etc.). To this end, it is necessary to identify the level of construction at which uncertainties are being modeled. Most of the studies in this area have focused on modeling of uncertainties at activity/process level. It means they have planned activity parameters to probabilistically change every time that activity or process is scheduled. These studies considered parameters such as activity 
duration (Puri and Martinez 2012; Ökmen and Öztaş 2008; Sadeghi et al. 2012; Shahin et al. 2010; Barraza 2010; Hong et al. 2011; Lee 2005; Lee and Arditi 2006), cost (Taghaddos et al. 2011) or both (Heravi and Faeghi 2012; Khamooshi and Cioffi 2012; Isidore and Back 2001; Isidore and Back 2002; Feng et al. 2000) in their models. Some others modeled uncertainties at project level, where for instance, project cost is studied as a probabilistic parameter (Gabriel et al. 2006). Limited number of researches, however, studied impact of uncertainties on a daily-level basis. These studies have contributed to development of stochastic models in order to estimate either performance of crews each day (Orabi et al. 2013) or number of daily assigned crews (Chen et al. 2012). For effective consideration of resource sharing in different construction levels, some researchers have used resource constraints (Orabi et al. 2013; Sadeghi et al. 2012; Vaziri et al. 2007) to examine outcomes of their stochastic models regarding resource limitations. Few researchers have also developed models to analyze allocation and sharing of limited resources at their project level (Khamooshi and Cioffi 2012; Barraza 2010) or portfolio level (Orabi et al. 2013; Gabriel et al. 2006) scheduling. There are also certain studies that attempted to find optimal resource allocation solutions (at project level) through various stochastic optimization methods (Heravi and Faeghi 2012; Vaziri et al. 2007; Zhang and Li 2004).

It is shown in the recent studies that results of stochastic simulation can provide decision makers with statistical outcomes of projects at certain confidence levels (Orabi et al. 2013). Many researchers have used simulation methods to model impact of uncertainties on indicated parameters. Depending on the nature of the construction work and the level of uncertainty modeling, different simulation methods have been implemented in existing 
models. Monte Carlo Simulation (Orabi et al. 2013; Heravi and Faeghi 2012; Ökmen and Öztaş 2008) and Discrete-Event Simulation (Puri and Martinez 2012; Taghaddos et al. 2011; Lee et al. 2010; Zhang and Li 2004) are among the most-used simulation methods. Some researchers have employed other methods, such as Chance-Constrained Programming (Gabriel et al. 2006), SIMPHONY simulation (Chen et al. 2012), CYCLONE simulation (Hong et al. 2011), or combined methodologies (Sadeghi et al. 2012; Shahin et al. 2010; Peña-Mora et al. 2008). However, the important issue in this area of study is using results of mentioned stochastic models to obtain a more realistic plan for resource utilization. Two main research gaps can be identified within the studies on resource utilization planning under uncertainty in construction. First, there is lack of research studies that properly model day-to-day change of productivity under uncertainties, since uncertainties such as weather condition can frequently affect crew productivity on a daily basis (Shahin et al. 2010). In addition, resource utilization planning of a group of projects competing for a limited pool of resources requires planners to examine different resource sharing policies to find optimal solutions. However, no reported research considered stochastic optimization of resource sharing at portfolio level. Accordingly, there is a need for a new model that covers these two important research gaps.

This paper therefore presents the development of a new simulation-optimization model, which simulates crew production rate instead of project or activity durations and in fact, considers the impact of uncertainties on the daily production rate of the resource. The developed model is capable of utilizing resources at three construction levels: activity, project and portfolio. This provides the model with ability of sharing a limited pool of 
resources among a portfolio of competing projects considering resource utilization, allocation and sharing policies. Furthermore, the multi-objective optimization model simultaneously minimizes completion time and cost of the portfolio, while taking into consideration the impact of alternative resource utilization scenarios. The results of the model provides decision makers with a comprehensive perspective on construction performance of the portfolio under uncertainty. Figure 1 shows general components and overall flow of the proposed model. In the simulation module, uncertainties and their impact on daily resource production rate contribute to estimation of resource consumption and construction performance estimates. Then, having duration and cost of the portfolio (i.e. result of network scheduling simulation for certain number of iterations) aside to preassumed alternative scenarios (i.e. decision variables), the model finds the optimum solutions for resource planning through multi-objective optimization process. The following sections of the paper present the development of the proposed model, an illustrative application example to demonstrate and discuss its capabilities, and eventually, conclusions and recommendations for future research.

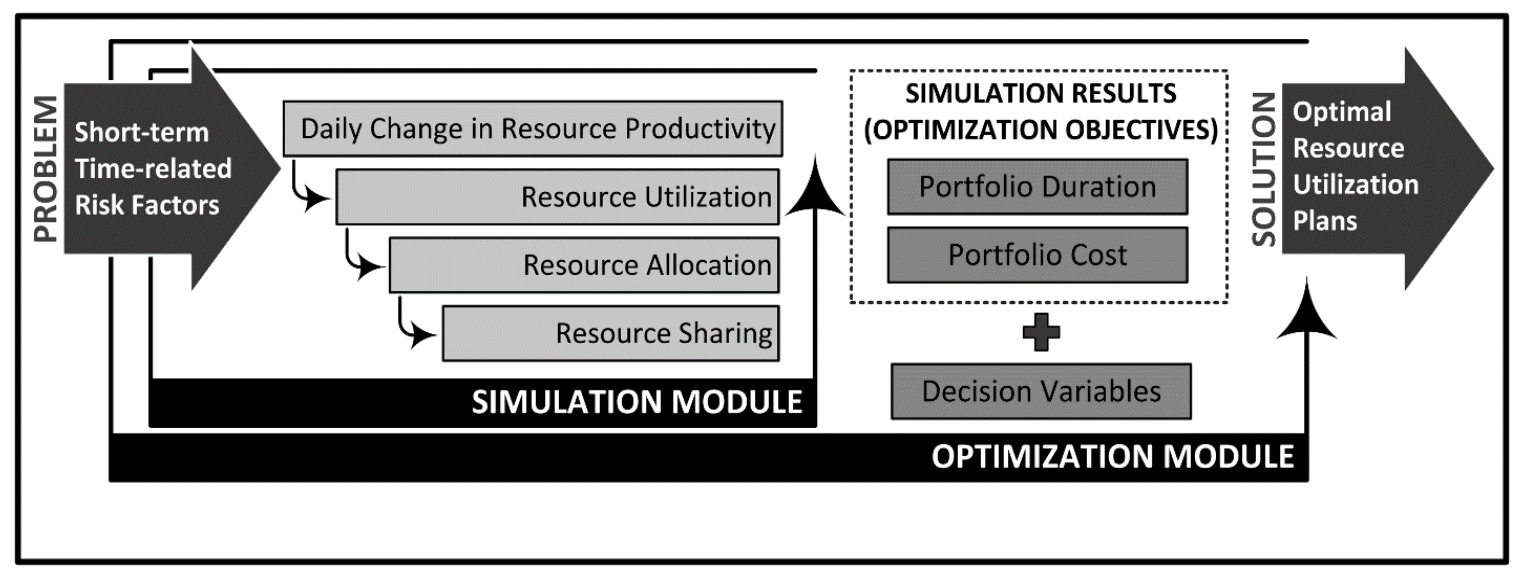

Figure 4.1. General components and overall flow of the model 


\subsection{Stochastic Simulation of the Portfolio Network}

The main purpose of the simulation module of the proposed model is to measure the impact of uncertainties on projects schedule and cost, through performing a day-to-day resource management analysis. To this end, the simulation module eventually produces duration and cost frequency distributions of the portfolio through capturing changes in crew production rate, on a day-to-day or even shift-to-shift basis. The model, which has been coded in $\mathrm{C}++$ programing language, is also capable of developing duration and cost distributions separately for different construction levels. The simulation module is based on Productivity Simulation Model (PSM) developed by Orabi et al. (2013) which simulates resource utilization in the following stages; first, utilizing resources at activity level, then allocating resources at project level and finally, sharing limited pool of resources among different projects at portfolio level. Before starting the simulation process, required input data are collected and prepared to be used in the model. Mentioned data include project and portfolio scheduling data, crew productivity data, resource availability data, project cost data, etc. Model uses collected data to initialize simulation procedure and perform analyses during different phases. Figure 2 shows overall flow and components of the simulation module at different analysis levels within each iteration. At resource usage level, the model simulates productivity of crews utilized to each activity and estimates daily performance and cost of activities based on resource availability and cost data. The result of activity level analysis is duration and cost of each activity. At resource allocation level, these outputs besides project network scheduling and indirect cost data are used to calculate project total duration and cost. This process is repeated for all projects of the portfolio and eventually, at resource sharing level, the model estimates total portfolio duration and cost 
considering prioritization of projects and portfolio cost data. The model repeats the mentioned procedure for limited number of iterations and in each iteration, uses crew productivity distributions to capture daily changes in crew production rates. To this end, Monte Carlo Simulation method has been implemented in the model to extract production rates from productivity distributions. Final outputs of the stochastic simulation process are duration and cost frequency distributions of portfolio throughout iterations.

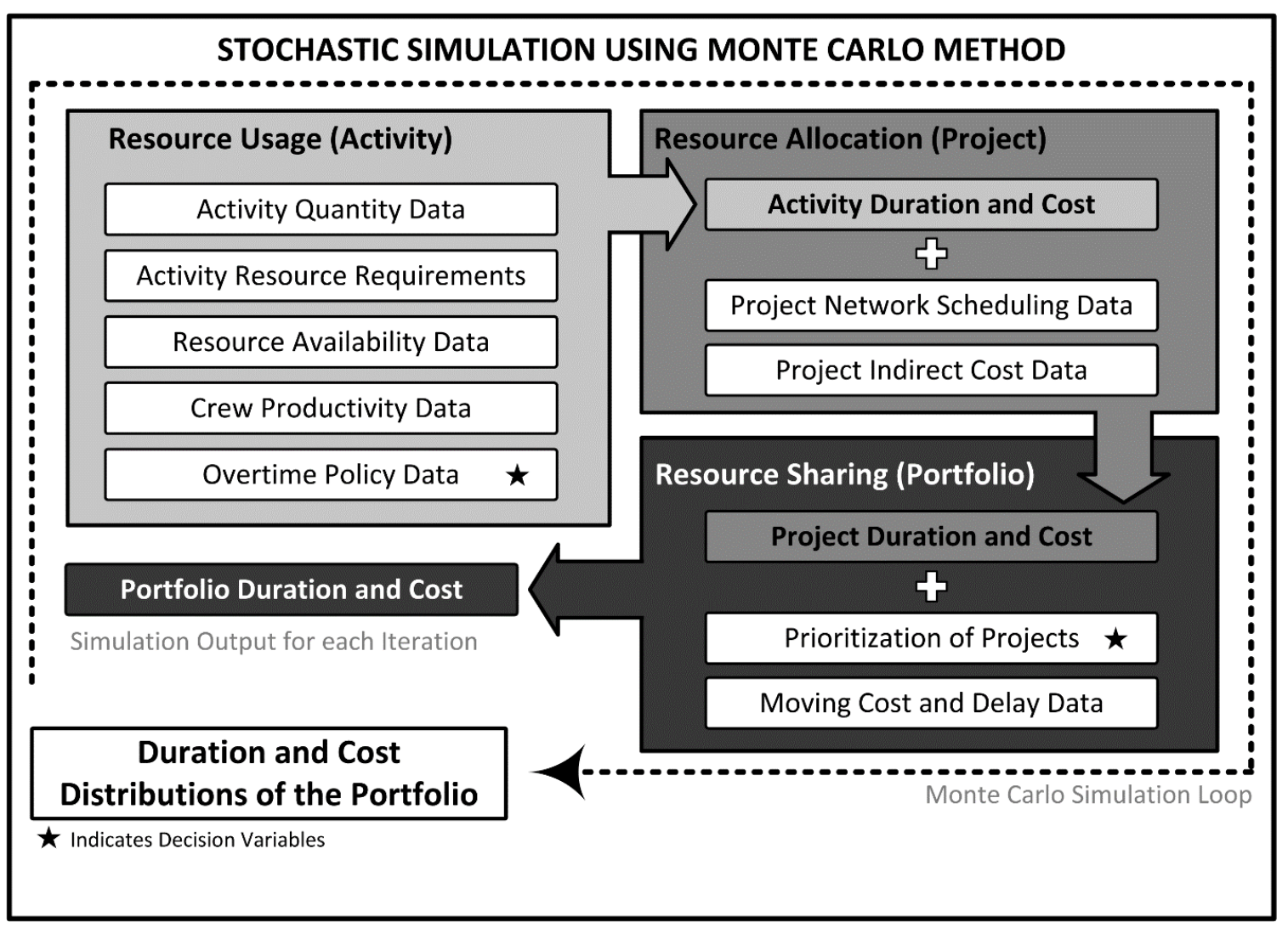

Figure 4.2. Analysis levels and general flow of the simulation module

Two different types of cost have been considered in the model. Direct costs, including crew cost rate (i.e. crew daily wage and burden) and material cost rate of each activity. 
The indirect cost, however, includes expenses that are not directly related to the amount of work performed throughout project. At project level, indirect cost is a fixed daily rate for each project to cover site and main office overheads. Additionally, in this paper, a mobilization cost rate has been considered for each specific equipment in a crew to represent cost of moving construction equipment between projects. The aforementioned cost contributes to the total indirect cost of the portfolio. It should be mentioned that the starred items in Figure 2 indicate decision variables of the optimization module, which are described in next sections.

\subsubsection{Resource Usage (RU) or Activity Level Procedures}

As shown in Figure 2, at the resource usage level, the model uses input data such as quantity of the work, resource requirements, resource availability, crew productivity and overtime policy data to estimate completion time and cost of each activity. This process involves two procedures; (1) activity scheduling and (2) duration calculation, which calculate activity start time and duration, respectively. Figure 3 shows a diagram of these procedures, their components, and required input data. Activity scheduling procedure uses Critical Path Method (CPM) to schedule activities within projects, and requires activity durations in addition to project milestones and time constraints. The model uses different production rates for construction crews in each working shift, to capture the impact of short-term change of uncertainties on activity duration and cost. This productivity change affects availability time-table of certain resources. Therefore, the simulation module schedules activities (project level) and calculates their durations (activity level), simultaneously. The model first estimates earliest possible start time of each activity based 
on completion times of preceding activities and/or project milestones. In this stage, actual activity start time depends on availability of the required resource (crew) in project resource pool. Unless the start time is postponed to a later date due to unavailability of a certain crew, the model schedules each activity on the estimated earliest date.

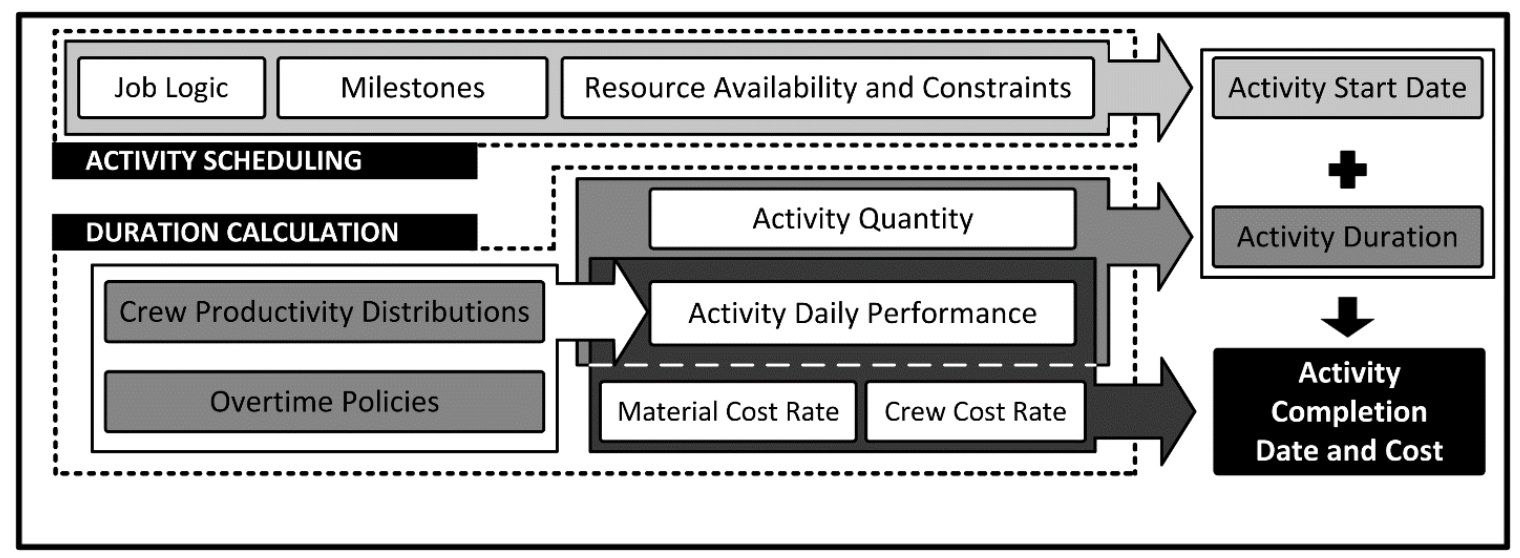

Figure 4.3. Activity level analysis from the simulation module

To calculate activity duration and cost through the second procedure, the model performs the following steps for each activity:

1. Developing a suitable crew productivity curve based on pre-specified frequency distribution type (normal, beta or triangular distributions) and pre-collected statistical data regarding productivity for each resource crew. Mentioned statistical data for each crew are most likely, optimistic and pessimistic production rates. The model uses Program Evaluation and Review Technique (PERT) equations to estimate mean and standard deviation of production rate distributions, as shown in Eq. 1 and 2. 


$$
\begin{gathered}
\mu_{\mathrm{n}}=\frac{\left(P_{\text {opt }}\right)_{n}+4 \times\left(\mathrm{P}_{\mathrm{ml}}\right)_{n}+\left(\mathrm{P}_{\mathrm{pes}}\right)_{n}}{6} \\
\sigma_{n}=\frac{\left(P_{\text {opt }}\right)_{n}-\left(\mathrm{P}_{\mathrm{pes}}\right)_{n}}{6}
\end{gathered}
$$

Where, $\left(\mu_{\mathrm{n}}\right)$ and $\left(\sigma_{\mathrm{n}}\right)$ are the mean and standard deviation of productivity distribution of crew $(n)$, respectively. $\left(\mathrm{P}_{\mathrm{opt}}\right)_{\mathrm{n}},\left(\mathrm{P}_{\mathrm{ml}}\right)_{\mathrm{n}}$, and $\left(\mathrm{P}_{\mathrm{pes}}\right)_{\mathrm{n}}$ represent the optimistic, most likely, and pessimistic production rates of crew $(n) .\left(\mu_{\mathrm{n}}\right)$ and $\left(\sigma_{\mathrm{n}}\right)$ are used to develop productivity frequency and probability distributions for each resource crew. Developed distributions are used to formulate inverse cumulative probability function for each crew to be used in step 3 .

2. Assigning number and length of required working shifts per day based on overtime policy alternative. Mentioned alternative, which is one of the decision variables of the optimization module, is allotted specifically to each project, as explained in the optimization section of this paper. Each alternative includes productivity and cost adjustment factors for crews working in different shifts.

3. Estimating an instant production rate for each crew working on each work-shift using Monte Carlo Simulation Method. To practically consider the effect of shortterm time-related uncertainties in resource productivity change, the model generates random probabilities for each crew in each shift, and extracts the corresponding production rates from inverse cumulative probability distribution 
(created in the step 1). The model is able to fit Triangular, Beta and Normal frequency distributions to productivity input data depending on the type and specifications of the crew. The model then modifies the estimated production rate using adjustment factor obtained in step 2 .

4. Calculating daily performance of the construction crews by repeating previous step for all shifts of the day, as formulated in Equation 3.

$$
D P=\sum_{n=1}^{N} \sum_{m=1}^{M}\left(P_{n m} \times f_{p-n}\right)
$$

In the above equation $(D P)$ is daily performance of each activity, $(N)$ is number of working shifts per day, $(M)$ is number of crews working concurrently in shift $(n)$, $\left(P_{n m}\right)$ represents estimated production rate of crew $(m)$ in shift $(n)$, and $\left(f_{p-n}\right)$ is productivity adjustment factor of the shift $(n)$. The phrase $\left(P_{n m} \times f_{p-n}\right)$ estimates the modified production rate of crew $(m)$ in shift $(n)$, as described in step 3.

5. Estimating daily crew cost of construction. Crew cost is one of the two components of the direct cost besides material cost. The model calculates modified crew cost for each crew working on each shift based on crew hourly wage and burden, and also cost adjustment factor described in step 2. Then estimates the daily crew cost similar to daily performance via adding up calculated costs of all crews worked entire day, as formulated in Equation 4. Material cost will be later calculated along with estimating activity duration. 


$$
D C C=\sum_{n=1}^{N} \sum_{m=1}^{M}\left(C C_{n m} \times f_{C-n}\right)
$$

6. In the Equation $4(D C C)$ is daily crew cost for the current activity, $(N)$ is number of working shifts per day, $(M)$ is number of crews working concurrently in shift $(n),\left(C C_{n m}\right)$ represents cost of crew $(m)$ in shift $(n)$, and $\left(f_{c-n}\right)$ is cost adjustment factor of the shift $(n)$.

7. Calculating activity duration. Through repeating steps 3 and 4 in a loop, the model adds up daily performance of the crews and counts number of days it takes until crews execute entire quantity of the activity. Using activity durations and start date, the model estimates the activity completion time as demonstrated in Figure 3.

8. Calculating total activity direct cost as formulated in Equation 5.

$$
A D C=\left(\sum_{d=1}^{D} D C C_{d}\right)+(M C \times A Q)
$$

In the above equation, $(A D C)$ is activity direct cost (i.e. activity completion cost), $(D)$ is activity duration as estimated in step $6,\left(D C C_{d}\right)$ is daily cost of the day $(d)$ as calculated in step 5, $(M C)$ is material cost rate (if any), and $(A Q)$ is quantity of material needed to complete the activity (e.g. amount of poured concrete).

Eventually as shown in Figure 3, the model estimates the activity completion time and cost, to be used in project-level scheduling simulation and cost calculation, respectively.

\subsubsection{Project and Portfolio Level Procedures}


As shown in Figure 2 at the project level, the model schedules activities using CPM based on project network data. Project duration then is calculated having start date of the first activity and completion date of the last activity. For the project completion cost, the model first calculates project direct cost by adding up completion cost of activities, then estimates project indirect cost via multiplying project duration by project daily indirect cost rate. Finally, total project cost is the summation of project direct and indirect costs, as formulated in Equation 6.

At portfolio level, the model shares limited pool of resources between competitive projects, which are scheduled based on pre-defined priorities. It means that projects with higher priority are allocated and utilized with resources sooner than others. Therefore, prioritization of the projects affects the amount of remaining available resources for lowpriority projects and eventually, affects activity, project and portfolio durations. Another factor that affects duration and cost of portfolio is equipment mobilization and demobilization. To capture the impact of moving equipment between projects during the construction, cost and delay of moving is considered in the proposed model. Moving of equipment affects the total portfolio indirect cost by adding a fixed amount per movement of each equipment. It also delays availability of resources that are released from a project for a fixed amount of time until they can be used in other projects. Mentioned delay would potentially affect the duration estimation in all analysis levels due to availability of enough resources to start activities. Portfolio duration is calculated based on start date of the first project and completion date of the last project. The model eventually estimates the total portfolio cost using Equation 6 


$$
T P C=\left(\sum_{p=1}^{P}\left(\sum_{a=1}^{A_{p}}\left(A D C_{a}\right)+\left(D_{p} \times I C_{p}\right)\right)\right)+T M C
$$

In the above equation, $(T P C)$ is total portfolio cost, $(P)$ is number of projects in the portfolio, $\left(A_{p}\right)$ is number of activities in the project $(p),\left(A D C_{a}\right)$ is activity direct cost of the activity $(a)$ as estimated in step $7,\left(D_{p}\right)$ is duration of project $(p),\left(I C_{p}\right)$ is the daily indirect cost rate of the project $(p)$, and finally, (TMC) represents the total moving cost of equipment and crews inside the portfolio, as described in the previous section. The final output of each simulation iteration, which is a pair of portfolio duration and cost, is used by the model to develop duration and cost frequency distribution curves as the result of simulation module. Output curves demonstrate the occurrence frequency of possible portfolio durations or costs. These distribution curves are used in the optimization module, in order to extract portfolio duration and cost based on risk attitude of the decision makers.

\subsection{Multi-Objective Optimization}

\subsubsection{Objectives and Constraints}

The main objective of the optimization module is to find optimum solutions for resource utilization planning problem that minimize time and cost of the portfolio, simultaneously. The optimization module develops planning scenarios based on decision variables and obtains duration and cost distributions in correspondence to each scenario (via simulation module). The result of the optimization module is a time-cost trade-off consisting of various optimum pairs of portfolio duration and cost under different risk attitudes. Figure 4 shows components and general flow of the multi-objective optimization module. This 
study considers four major modeling constraints in order to practically approach the mentioned optimization problem. The first two are time-related constraints including (1) each projects should start on a pre-specified date (i.e. mandatory start milestone), and (2) each project should be continuously executed until completion without any pause. The rest are resource-related constraint: (3) the resource pool which is shared between projects within the portfolio is limited (in case of total available amount of crews and material per day), and (4) maximum number of crews that can simultaneously work on an activity is limited to avoid jobsite conflicts and meet safety requirements. This limitation may vary for different activities and projects.

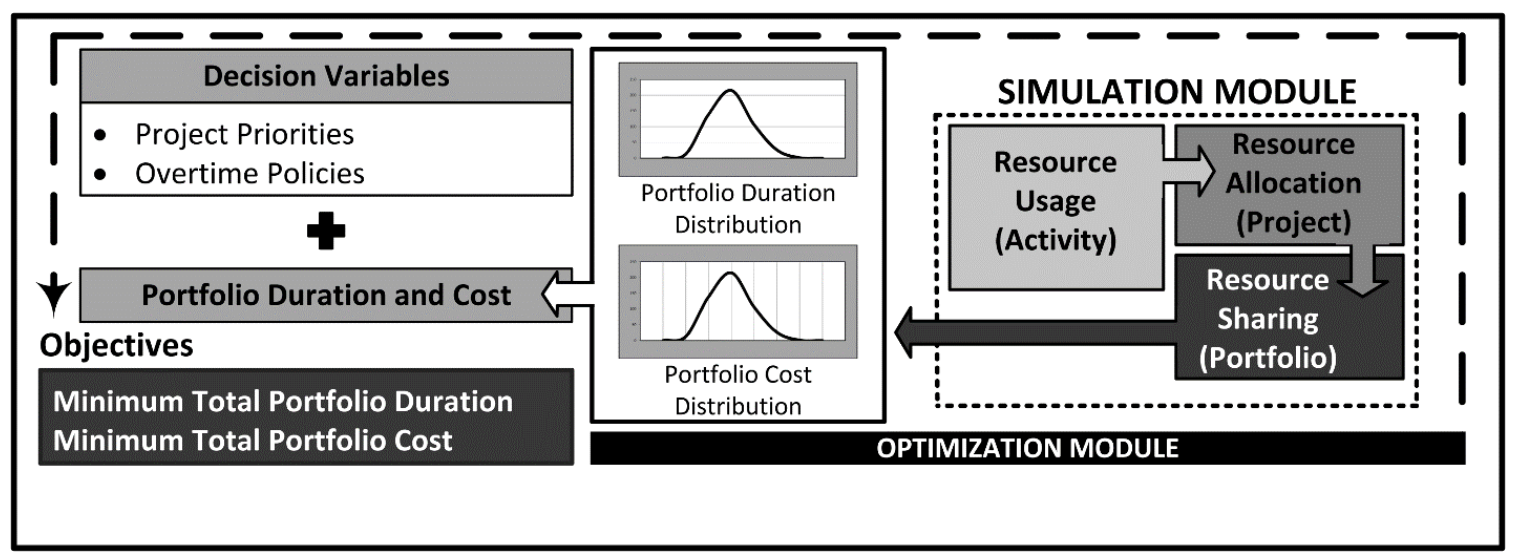

Figure 4.4. Optimization module general flow and components

\subsubsection{Decision Variables}

Considering mentioned constraints, the model examines the impact of two main decision variables on optimization objectives, as shown in Figure 4: (1) prioritizing projects of the portfolio for scheduling and resource consumption purposes, and (2) applying different overtime working policies to projects (e.g. multiple working shifts, different shift lengths, 
etc.) These decision variables widely affect both resource availability and productivity, and consequently duration and cost.

The first decision variable examines how prioritization of the projects affects optimization objectives. Due to the time-related constraints, each project should have access to at least a minimum number of crews required for execution, from the first day throughout its construction period (lower resource limit). On the other hand, resource-related constraints impose a limit for maximum number of crews available and/or allowed to be assigned to a project each day (upper resource limit). In terms of availability, projects with higher priority are assumed to be provided with their maximum number of crews during execution, while (1) maintaining number of resources between lower and upper limit, and (2) leaving enough resources for projects with lower priority to start and continue. In terms of productivity, projects with higher priority have the chance to be utilized with more productive crews, if available. Therefore, this approach leaves the low-priority projects with underutilized performance capacity and relatively low productivity resources. As the second variable, use of different overtime policy alternatives affects the resource availability limits by changing the number of working shifts per day. It also has an impact on production rate through applying productivity adjustment rates. In addition, OTP alternatives can directly modify direct cost of the project via cost adjustment factors. Thus, using the combination of mentioned decision variables, the model is capable of developing a wide spectrum of resource utilization scenarios in order to obtain considerable potential solutions. 


\subsubsection{Model Implementation}

The optimization engine of the proposed model is Non-Dominated Sorting Genetic Algorithm (Deb et al. 2000). Multi-objective nature of the problem and effectiveness of NSGA-II in generating near optimal solutions are the reasons to select this algorithm for the proposed model. The model starts by generating a random population of solutions and produces next generations via operations such as selection, crossover, and mutation throughout the population. It continues producing generations and eventually extracts nondominated optimal or near optimal sets of solutions from the final population. In each generation of the NSGA-II, the model (1) creates potential solutions (chromosomes) based on decision scenarios, (2) performs Monte Carlo stochastic simulation for all of the solutions (entire population), and (3) produces portfolio duration and cost distribution curves in order to examine optimization objectives and pick optimal solutions. As shown in Figure 4, the model picks one pair of duration and cost from the distributions based on different risk attitudes (or confidence levels) of decision makers. To this end, similar to the procedure described in step 3 of activity-level simulation the model first develops inverse cumulative probability function of each distribution (See Figure 5). Then, extracts portfolio duration and cost corresponding to the risk-attitude of the decision makers from the curves. To this end, the model uses Table 1, which lists 4 different risk attitudes used in this study and their corresponding assumed probabilities. Eventually, the model returns a unique Pareto Front for each probability, which demonstrates a non-dominated time-cost tradeoff at certain risk attitude. The result helps managers have a more realistic decision making process due to consideration of their risk attitude toward selecting optimal solutions. 
Table 4.1. Risk attitudes and corresponding probabilities

\begin{tabular}{ccc}
\hline & Confidence Level & \\
Risk Attitude & (on resource productivity) & Probability \\
\hline Highly Risk-Averse & Very Low & $90 \%$ \\
Risk-Averse & Low & $75 \%$ \\
Risk-Seeking & High & $60 \%$ \\
Highly Risk-Seeking & Very High & $45 \%$ \\
\hline
\end{tabular}

Table 1 suggests that lower confidence on performance of the resources under uncertainty leads to more risk-averse attitudes regarding selection of solutions, and should be indicated by higher cumulative probabilities when deciding about extracting time and cost. For instance, when the risk attitude is considered to be risk-averse (probability is $75 \%$ ), decision makers select their desired resource utilization plan from the non-dominated solutions depicted on the $75 \%$-Tradeoff. Due to the uncertainties, solutions in this tradeoff are likely to exceed their suggested optimum time and cost in $25 \%$ of time. Thus, any decision made based on this attitude is obviously more risk-averse than choosing, for example, $45 \%$-Tradeoff. The latter, similarly, exposes managers to around $55 \%$ likelihood of time and cost overrun. It can also be interpreted in another way: managers can find out how much they may save as for taking different risks. 


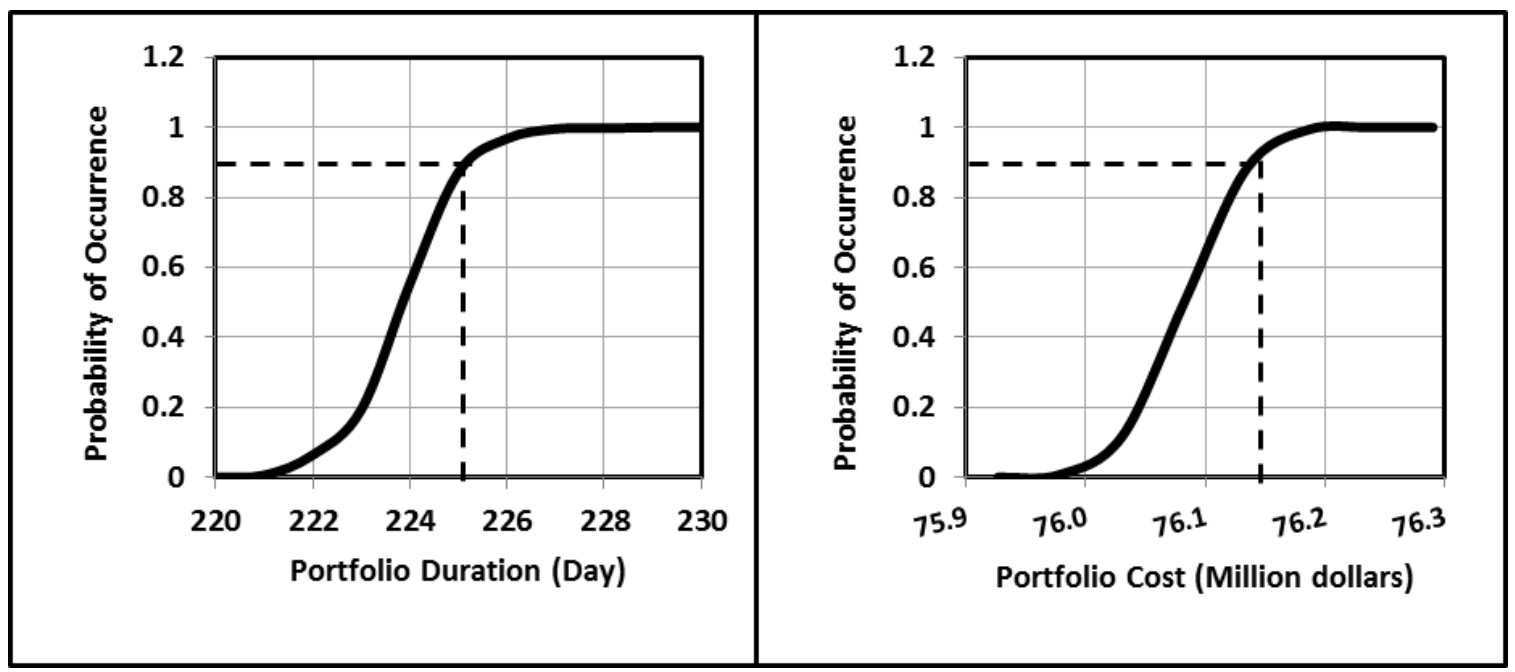

Figure 4.5. Extracting portfolio duration and cost from stochastic simulation outputs (distributions) based on pre-defined confidence levels

\subsection{Application Example and Results}

To illustrate usage and capabilities of the developed model, an application example is analyzed and the results are represented and discussed. The application example is based on previous study on recovery of infrastructure systems (Orabi et al. 2010) and represents reconstruction of a transportation network in Sioux Falls, SD. As mentioned in previous sections, different types of input data are required for the model to complete the analysis. These input data include (1) network scheduling, resource requirements and indirect cost data (Table 2), (2) crew productivity, availability and moving impact data (Table 3), and (3) overtime policy alternatives along with corresponding productivity and cost adjustment factors (Table 4). Regarding resource-related constraints, it should be mentioned that in this example only one crew can work in each shift of a specific activity. It is also assumed that the resource pool is capable of supporting all projects to have their minimum required resource to start and continue. 
Figure 6 shows the time-cost tradeoff for all non-dominated solutions generated by the model. In the figure, results of the stochastic optimization are demonstrated along with optimal deterministic results. Deterministic results prove the significant impact of considering short-term risk factors on time and cost estimate. As expected, assuming optimistic crew productivity leads to lower duration and cost, while pessimistic presumption causes overestimation. Wide range of solutions indicates that the portfolio completion time and cost are highly sensitive to different resource planning alternatives (i.e. decision variables).

Table 4.2. Crew productivity distributions, cost and availability data

\begin{tabular}{|c|c|c|c|c|c|c|c|c|}
\hline \multirow[b]{2}{*}{ ID } & \multirow[b]{2}{*}{ Dist. } & \multirow[b]{2}{*}{ Unit } & \multirow[b]{2}{*}{$\begin{array}{c}\text { Cost } \\
\text { (\$/Shift) }\end{array}$} & \multicolumn{3}{|c|}{$\begin{array}{c}\text { Productivity Rates } \\
\text { (Unit/Shift) }\end{array}$} & \multicolumn{2}{|c|}{$\begin{array}{c}\text { Moving Impacts } \\
\text { (Per Move) }\end{array}$} \\
\hline & & & & Pes. & ML & Opt. & $\begin{array}{l}\text { Cost } \\
(\$)\end{array}$ & $\begin{array}{l}\text { Delay } \\
\text { (Days) }\end{array}$ \\
\hline B-08 & Beta & $\mathrm{CY}$ & 4,363 & 10,200 & 11,700 & 14,000 & 65 & 1 \\
\hline B-10M & Beta & $\mathrm{CY}$ & 1,362 & 2,000 & 2,220 & 3,000 & 70 & 1 \\
\hline B-12F & Beta & $\mathrm{CY}$ & 993 & 55 & 70 & 80 & 210 & 2 \\
\hline B-19A & Beta & $\mathrm{LF}$ & 3,542 & 140 & 160 & 195 & 230 & 2 \\
\hline B-26 & Tri. & SY & 4,313 & 1,530 & 1,760 & 1,820 & 460 & 3 \\
\hline B-43 & Normal & Ea. & 3,265 & 4 & 6 & 8 & 110 & 1 \\
\hline B-78 & Tri. & $\mathrm{LF}$ & 1,646 & 3,200 & 3,660 & 4,350 & 240 & 2 \\
\hline $\mathrm{C}-02 \mathrm{~A}$ & Tri. & $\mathrm{LF}$ & 1,477 & 100 & 110 & 121 & 50 & 1 \\
\hline C-14A & Normal & $\mathrm{CY}$ & 7,700 & 15 & 20 & 26 & 330 & 2 \\
\hline C-14B & Normal & $\mathrm{CY}$ & 7,415 & 16 & 20 & 27 & 450 & 3 \\
\hline C-14C & Normal & $\mathrm{CY}$ & 3,297 & 28 & 40 & 49 & 210 & 1 \\
\hline
\end{tabular}


Table 4.3. Project scheduling, resource requirements and indirect cost data

\begin{tabular}{|c|c|c|c|c|c|c|c|c|}
\hline \multirow[b]{2}{*}{ Project } & \multirow[b]{2}{*}{ Activity } & \multirow[b]{2}{*}{ Prec. } & \multirow[b]{2}{*}{ Succ. } & \multirow[b]{2}{*}{ Unit } & \multirow[b]{2}{*}{ Quantity } & \multirow{2}{*}{$\begin{array}{c}\text { Crew } \\
\text { ID }\end{array}$} & \multicolumn{2}{|c|}{ Cost } \\
\hline & & & & & & & $\begin{array}{c}\text { Material } \\
\text { (\$/unit) }\end{array}$ & $\begin{array}{l}\text { Indirect } \\
\text { (\$/day) }\end{array}$ \\
\hline \multirow[t]{6}{*}{ A } & 1 & - & 2,3 & $\mathrm{CY}$ & 1,300 & C-14A & 630 & 1000 \\
\hline & 2 & 1 & 3 & $\mathrm{CY}$ & 580 & C-14A & 630 & \\
\hline & 3 & 1,2 & 4,5 & $\mathrm{CY}$ & 1,540 & C-14B & 630 & \\
\hline & 4 & 3 & 5 & SY & 3,360 & B-26 & 550 & \\
\hline & 5 & 3,4 & 6 & LF & 260 & B-78 & 140 & \\
\hline & 6 & 5 & - & $\mathrm{LF}$ & 260 & $\mathrm{C}-2 \mathrm{~A}$ & 100 & \\
\hline \multirow[t]{6}{*}{ B } & 1 & - & 2,3 & $\mathrm{CY}$ & 1,950 & C-14A & 630 & 1000 \\
\hline & 2 & 1 & 4 & $\mathrm{CY}$ & 850 & C-14A & 630 & \\
\hline & 3 & 1 & 4 & CY & 2,040 & C-14B & 630 & \\
\hline & 4 & 2,3 & 5 & SY & 4,450 & B-26 & 550 & \\
\hline & 5 & 4 & 6 & $\mathrm{LF}$ & 350 & B-78 & 140 & \\
\hline & 6 & 5 & - & LF & 350 & $\mathrm{C}-2 \mathrm{~A}$ & 100 & \\
\hline \multirow[t]{12}{*}{$\mathrm{C}$} & 1 & - & 2,4 & $\mathrm{CY}$ & 6,600 & B-8 & 300 & 1200 \\
\hline & 2 & 1 & 3,6 & $\mathrm{CY}$ & 18,150 & B-10M & 250 & \\
\hline & 3 & 2 & 7 & $\mathrm{LF}$ & 1,140 & B-19A & 320 & \\
\hline & 4 & 1 & 5 & CY & 15,700 & $\mathrm{~B}-12 \mathrm{~F}$ & 820 & \\
\hline & 5 & 4 & 7,8 & Ea. & 33 & B-43 & 430 & \\
\hline & 6 & 2 & 8 & $\mathrm{CY}$ & 9,400 & C-14C & 630 & \\
\hline & 7 & 3,5 & 9 & $\mathrm{CY}$ & 1,620 & C-14A & 630 & \\
\hline & 8 & 5,6 & 10 & $\mathrm{CY}$ & 720 & C-14A & 630 & \\
\hline & 9 & 7 & 11 & $\mathrm{CY}$ & 1,920 & C-14B & 630 & \\
\hline & 10 & 8 & 11 & SY & 4,200 & B-26 & 550 & \\
\hline & 11 & 9,10 & 12 & $\mathrm{LF}$ & 330 & B-78 & 140 & \\
\hline & 12 & 11 & - & $\mathrm{LF}$ & 330 & $\mathrm{C}-2 \mathrm{~A}$ & 100 & \\
\hline \multirow[t]{12}{*}{$\mathrm{D}$} & 1 & - & 2,4 & $\mathrm{CY}$ & 4,060 & B-8 & 300 & 1200 \\
\hline & 2 & 1 & 3,6 & CY & 11,150 & B-10M & 250 & \\
\hline & 3 & 2 & 7 & $\mathrm{LF}$ & 700 & B-19A & 320 & \\
\hline & 4 & 1 & 5 & $\mathrm{CY}$ & 9,640 & B-12F & 820 & \\
\hline & 5 & 4 & 7,8 & Ea. & 20 & B-43 & 430 & \\
\hline & 6 & 2 & 8 & $\mathrm{CY}$ & 5,770 & C-14C & 630 & \\
\hline & 7 & 3,5 & 9 & $\mathrm{CY}$ & 1,000 & C-14A & 630 & \\
\hline & 8 & 5,6 & 10 & $\mathrm{CY}$ & 440 & C-14A & 630 & \\
\hline & 9 & 7 & 11 & $\mathrm{CY}$ & 1,180 & C-14B & 630 & \\
\hline & 10 & 8 & 11 & SY & 2,580 & B-26 & 550 & \\
\hline & 11 & 9,10 & 12 & LF & 200 & B-78 & 140 & \\
\hline & 12 & 11 & - & $\mathrm{LF}$ & 200 & $\mathrm{C}-2 \mathrm{~A}$ & 100 & \\
\hline \multirow[t]{5}{*}{$\mathrm{E}$} & 1 & - & 2 & $\mathrm{CY}$ & 620 & C-14A & 630 & 1000 \\
\hline & 2 & 1 & 3 & $\mathrm{CY}$ & 1,650 & C-14B & 630 & \\
\hline & 3 & 2 & 4 & SY & 3,610 & B-26 & 550 & \\
\hline & 4 & 3 & 5 & $\mathrm{LF}$ & 280 & B-78 & 140 & \\
\hline & 5 & 4 & - & LF & 280 & C- $2 \mathrm{~A}$ & 100 & \\
\hline
\end{tabular}


Table 4.4. Overtime policy alternatives

\begin{tabular}{|c|c|c|c|c|c|c|c|}
\hline \multirow{2}{*}{$\begin{array}{c}\text { OTP } \\
\text { Alt. }\end{array}$} & \multirow{2}{*}{$\begin{array}{l}\text { Week } \\
\text { Days }\end{array}$} & \multirow{2}{*}{$\begin{array}{l}\text { Shifts } \\
\text { Per Day }\end{array}$} & \multirow{2}{*}{$\begin{array}{l}\text { Hours } \\
\text { Per Shift }\end{array}$} & \multicolumn{2}{|c|}{ Adjustment Factor (\%) } & \multirow{2}{*}{$\begin{array}{l}\text { Cycle Time } \\
\text { Coef. }\end{array}$} & \multirow{2}{*}{$\begin{array}{c}\text { Daily Cost } \\
\text { Coef. }\end{array}$} \\
\hline & & & & Productivity & Cost & & \\
\hline 1 & 5 & 1 & 8 & 100 & 100 & 1.00 & 1.00 \\
\hline 2 & 5 & 1 & 12 & 76.25 & 133.3 & 0.87 & 1.75 \\
\hline 3 & 5 & 2 & 12 & 68.75 & 153.3 & 0.48 & 2.23 \\
\hline 4 & 7 & 1 & 8 & 88.75 & 128.6 & 1.13 & 1.45 \\
\hline 5 & 7 & 1 & 12 & 68.75 & 152.4 & 0.97 & 2.22 \\
\hline 6 & 7 & 2 & 12 & 62 & 175.25 & 0.54 & 2.83 \\
\hline
\end{tabular}

In case of stochastic optimization, alternative plans would result in $\$ 3.5 \mathrm{M}$ potential cost difference and about a year of variation in portfolio duration. However, not all the solutions are desirable in most cases due to the time and budget limitations. Therefore, decision makers need to find certain resource utilization plans that meet their time and cost restrictions. Based on time-cost similarities, 9 groups of solutions (called resource utilization planning clusters) have been identified throughout the stochastic tradeoff. Results show that solutions in each cluster mainly share a similar combination of overtime policy alternatives (Table 4) for projects. Each combination is represented with an OTP index that indicates which overtime policy alternatives have been applied to each of the five projects of the portfolio. 


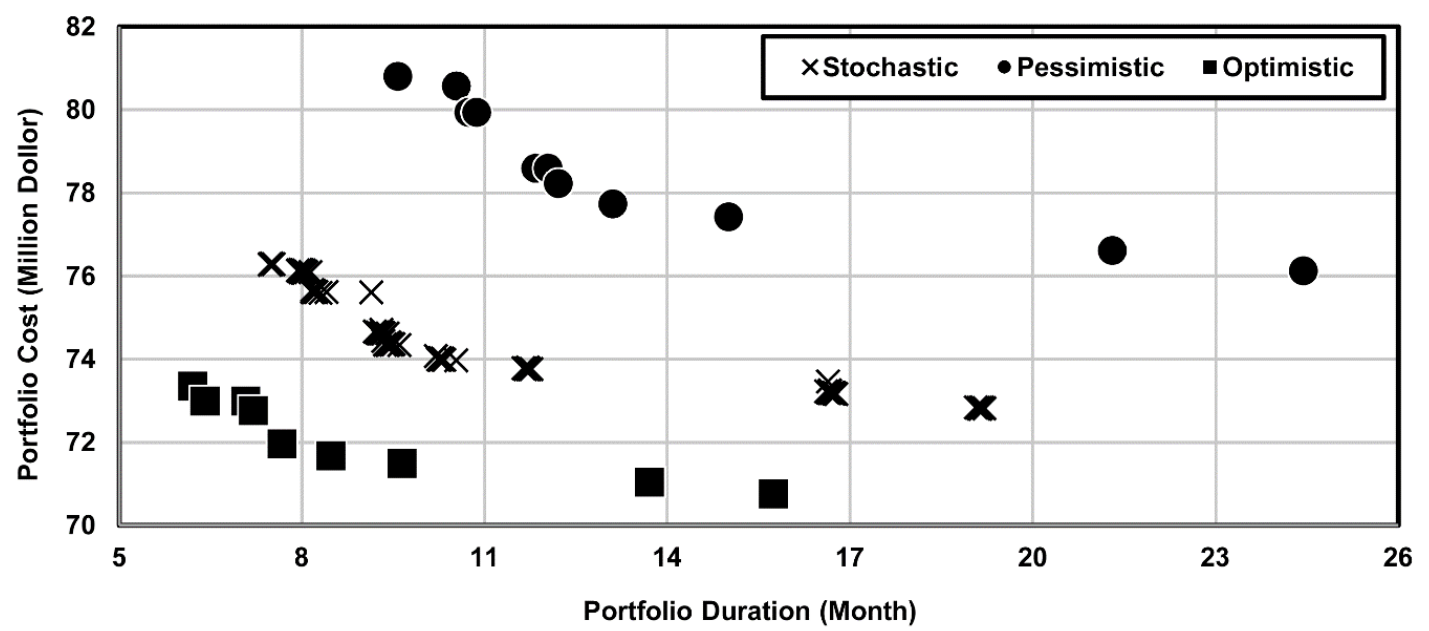

Figure 4.6. Portfolio Time-Cost tradeoff

Figure 7 shows resource utilization planning clusters, their related OTP Index, and also their associated duration and cost trends (considering risk-averse attitude). For instance, in cluster \#4, OTP alternatives $1,2,3,3$, and 1 are suggested for projects $\mathrm{A}$ to $\mathrm{E}$, respectively (i.e. OTP index of the cluster 4 is 1-2-3-3-1). Solutions of each cluster fall into limited ranges of portfolio time and cost. As shown in the figure, adding extra working days, shifts and hours to construction work calendar (i.e. using alternatives such as 3 or 6) reduces portfolio duration while increasing the total cost. On the other hand, longest duration and minimum cost are obtained when all projects used regular working timetable (i.e. cluster 9 which suggests alternative 1 for the entire portfolio). For each overtime policy alternative, cycle time coefficient indicates the time required for the crew to complete a regular 8-hours job in proportion with alternative 1 (i.e. regular work policy). Similarly, daily cost coefficient modifies cost of finishing the mentioned cycle time compared to alternative 1. According to Figure 7, alternatives 4 and 5 have not been used in none of non-dominated OTP indexes. Since these alternatives have both higher cycle 
time and daily cost coefficients than alternatives 1 and 2, respectively, solutions utilized with these alternatives are more likely to have higher time and cost, and consequently become dominated by other solutions. Alternative 6 has the same relation with alternative 3 , however, crews produce significantly higher when utilized with alternative 3 and 6 comparing to other alternatives. Therefore, as reflected in Figure 7, alternative 6 has been suggested by the model in the first three clusters before getting dominated by other alternatives.

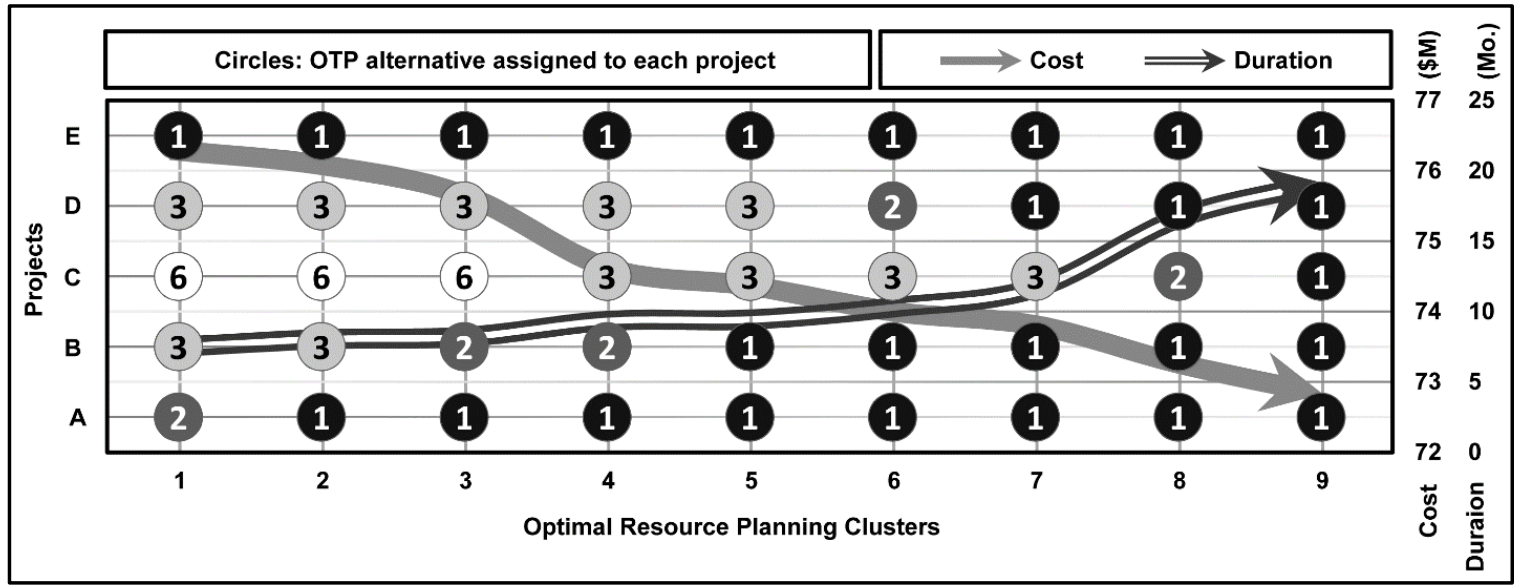

Figure 4.7. Optimal resource planning clusters with sample solutions from riskaverse attitude

Figure 8 shows optimal resource utilization solutions for three sample clusters (1, 5 and 8$)$. Solutions in each cluster show a cost variation of about $\$ 80 \mathrm{~K}$ on average, which indicates the significant impact of decisions both about resource planning and risk attitude on portfolio outcomes. Table 5 shows all solutions inside the mentioned three sample clusters in addition to the deterministic portfolio outcomes (assuming most likely productivity (ML)) for each cluster. Figure 8 also demonstrates duration and cost differences of each solution compared to cluster's ML solution on right and top axes, respectively. As shown, 
solutions within each cluster are mostly scattered around ML solution duration-wise, but all of them resulted in lower relative cost. It means that under uncertainty, crews work relatively more cost efficient than if assumed to work deterministically with their most likely production rate. After choosing desired cluster based on time and budget limitations, planners will need to decide about resource planning solutions considering their risk attitude. Each cluster contains non-dominated optimal time-cost tradeoff for different risk attitudes. As expected, more risk seeking attitude toward productivity of the resources under uncertainty results in lower overall time and cost.

By selecting certain tradeoffs, managers demonstrate how far they desire to put themselves under risk of time and cost overrun and consequently, examine how much optimal outcomes vary regarding their decision. As an example, each "highly risk-averse" tradeoff represents optimal solutions with $10 \%$ likelihood of time and cost overrun under uncertainty. Instead, considering the "risk-seeking" tradeoff (i.e. $40 \%$ probability of overrun) would relatively result in saving of up to $\$ 60 \mathrm{~K}$ in case of cluster 5 , as shown in Figure 8. Similarly, switching between tradeoffs results in a potential delay or advance in project completion, which eventually affects total cost through incentives or liquidated damages. 
Table 4.5. Resource planning sample clusters and solutions

\begin{tabular}{|c|c|c|c|c|c|c|}
\hline \multirow[b]{2}{*}{ Cluster } & \multirow[b]{2}{*}{$\mathrm{P}$} & \multicolumn{3}{|c|}{$\begin{array}{c}\text { Non-dominated Stochastic } \\
\text { Solutions }\end{array}$} & \multicolumn{2}{|c|}{$\begin{array}{l}\text { Non-dominated Deterministic } \\
\text { Solutions (Most Likely) }\end{array}$} \\
\hline & & Order & $\begin{array}{l}\text { Time } \\
\text { (Day) }\end{array}$ & $\begin{array}{c}\text { Cost } \\
(\$)\end{array}$ & $\begin{array}{l}\text { Time } \\
\text { (Day) }\end{array}$ & $\begin{array}{c}\text { Cost } \\
(\$)\end{array}$ \\
\hline \multirow{6}{*}{1} & 45 & A-E-B-D-C & 224 & $76,281,176$ & 224 & $76,575,200$ \\
\hline & 60 & B-A-D-E-C & 224 & $76,290,232$ & & \\
\hline & 60 & E-A-B-D-C & 225 & $76,286,064$ & & \\
\hline & 75 & B-A-D-C-E & 225 & $76,283,248$ & & \\
\hline & 90 & B-A-E-C-D & 225 & $76,295,992$ & & \\
\hline & 90 & B-D-C-A-E & 226 & $76,286,344$ & & \\
\hline \multirow[t]{11}{*}{5} & 45 & E-A-D-B-C & 280 & $74,445,728$ & 286 & $74,585,048$ \\
\hline & 45 & A-E-B-D-C & 281 & $74,348,488$ & & \\
\hline & 60 & D-B-C-E-A & 281 & $74,357,264$ & & \\
\hline & 60 & D-C-B-E-A & 282 & $74,345,392$ & & \\
\hline & 75 & B-D-E-A-C & 282 & $74,376,592$ & & \\
\hline & 75 & D-B-E-C-A & 283 & $74,363,312$ & & \\
\hline & 75 & B-E-D-A-C & 284 & $74,353,984$ & & \\
\hline & 90 & D-B-C-E-A & 283 & $74,404,680$ & & \\
\hline & 90 & D-A-B-C-E & 284 & $74,369,168$ & & \\
\hline & 90 & E-B-D-A-C & 285 & $74,363,432$ & & \\
\hline & 90 & D-B-A-C-E & 288 & $74,344,080$ & & \\
\hline \multirow[t]{10}{*}{8} & 45 & B-C-A-E-D & 498 & $73,225,248$ & 500 & $73,370,160$ \\
\hline & 45 & D-A-E-B-C & 499 & $73,194,224$ & & \\
\hline & 45 & A-B-C-D-E & 500 & $73,186,856$ & & \\
\hline & 60 & B-A-E-C-D & 500 & $73,185,192$ & & \\
\hline & 60 & B-D-C-E-A & 501 & $73,181,560$ & & \\
\hline & 75 & B-A-C-D-E & 500 & $73,257,096$ & & \\
\hline & 75 & C-D-A-B-E & 501 & $73,183,888$ & & \\
\hline & 75 & A-E-D-B-C & 502 & $73,173,688$ & & \\
\hline & 90 & B-A-D-C-E & 502 & $73,198,520$ & & \\
\hline & 90 & B-A-E-C-D & 503 & $73,161,176$ & & \\
\hline
\end{tabular}




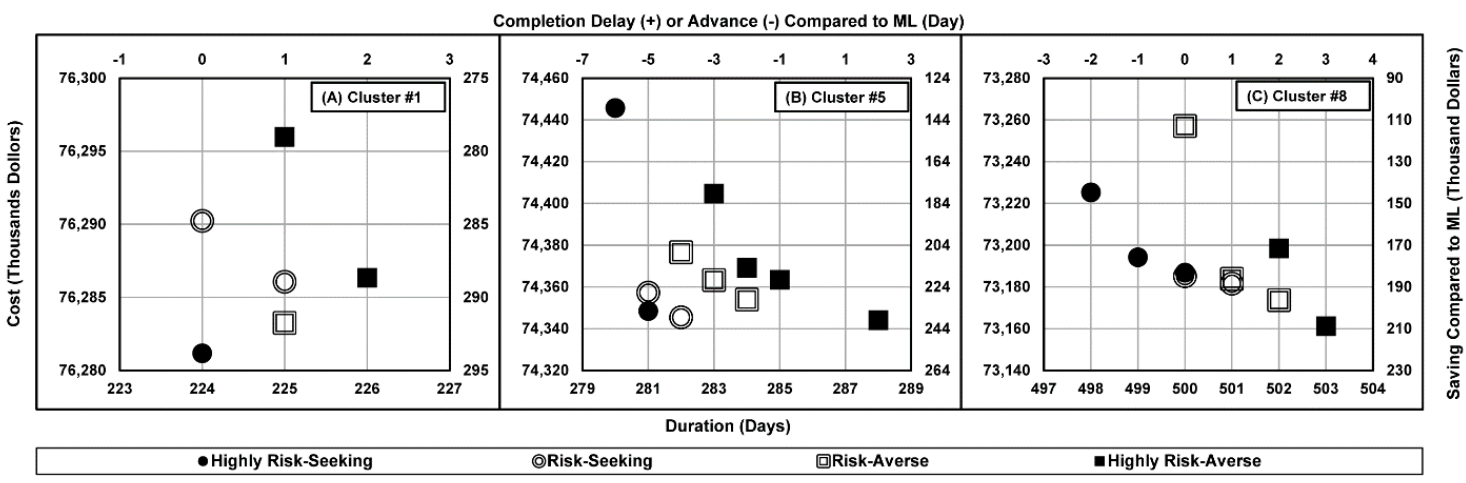

Figure 4.8. Portfolio time-cost tradeoff in sample clusters

As the final step for decision making process, solutions suggested for each risk attitude are used to investigate the impact of different prioritization scenarios on portfolio outcomes. The figure demonstrates that variation in project prioritization results in different optimal pairs of time and cost, although, no evidence regarding presence of a significant correlation between them was found in this application example. In this study, utilizing an activity with multiple crews at the same time is not allowed. However, if allowed, it is expected to observe more significant impact of prioritization on the outcomes since it results in unequal sharing of resources among projects. Statistical analysis of prioritization for all 5 projects is represented in Figure 9. The figure shows how frequent each project is placed in different priorities within all non-dominated optimal solutions. For instance, project (A) has been mostly placed in the second order, while it is suggested that project (C) has more impact when placed in last preferences. It is also shown that the optimal solutions indicate no preference for placing projects in 4th order, and suggest that order of project (E) would not significantly impact optimal solutions. 


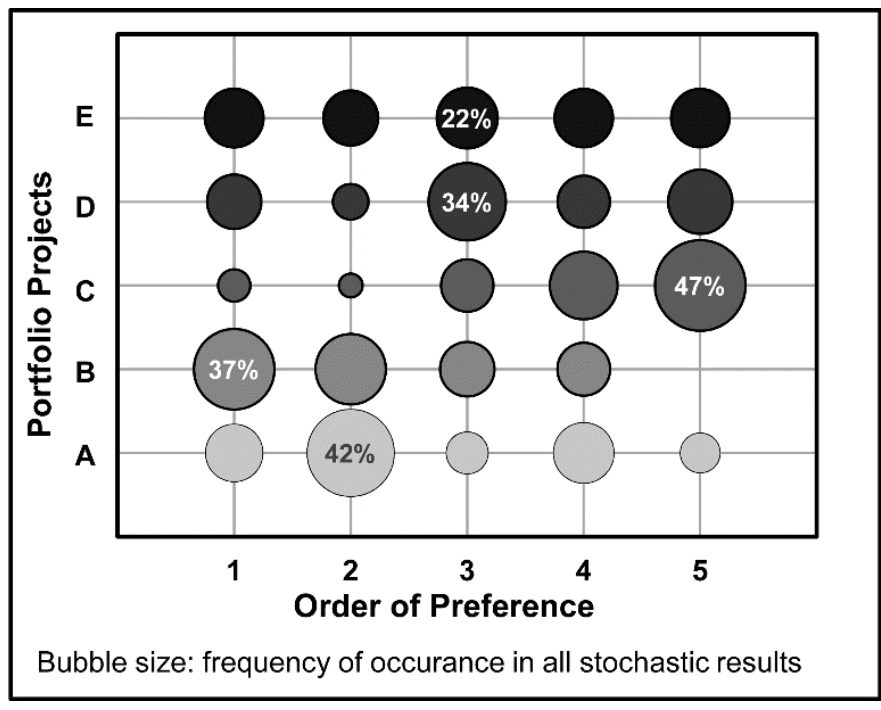

Figure 4.9. Portfolio time-cost tradeoff in sample clusters

\subsection{Summary and Conclusions}

This research represents the development of a stochastic simulation-optimization model to provide planners with optimal resource utilization solutions under uncertainty. The main contribution of the model is to fill two important research gaps identified in previous studies within the area of construction resource utilization under uncertainty. First, modeling of day-to-day change of productivity under uncertainties in construction, since many uncertainties can frequently affect resource production rates on a daily basis. Second, planning of resource utilization in a portfolio of projects considering limited pool of resources and different resource sharing policies. To this end, Monte Carlo Simulation Method is employed to simulate stochastic nature of time-related risk factors on crew production rate instead of project or activity duration. In addition, the simulation module shares a limited pool of resources at activity, project and portfolio levels, and estimates 
completion time and cost of the portfolio regarding desired risk attitude of planners. The NSGA-II multi-objective optimization method has been also employed to simultaneously minimize portfolio completion time and cost, and help decision makers find optimal resource utilization and sharing scenarios for their construction portfolio.

Results of the developed model provides construction decision makers with a broader and more realistic perspective on resource utilization planning of their projects. The model develops non-dominated optimal time-cost tradeoffs and allows managers to narrow-down their solutions regarding their overall time and budget limitations, and also risk attitude. At a certain risk attitude, the model provides decision support material in order to answer how resource utilization and sharing policies affect portfolio outcomes (through examining various overtime policy alternatives and project preferences). Following limitations of the proposed model can be addressed in the future studies: (1) instead of solely random-based generation, daily change in productivity can follow a more realistic pattern (such as learning and forgetting patterns), (2) more than one crew can be allowed to concurrently work in a shift, (3) and profit analysis with regards to risk attitude would be added to the model to enhance bidding estimates. 


\section{CHAPTER FIVE \\ RISK-BASED DECISION MAKING \\ ON CORPORATE RESOURCE PLANNING}

\subsection{Overview}

This chapter presents the development of a model for investigating the impact of risk-based approach toward network outcomes on corporate level decision making in construction industry. This study contributes to development of model to use outcomes of the previously developed models in second and third chapters in order to create tradeoffs for profitability and liquidity (short available cashable assets) under uncertainty. This model enables corporate managers to understand impact of different resource utilization and sharing policies on overall outcome of their project and to choose among optimum planning solutions that satisfy their profit margin and capital limitations. This research enables corporate decision makers to make more realistic estimates and make more reliable decision for profitability of their company, and understand consequences of their decisions in short and long term based on what if scenarios. The proposed simulation-optimization model provides decision makers with different solutions for profitability and liquidity of their corporate based on non-dominated optimal time-cost tradeoffs and demonstrates how overall time and budget limitations, as well as risk utility, can affect the decision-making process. 


\subsection{Introduction}

Competitive bidding typically challenges contractors to stay in business by reducing contingency and limiting profit margin, which impose more prudent resource utilization and allocation decisions during both planning and construction phases of projects. Many of these decisions are affected by uncertainty in resource production and construction performance due to several factors such as weather, managerial practices, job-type, and market conditions, among others. Construction decision makers will therefore have varied approaches to dealing with these uncertainties based on each individual's risk utility or behavior. Therefore, when deciding on resource utilization and allocation practices under uncertainty, decision makers need to have a proper perspective of their own approaches toward risk (Kim and Reinschmidt 2010). To better investigate the impact of risk utilities, it is required to first understand how uncertainties affect projects. Applying uncertainties to resource utilization plan has been proved to affect project completion outcomes (e.g. duration and cost). As an example, modeling the efficiency and/or continuousness of resource utilization for weather-sensitive activities has shown to output a wide range of project durations, when repeated in presence of stochastic weather conditions (Shahin et al. 2010; Lee et al. 2009). Similarly, many studies suggested major cost variations in construction when efficiency and performance are probabilistically modeled (Heravi and Faeghi 2012). Existing literature have modeled uncertainties in different resource planning levels. Limited number of researches studied impact of uncertainties on daily-level basis (Orabi et al. 2013; Chen et al. 2012), while most of the studies in this area have focused on activity/process level. Among those there are various models considering parameters such as activity duration (Ökmen and Öztaş 2008; Lee 2005; Hong et al. 2011; Lee and Arditi 
2006), activity cost (Taghaddos et al. 2011) or both (Isidore and Back 2002; Feng et al. 2000). Some others modeled uncertainties at project level, where for instance, project cost is studied as a probabilistic parameter (Gabriel et al. 2006). Few researchers have also developed models to analyze allocation and sharing of limited resources at the portfolio level (Barraza 2010).

On the other hand, investigating risk utilities requires to note that managers' level of confidence on performance of resources under uncertainty affects the amount of risk they are willing to take regarding planning decisions. It is shown in the recent studies that results of stochastic simulation can provide decision makers with statistical outcomes of projects at certain confidence levels (Orabi et al. 2013). Many studies developed stochastic simulation models to capture uncertainty in construction (Puri and Martinez 2012; Gabriel et al. 2006; Chen et al. 2012; Peña-Mora et al. 2008). There are also certain studies that attempted to find optimal resource allocation solutions (at project level) through various stochastic optimization methods (Heravi and Faeghi 2012; Vaziri et al. 2007; Zhang and Li 2004). However, three main research gaps can be identified within the existing literature. Uncertainties are claimed to frequently affect resource performance on a daily basis. However, there is lack of research studies that accurately model contingencies affecting daily performance of construction under uncertainties. In addition, consideration of resource planning for a group of projects consuming limited resources seems required for an improved and realistic decision making. However, no reported research considered stochastic optimization of resource sharing at portfolio level. In addition, there is a need 
for new research to investigate impact of risk utilities on decision making in planning phase.

Finally, decision makers at corporate level need to have a broad perspective on their network, resources possibilities and risk utility of their project managers in order to improve their decisions with regards to reliability of potential outcomes. This paper therefore, presents the development of a new simulation-optimization model to cover the identified research gaps and consequently facilitate the investigation of risk utility on reliability of corporate level construction outcomes. The developed model consists of simulation and optimization modules, as well as decision support material which are introduced in next sections of the paper.

\subsection{Stochastic Simulation Module}

The main purpose of the simulation module is to measure the impact of uncertainties on projects schedule and cost, through performing a day-to-day resource management analysis. To this end, the simulation module eventually produces duration and cost frequency distributions of the portfolio through capturing changes in construction performance. The simulation module is based on Productivity Simulation Model (PSM) developed by Orabi et al. (2013) which simulates resource utilization in three levels: activity, project and portfolio levels. To develop mentioned frequency distributions the simulation module performs the following steps (See Figure 1):

1. Develop crew productivity curves based on statistical data regarding productivity for each resource crew (i.e. most likely, optimistic and pessimistic production 
rates). The model uses Program Evaluation and Review Technique (PERT) to estimate mean and standard deviation of production rate distributions. Developed distributions are used to formulate inverse cumulative probability function for each crew to be used in step 3 .

2. Assign overtime policy (OTP) to each project via specifying number and length of required working shifts per day. OTP alternatives, as one of the decision variables of the optimization module, is allotted specifically to each project, as explained in the optimization module. As shown in Table 1, each alternative includes productivity and cost adjustment factors for crews working in different shifts.

3. Estimate an instant production rate for each crew working on each work-shift using Monte Carlo Simulation Method. The module generates random probabilities for each crew in each shift, and extracts the corresponding production rates from inverse cumulative probability distribution (explained in the step 1). The module then modifies the estimated productivity using adjustment factor from step 2.

4. Calculate daily performance of the construction crews by repeating previous step for all shifts of the day. 
Table 5.1. Overtime policy alternatives

\begin{tabular}{|c|c|c|c|c|c|}
\hline OTP & \multirow{2}{*}{ Week } & Shifts & Hours Per & \multicolumn{2}{|c|}{ Adjustment Factor (\%) } \\
\cline { 5 - 6 } & \multirow{2}{*}{ Days } & Per Day & Shift & Productivity & Cost \\
\hline 1 & 5 & 1 & 8 & 100 & 100 \\
\hline 2 & 5 & 1 & 12 & 76.25 & 133.3 \\
\hline 3 & 5 & 2 & 12 & 68.75 & 153.3 \\
\hline 4 & 7 & 1 & 8 & 88.75 & 128.6 \\
\hline 5 & 7 & 1 & 12 & 68.75 & 152.4 \\
\hline 6 & 7 & 2 & 12 & 62 & 175.25 \\
\hline
\end{tabular}

5. Estimating daily crew cost of construction, as one of the two components of the direct cost besides material cost. The module calculates modified crew cost for each crew working on each shift based on crew hourly wage and burden, and also cost adjustment factor described in step 2. Then, estimates the daily crew cost similar to daily performance via adding up calculated costs of all crews worked entire day. Material cost will be later calculated along with estimating activity duration. 


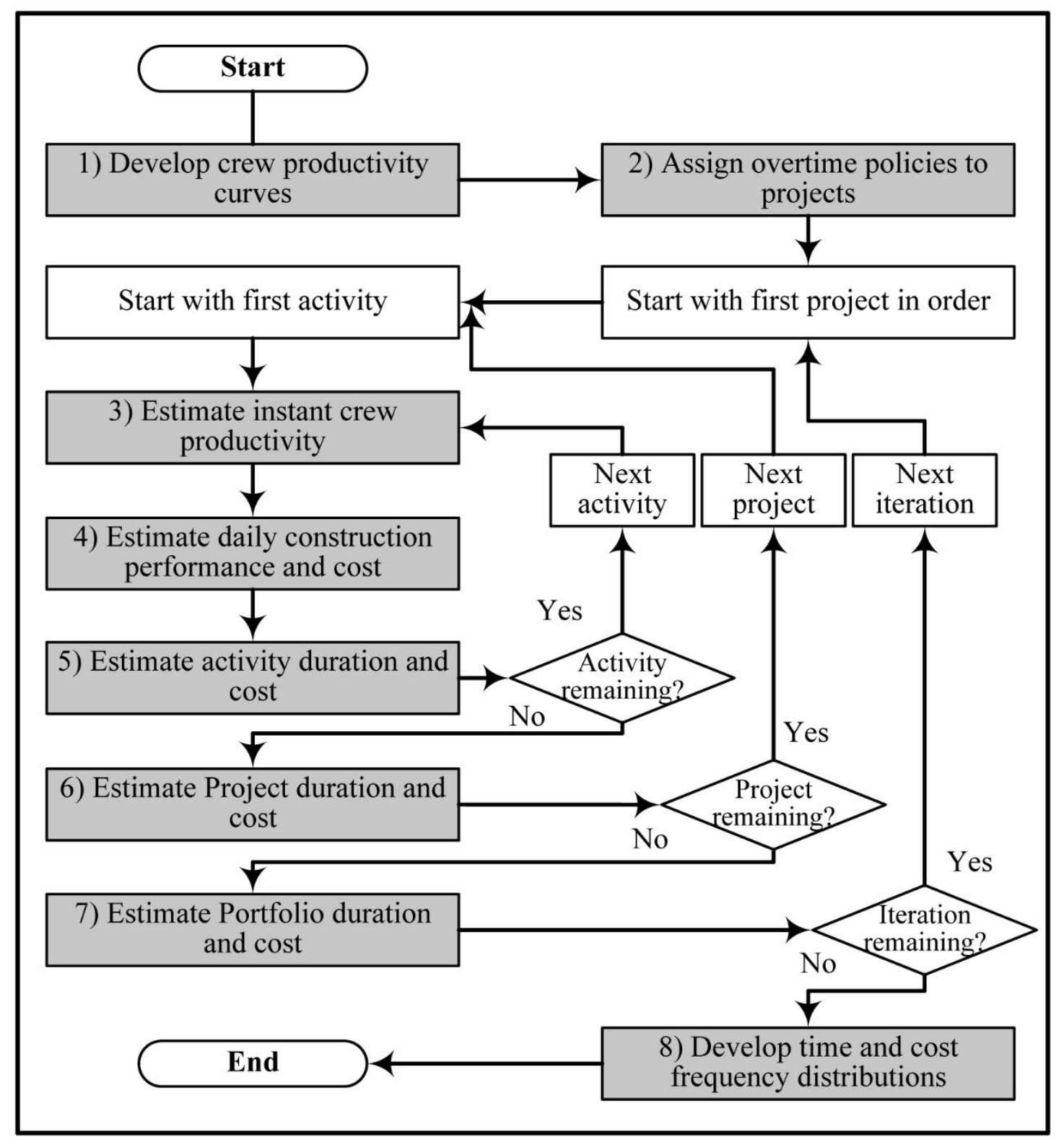

Figure 5.1. Flowchart of the simulation module

6. Calculate activity duration. Through repeating steps 3 and 4 in a loop, the module adds up daily performance of the crews and counts number of days it takes until crews execute entire quantity of the activity. 
Calculating total activity direct cost. Eventually the model estimates the activity completion time and cost, to be used in project-level scheduling simulation and cost calculation, respectively.

7. Calculate project duration and cost. At the project level, the module schedules activities using CPM and estimates total duration of the project. As for cost, total direct cost is calculated via adding up activity direct costs. The module calculates project indirect cost considering daily site maintenance and overhead costs.

8. Calculate portfolio duration and cost. At portfolio level, the module shares limited pool of resources between competitive projects, which are scheduled based on predefined priorities (see optimization module). It means that projects with higher priority are utilized with resources sooner than others. Therefore, prioritization of the projects affects the amount of remaining available resources for low-priority projects and eventually, affects activity, project and portfolio durations. Portfolio duration is calculated based on start date of the first project and completion date of the last project. The model eventually estimates the total portfolio cost using by adding up all projects' direct costs and indirect costs.

9. Develop time and cost frequency distributions. The final output of each simulation iteration, which is a pair of portfolio duration and cost, is used by the module to develop duration and cost frequency distribution curves. Output curves demonstrate the frequency of possible portfolio durations or costs. These distribution curves are used in the optimization module, in order to extract portfolio duration and cost based on risk utility of the decision makers. 


\subsection{Cost and Profit Calculation}

The main objective of the optimization module is to find optimum solutions for resource utilization planning problem that minimize time and cost of the portfolio. The optimization module develops planning scenarios based on decision variables and obtains duration and cost distributions in correspondence to each scenario. To this end, Non-Dominated Sorting Genetic Algorithm (Deb et al. 2000) has been used as optimization engine. Multi-objective nature of the problem and effectiveness of NSGA-II in generating near optimal solutions are the reasons to select this algorithm for the proposed model. Figure 2 shows components and general flow of the multi-objective optimization module. The proposed model examines the impact of two main decision variables on optimization objectives: (1) prioritizing projects of the portfolio for scheduling and resource consumption purposes (sharing priorities), and (2) applying different overtime working policies to projects (e.g. multiple working shifts, different shift lengths, etc.) These decision variables widely affect both resource availability and performance, and consequently duration and cost. The former examines how prioritization of the projects affects optimization objectives through ordering projects for resource allocation. The latter, tests the outcomes through providing different performance capacities during execution. The result of the optimization module is a time-cost trade-off consisting of various optimum pairs of portfolio duration and cost at certain risk utility. 


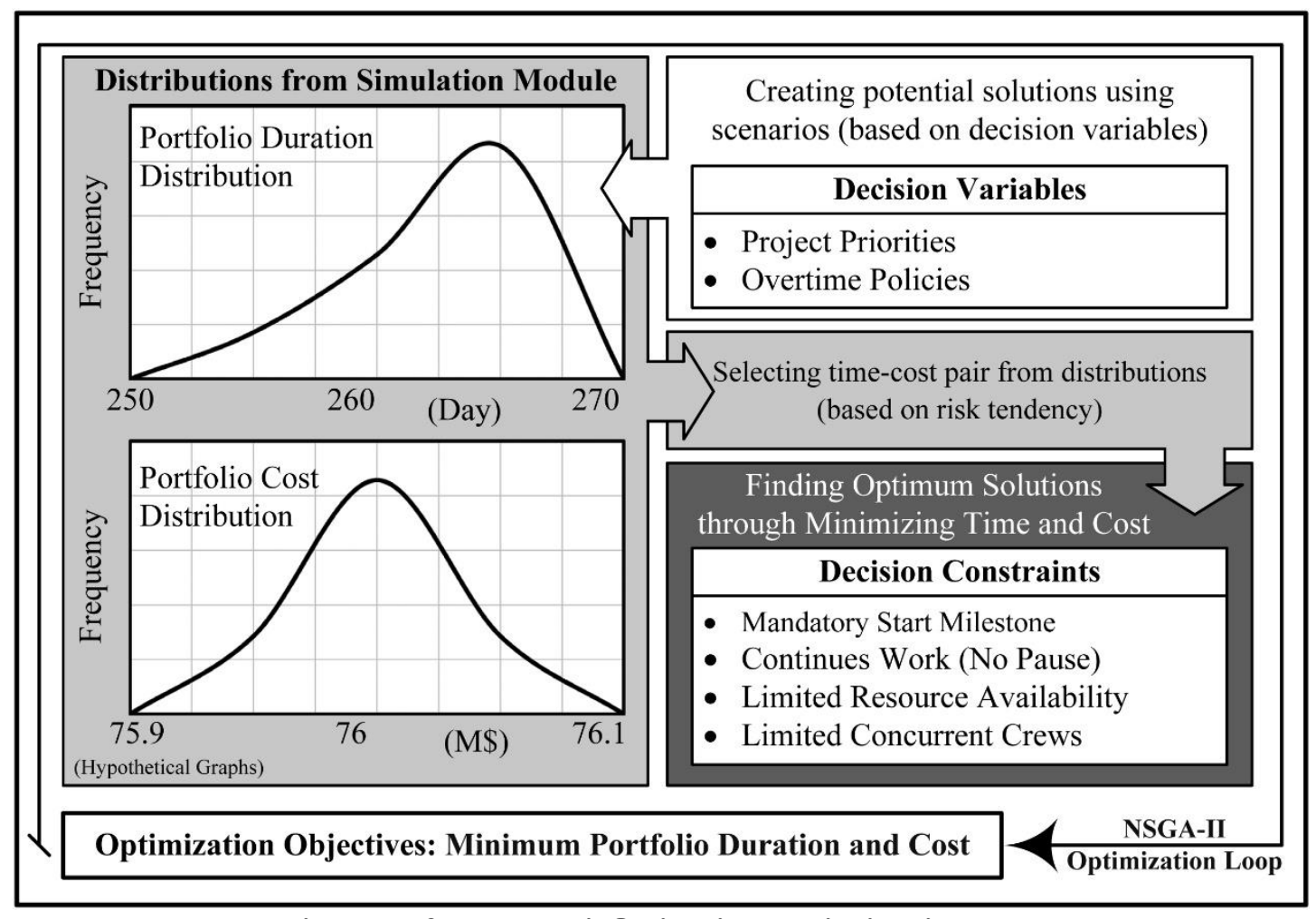

Figure 5.2. Multi-Objective optimization module

This study considers four major modeling constraints in order to practically approach the mentioned optimization problem. The first two are time-related constraints including (1) each projects should start on a pre-specified date (i.e. mandatory start milestone), and (2) each project should be continuously executed until completion without any pause. The rest are resource-related constraint: (3) the resource pool which is shared between projects within the portfolio is limited (in case of total available amount of crews and material per day), and (4) maximum number of crews that can simultaneously work on an activity is limited to avoid jobsite conflicts and meet safety requirements. This limitation may vary for different activities and projects.

The model starts by generating a random population of solutions and produces next generations via operations such as selection, crossover, and mutation throughout the 
population. It continues producing generations and eventually extracts non-dominated optimal or near optimal sets of solutions from the final population. In each generation of the NSGA-II, the model (1) creates potential solutions (chromosomes) based on decision scenarios, (2) utilizes the simulation module to develop time and cost distributions for each solution, (3) selects a pair of time-cost from distributions (based on pre-identified risk utility) as the fitness of each solution, and eventually (4) finds optimum solutions and envelops stochastic time-cost trade-off. In order to select time-cost pairs for each solution, the model extracts duration and cost corresponding to the risk utility of the decision makers from the inverse cumulative probability function of each distribution. Table 2 lists four hypothetical probability percentages to represent different risk utilities. It is suggested that lower confidence on performance of the resources under uncertainty leads to lower riskseeking approach regarding project estimations. For instance, in case of highly risk-averse approach, the module selects the maximum cost with which the portfolio would finish in $90 \%$ of the times (i.e. simulation iterations).

Table 5.2. Risk utilities and corresponding probabilities

\begin{tabular}{|c|c|c|}
\hline Risk utility & $\begin{array}{c}\text { Confidence Level } \\
\text { (on performance) }\end{array}$ & Probability \\
\hline Highly Risk-Averse & Very Low & $90 \%$ \\
\hline Risk-Averse & Low & $75 \%$ \\
\hline Risk-Seeking & High & $60 \%$ \\
\hline Highly Risk-Seeking & Very High & $45 \%$ \\
\hline
\end{tabular}




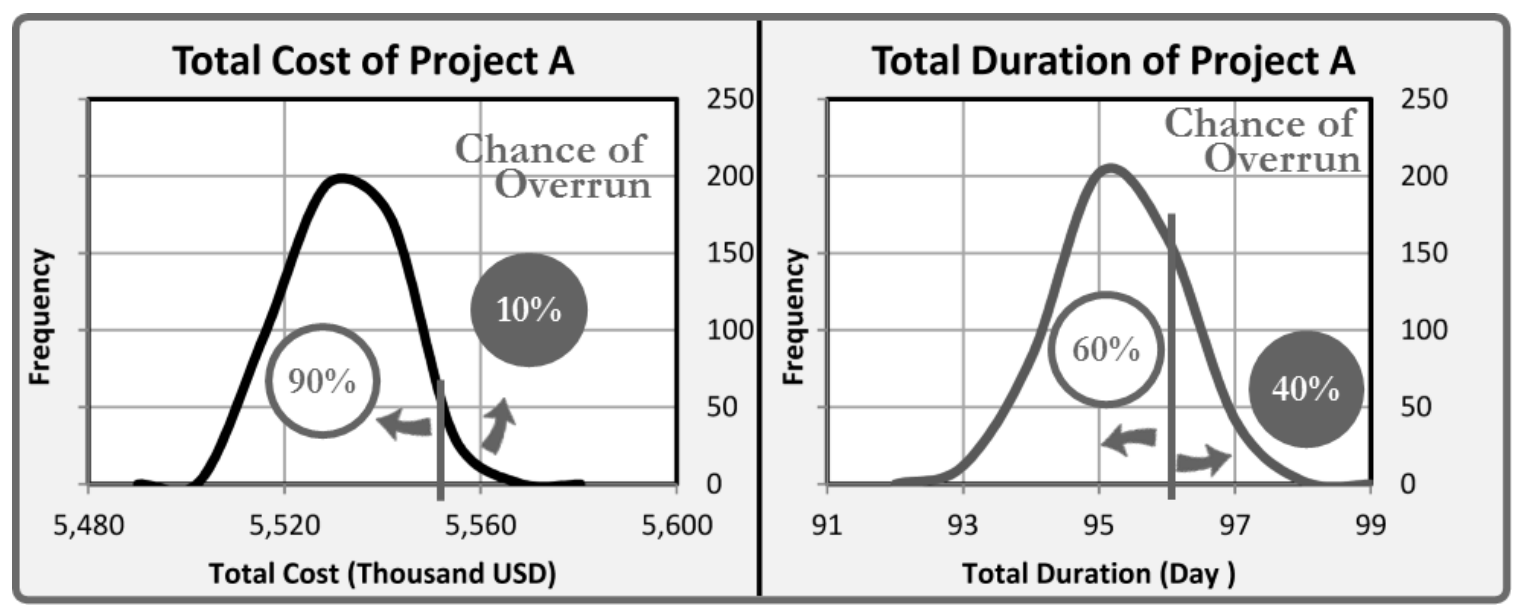

Figure 5.3. Explanation of risk utility

Having time and cost of projects would along with contract time and value the model estimates profitability of at the corporate level. Then using cash flow analysis, the model develops profitability-liquidity tradeoffs regarding different resource planning scenarios. Developed tradeoffs enable decision makers to choose what to do with their network of projects as well as how reliable their decision would be based on most likely values and the risk utility of project managers.

\subsection{Model Application}

The proposed model is examined using an application example based on previous study on recovery of infrastructure systems (Orabi et al. 2010) consisting of a portfolio of 5 projects. Figure 3 shows the resulting time-cost trade-off of non-dominated optimal solutions after analysis of the example by the model modules. In the figure, results of the stochastic optimization are demonstrated along with optimal deterministic results. Deterministic 
results prove the significant impact of considering uncertainties on performance, and consequently time and cost estimate. As expected, assuming optimistic crew productivity leads to lower duration and cost, while pessimistic presumption causes overestimation. Wide range of solutions indicates that the portfolio completion time and cost are highly sensitive to different resource planning alternatives (i.e. decision variables). However, not all the solutions are desirable in most cases, due to the time and budget limitations. Therefore, decision makers need to find certain resource utilization plans that meet their time and cost restrictions.

Based on time-cost similarities, optimal solutions can be divided in different groups throughout the stochastic tradeoff. Results show that each group mainly share a similar combination of overtime policy alternatives (Table 1) for projects. Putting together the outputs of the model for different risk utilities, each group of solutions consists of multiple tradeoffs. Therefore, decision makers would be able to decide about resource planning solutions considering their risk utility. Figure shows optimal resource utilization solutions for three sample groups considering highly risk-averse and highly risk-seeking risk approaches. As expected, more risk seeking approach toward performance under uncertainty results in lower overall time and cost. Switching between tradeoffs, managers can demonstrate how far they desire to put themselves under risk of time and cost overrun and consequently, examine how much optimal outcomes vary regarding their decision. 


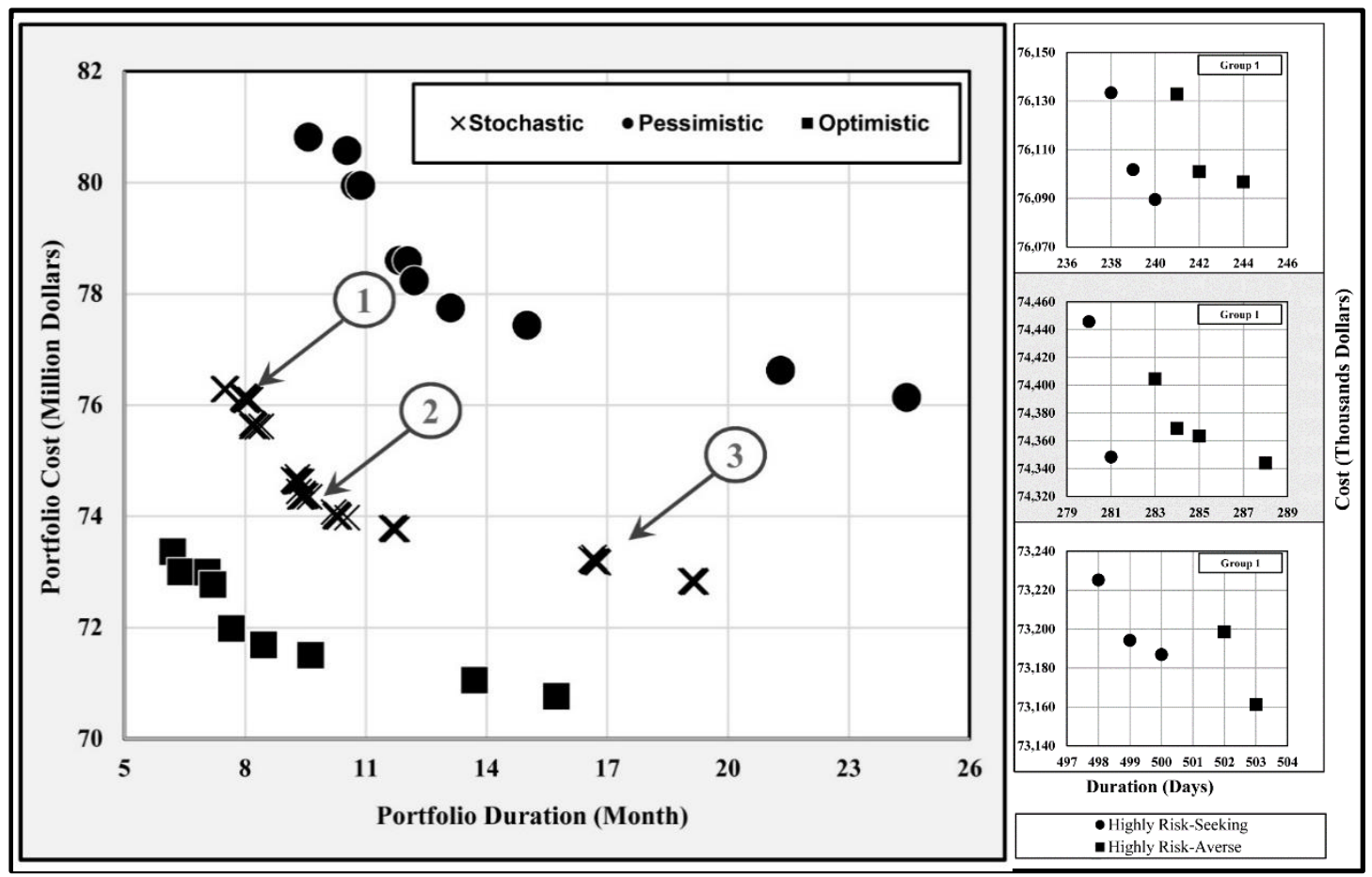

Figure 5.4. Application example results

In addition a case study of 3 construction projects from South Florida (two high-rise concrete buildings and one horizontal bridge/rail system) from a contractor company has been considered to understand the application of model, and also to validate the process.

Results are shown in the following graphs:
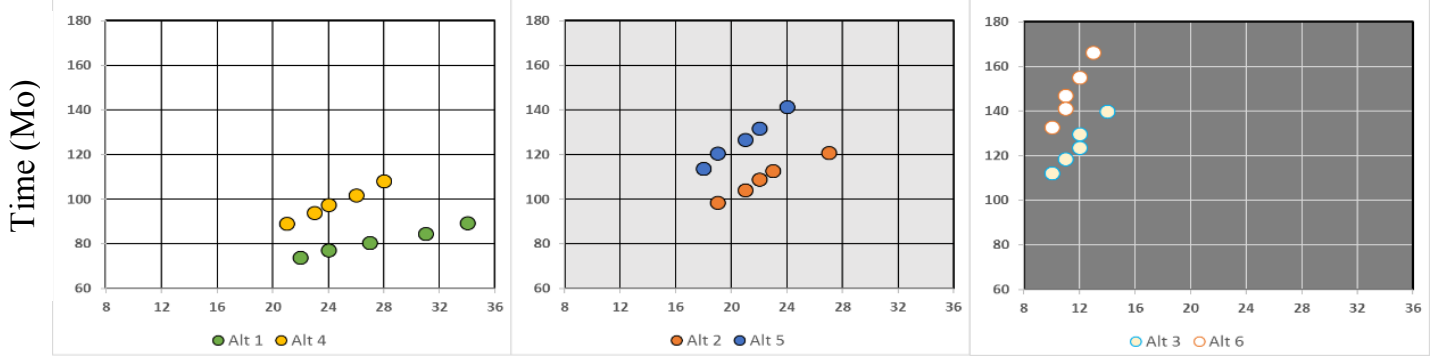

Cost $(\$ M)$

Figure 5.5. Time-Cost under different resource utilization plans 
Figure 5 shows time and cost outcome of the project considering different risk perceptions on resource productivity and also various resource utilization planning alternative. The results show planning for more work during week, including planning for night shifts results in less uncertainty range for outcomes, however, leads to higher cost for of construction projects.

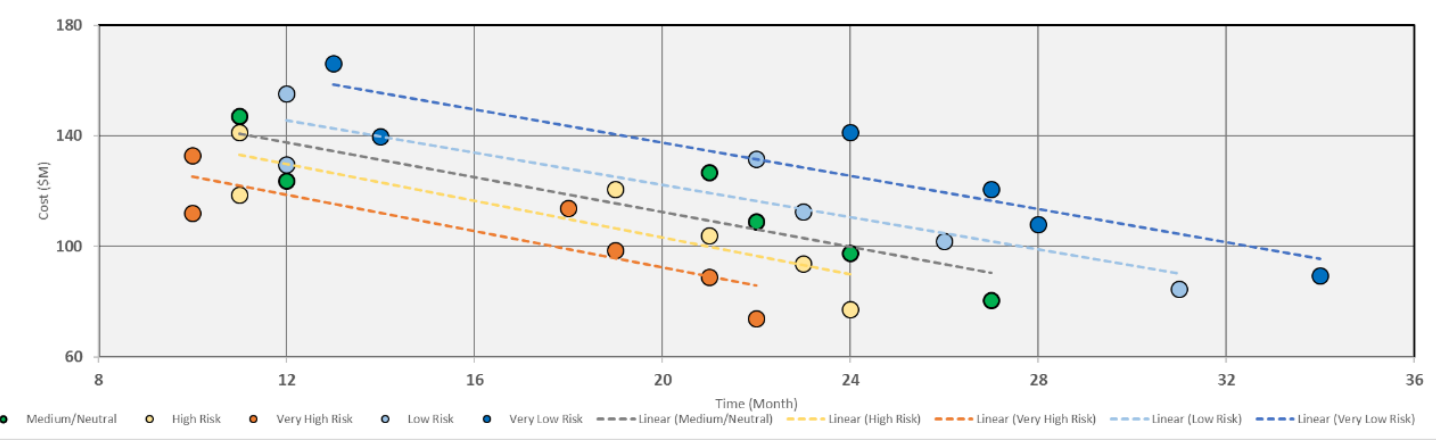

\section{Figure 5.6. Time-Cost under different resource utilization plans and risk perceptions}

Figure 6 shows overall time and cost outcome of the project considering different risk perceptions on resource productivity and also various resource utilization planning alternative. The results show the range of outcomes regarding specific risk perceptions on resource productivity, for instance, how taking low risks leads to higher cost and time outcome for the project. 

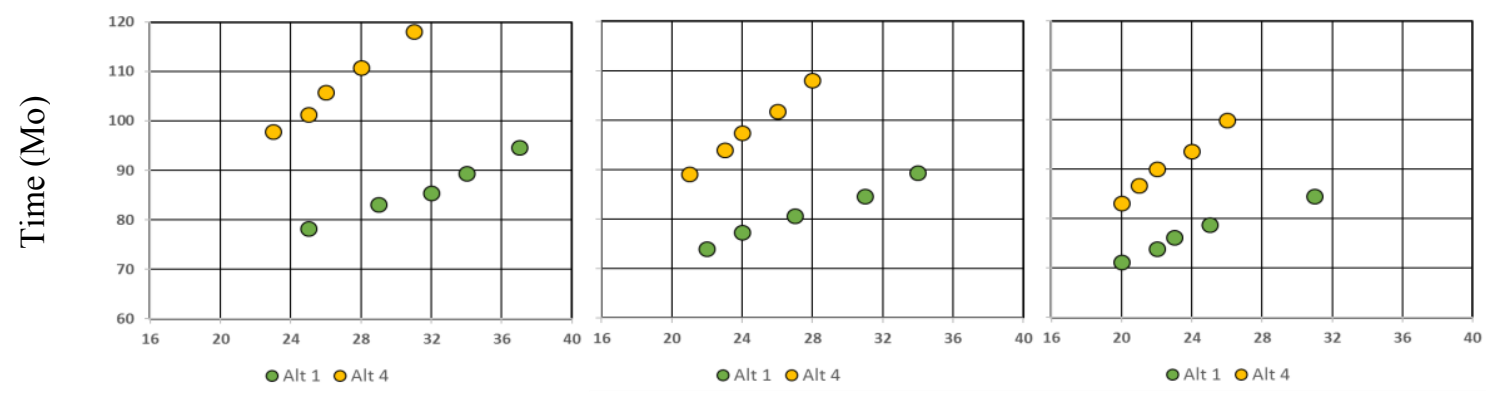

Cost $(\$ M)$

Figure 5.7. Time-Cost under different resource sharing priorities and risk perceptions considering regular working hours

Figure 7 shows overall time and cost outcome of the project considering different risk perceptions on resource productivity and also various resource sharing priorities. These outcomes are based on utilizing resources in order to have regular working hours in week. The results show that giving higher priority to projects which are in their early stages (left) results in higher uncertainty range for outcomes in oppose to giving priority to projects which are in their mid-stages (right).
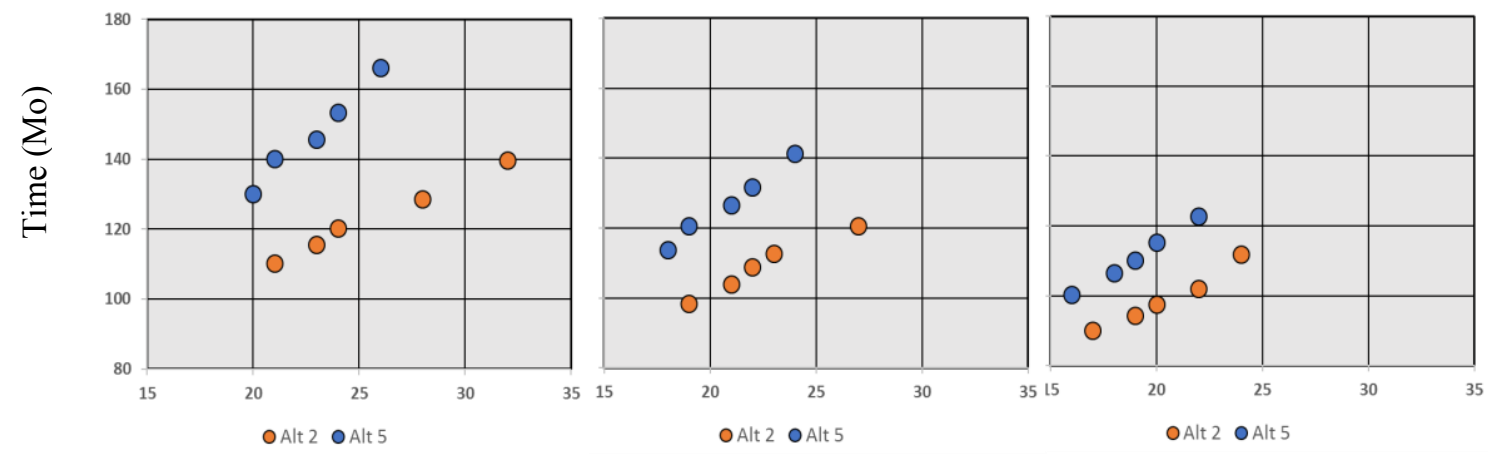

Cost (\$M)

Figure 5.8. Time-Cost under different resource sharing priorities and risk perceptions considering extra working hours 
Figure 8 shows overall time and cost outcome of the project considering different risk perceptions on resource productivity and also various resource sharing priorities. These outcomes are based on utilizing resources in order to have more working hours in each shift. The results show that giving higher priority to projects which are in their early stages (left) results in higher uncertainty range for outcomes in oppose to giving priority to projects which are in their mid-stages (right).
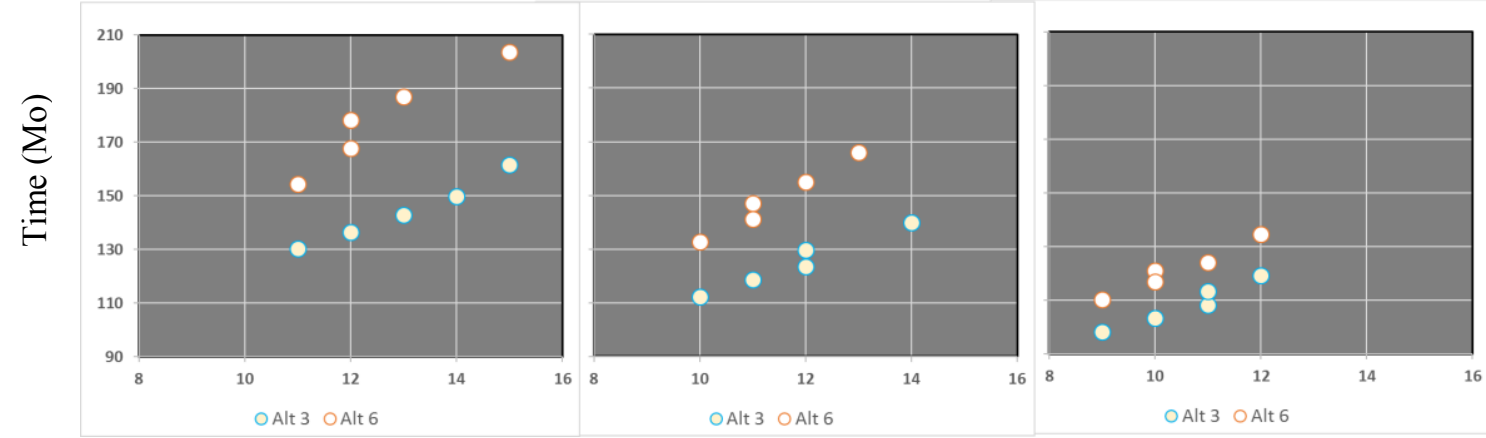

Cost $(\$ M)$

\section{Figure 5.9. Time-Cost under different resource sharing priorities and risk perceptions considering added night shifts}

Figure 9 shows overall time and cost outcome of the project considering different risk perceptions on resource productivity and also various resource sharing priorities. These outcomes are based on utilizing resources in order to have more working hours in each shift and also working in night shifts. The results show that giving higher priority to projects which are in their early stages (left) results in higher uncertainty range for outcomes in oppose to giving priority to projects which are in their mid-stages (right). 


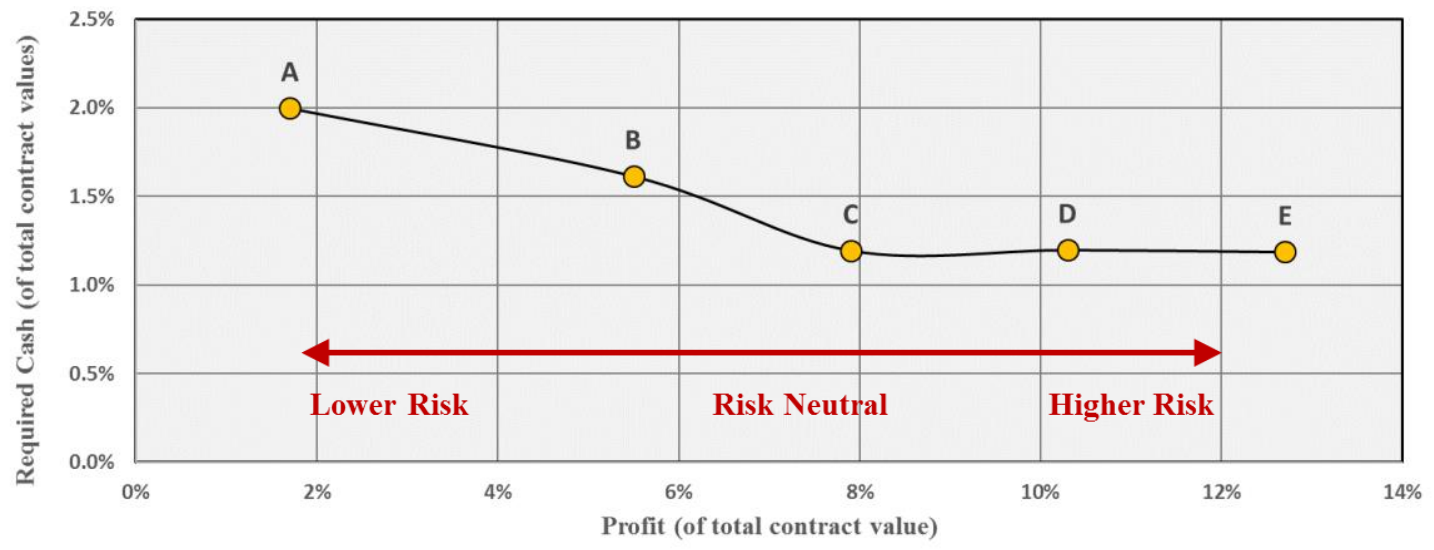

Figure 5.10. Resource management solutions and their profit-cash tradeoff

Figure 10 shows overall Profit and required cash for the corporation considering different risk perceptions on resource productivity and also various resource utilization planning alternative. The results show the range of outcomes regarding specific risk perceptions on resource productivity, for instance, how taking low risks (right of the graph) leads to higher profit and relatively lower required cash to continue the construction.

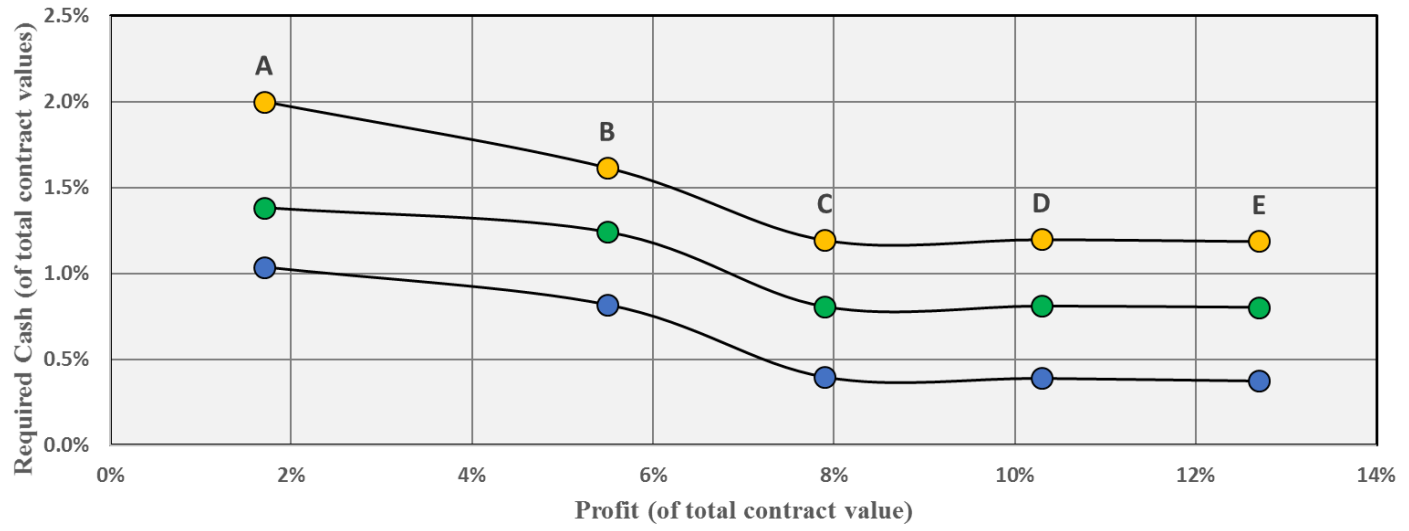

Figure 5.11. Resource management solutions and their profit-cash tradeoff for 6 , 12 and 18 month periods 
Figure 11 shows overall Profit and required cash for the corporation considering different risk perceptions on resource productivity and also various resource utilization planning alternative. The results show the range of outcomes regarding specific risk perceptions on resource productivity and for three planning periods of 6 months (top), 12 months (middle) and 18 months (bottom). For instance, using the same planning scenarios, company needs to inserts less amount of cash for operations after 18 months than a year.

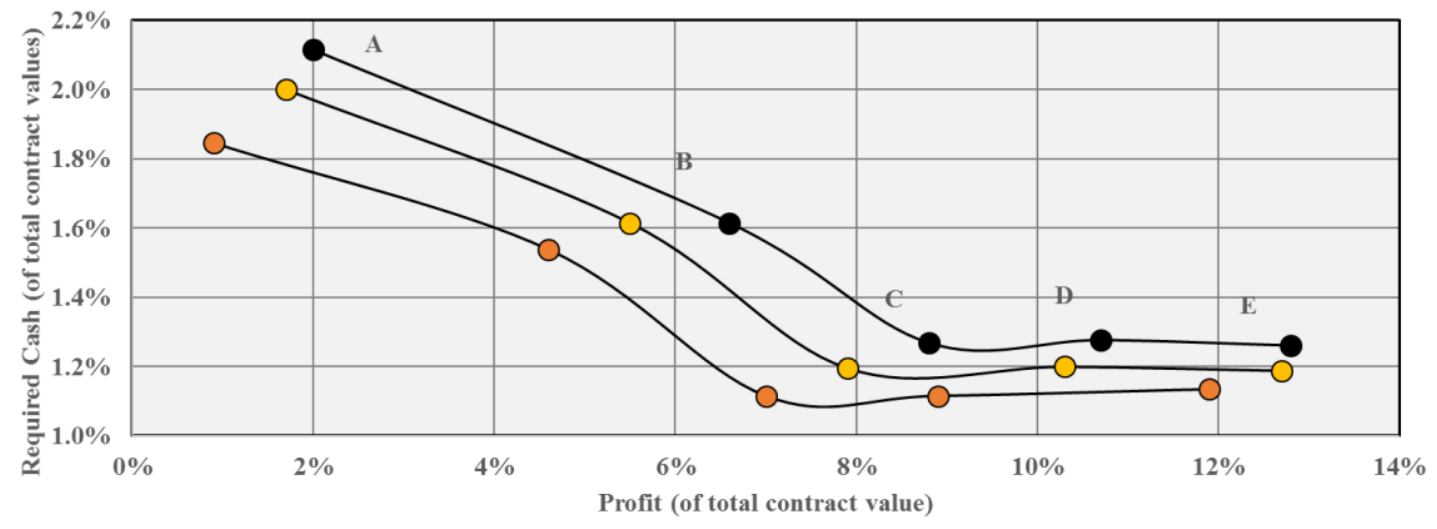

Figure 5.12. Resource management solutions and their profit-cash tradeoff for various resource sharing priorities

Figure 12 shows overall Profit and required cash for the corporation considering different risk perceptions on resource productivity and also various resource utilization planning alternative. The results show the range of outcomes regarding specific risk perceptions on resource productivity and for three different resource sharing priority policies. Results show that giving the priority to projects which are in their early stages (orange points) leads to lower profitability and also lower required cash. On the other hand, if corporate managers decide to give higher priority to mid-stage projects (black points), the company will be facing higher profitability yet with less uncertain range of outcomes. 


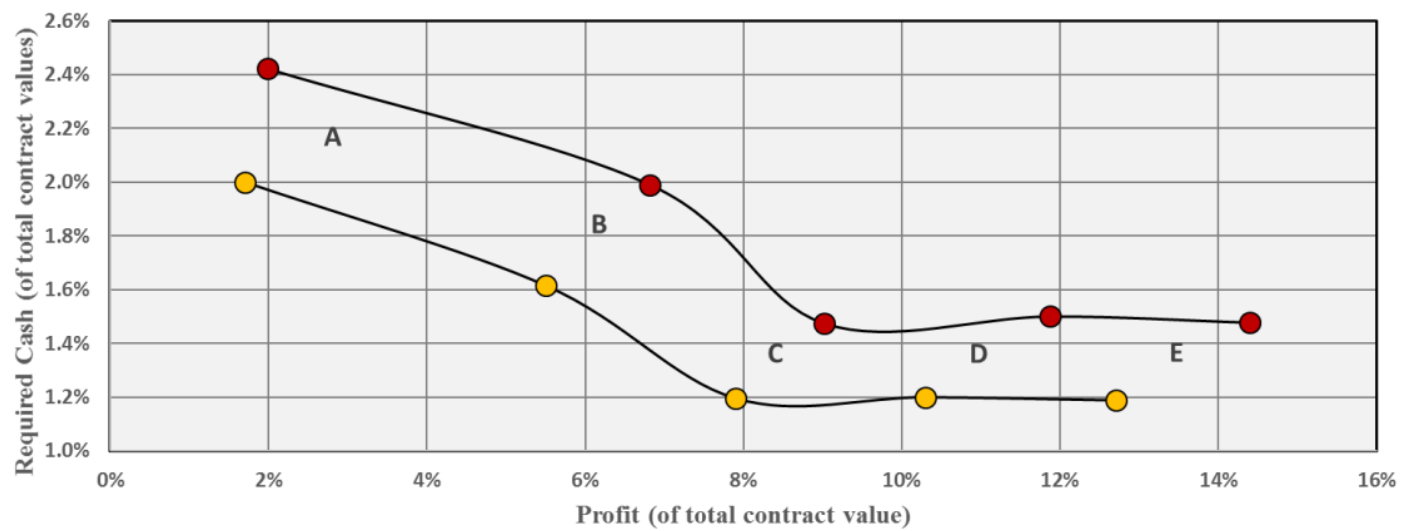

Figure 5.13. Resource management solutions and their profit-cash tradeoff in case of expanding network with a new project (red)

Figure 13 shows planning outcomes for profitability of the company and also amount of required cash to continue construction in case of remaining with current projects (yellow) or adding forth project to the network (red) (i.e. going for a bid). Graph shows overall Profit and required cash for the corporation considering different risk perceptions on resource productivity and also various resource utilization planning alternative. The results show that based on network arrangement, adding a new project to network raise corporate profit yet requires decision makers to provide and insert more cash to the network to achieve planned profit.

\subsection{Conclusions}

This research represents the development of a stochastic simulation-optimization model to provide planners with optimal resource utilization solutions under uncertainty. The main contribution of the model is to fill four important research gaps identified in previous studies within the area of construction planning under uncertainty: Need for (1) more realistic and accurate planning considering contingencies affecting daily construction 
performance, (2) decision making based on resource planning for a group of projects consuming limited resources, (3) investigating impact of risk utilities on decision making in planning phase, and (4) decision making for corporate level construction management based on corporate profit and liquidity (short term cashable assets).

To this end, PSM from the literature is employed to simulate stochastic nature of risk factors on performance of construction networks. The NSGA-II multi-objective optimization method has been also employed to minimize portfolio time and cost. Then, model calculates profit and liquidity at the corporate level and provides managers with resource planning options, their respective outcomes and also their reliability. Results of the developed model provides construction decision makers with a broader and more realistic perspective on resource utilization planning of their projects. The model develops non-dominated optimal time-cost tradeoffs and allows managers to narrow-down their solutions regarding overall time and budget limitations, and also their risk utility. 


\section{CHAPTER SIX}

\section{CONCLUSIONS AND FUTURE RESEARCH}

\subsection{Summary}

The main goal of this research is to address reported failure in achieving goals and objectives in construction industry. Among the main problems to be solved in order to address the mentioned failure, the focus of this research is on the following areas:

1. Addressing unrealistic expectations that affect construction performance and efficiency due to lack of proper capturing of uncertainties in resource utilization planning.

2. Addressing lack of accuracy in time and cost estimation of projects due to failure in properly understanding impact of resource sharing priorities on time and cost of each individual project.

3. Addressing problems in making decisions with regards to selecting projects to bid in competitive market and also failure in achieving planned profitability and amount of required cash due to lack of proper understanding on corporate resource management outcomes under uncertainty. 
Therefore, this research has been conducted to develop a risk-based decision support at different levels of construction. The developed model captures uncertainties that affect project processes and considers managers risk utility toward performance of their projects to develop solutions for abovementioned problems. The model considers uncertainties for more realistic expectations toward planning for performance and efficiency of resources and construction tasks. Then develops optimal resource utilization planning solutions in order to improve time-cost estimation in project under uncertainties. Developed solutions provide decision makers with minimized overall cost and duration of their projects considering their own risk utility (i.e. risk tendency).

Eventually at corporate level, this research provides managers with a broad perspective of the profitability of their network of project and the potential consequences of their decisions regarding (1) expanding their network and entering new bids, (2) replanning and rescheduling of their projects in case of adding new project or any other change in network, and (3) improving performance and efficiency of construction processes and also accuracy of their expectations via providing reliability of solutions under uncertainty comparing to most likely outcomes of the processes.

\subsection{Grand Achievements}

This research contributes to three evolutionary developments in the area of decision making for construction.

1. Enhancing decisions at corporate management level through development of riskbased trade-offs between profitability and liquidity (short available cashable assets) and providing resource planning solutions considering risk utility of managers. This 
enables decision makers to consider how reliable their choice of solution would be under uncertainty knowing most likely outcomes of their network of construction project. The finding of this research with regard to this area is that taking lower risks result in lower profit, and also adds higher uncertainty to amount of required cash.

Main decision objectives at this level is making proper choices regarding adding project to the network, acquiring required credits and loans to maintain cash-flow of the network, and sharing resources or cash over portfolio of projects. To this end, the decision criteria are (1) limitations in amount capital as well as resource caps, (2) fixed contracts values and stakeholder expectations, and (3) risk utility of project managers. Developed model support decision makers in case of questions such as to go or not to go with a bid, what are the consequences of this decision and what are the required changes and provisions in the network of projects in case of any decision. This research then provides decision makers with different future financial consequences of the decision as well as how reliable choose consequences would be, and enables them to select a solution that satisfies companies profit margin considering realistic and reliable what if scenarios.

Enhancing decisions at project management level considering impact of risk perceptions on outcome of projects under different sharing priorities, which is possible through development of risk-based trade-offs between time and cost of project, and providing resource planning solutions considering manager's confidence toward performance of their resources under uncertainty. This enables 
decision makers to consider how reliable their choice of solution would be under uncertainty knowing most likely outcomes of their network of construction project and making realistic choices with regards to allocation of resources in their projects. Findings of this research show that giving the resource usage priority to projects in early stage would result in higher uncertainty in both time and cost outcomes.

Main decision objectives at this level is making proper choices regarding estimation of time and cost of project under uncertainty and use of optimum resource utilization scenarios to obtain desired pair of time and cost. To this end, the decision criteria are (1) fixed contract value and duration, (2) limitations in project resources and construction site capacities, and (3) decision made in upper level (corporate management) as described in previous level. Developed model supports decision makers in case of questions such as what resource allocation planning to choose for current and/or new projects as well as what are the required changes type and limit of resources in case of any decision. This research then provides decision makers with different optimum solutions for resource utilization along with their corresponding minimum time and cost and enables them to select a solution that satisfies contract values and profit margins considering realistic and reliable what if scenarios.

2. Enhancing decisions at project and corporate management level through development of performance and efficiency frequency outcome distributions based on stochastic simulation of the construction processes under uncertainty, and investigating the impact of risk perceptions on project outcomes with regards to 
different resource utilization plans. This enables decision makers to fully understand impact of risk factors on the performance and efficiency of their resources and make proper choices regarding short-term planning of their processes in order to make more realistic and reliable estimates of their time and cost. Findings of this research show that planning to put more working hours on a project would result in higher uncertainty of cost outcomes with regards to different risk utilities.

Main decision objectives at this level is accurate estimation of performance and efficiency of activities under everyday risk factors that affect construction execution. To this end, the decision criteria are (1) limitations in amount of available resources (daily cap, maximum total number of concurrent working crews, etc.) and (2) fixed time milestones within the project time span. Developed model support decision makers in case of questions such as what are impacts of uncertainties on daily performance, as well as how to investigate impact of different type of uncertainties on efficiency of construction processes. This research then provides decision makers with different performance and efficiency graphs, as well as process/task duration and cost distributions under uncertainties.

\subsection{Contributions}

\subsubsection{Contribution to Body of Knowledge}

This research makes evolutionary contributions to both body of knowledge and practice, as following: 
1. impact of risk factors on performance and efficiency of construction processes.

2. Better understanding on impact of Risk Utilities on Project Outcomes Under Different Utilization Plans

3. Better understanding on impact of Risk Utilities on Project Outcomes Under Different Priority Plans

4. Better understanding on impact of Risk Utilities on DM regarding Corporate Objectives Under Different Resource Management Approaches

\subsubsection{Contribution to Body of Practice}

1. Obtaining more realistic support on decision making with regards to choosing resource utilization plans under uncertainty and being enabled to select different potential outcomes of performance and efficiency based on limited resource criteria as well as personal risk utility.

2. Improved decision making regarding allocating resources over each project as well as sharing resources among corporate network. This research enables managers to be aware of their realistic choices of resource planning, choose among optimum solutions that satisfy their time, cost and profit margin, obtain what if scenarios regarding their different sets of decisions and finally understand reliability of decisions based on their risk attitude.

3. Making more reliable decisions on whether to expand their network of projects (to go or not to go for a bid). This research enables corporate decision makers to make 
more realistic estimates and make more reliable decision for profitability of their company, and understand consequences of their decisions in short and long term based on what if scenarios.

\subsection{Recommendation for Future Research}

The following contributions are recommended for future research based on limitations of the current study:

1. Obtaining more accurate data regarding risk utility of project managers in order to improve reliability of decisions. Using risk utility of managers to model the construction network required accurate surveying and sensitivity analysis since it is a subjective area for decision making. Future research would benefit from comprehensive observation of decision behavior project managers to study reliability of their choices with regards to their confidence toward resource performance, their expertise and their experience, as well as work type and job situation.

2. Considering more complete criteria for making models and results: the current research considers limited types of uncertainties, limited types of resources and their caps, and also limited resource utilization planning scenarios in order to develop models and tradeoffs. Future research would benefit from using more extensive resource usage scenarios as well as detailed uncertainty categorization to create more useful and accurate decision support material. 
3. Considering more criteria for making decisions regarding expansion of corporate network (going for bid and adding new projects) other than just profitability and amount of short term cashable assets (liquidity). This includes, but not limits to, market competitiveness analysis, job type categorization, creditability of the contractor in market, job location and situation, etc.

4. Considering different types of contractors: the current research only considers Deign-Bid-Build contractors in order to provide decision making support material. Future research would benefit from consideration of different types of contractors, such as Design-Builders, to enable all type of contractors make reliable and more improved decisions regarding their corporate outcomes. This would especially benefit construction industry of South Florida since number of heavy infrastructure projects is going up rapidly.

5. Ideally future research would highly benefit from development of models that integrate perspective of contractors and owners on decision making in order to provide the industry with more realistic and useful decision support material. This would definitely benefit (1) owners with lots of cost saving and a better perspective on contractors and their abilities, (2) contractors with more reliable profit and also better perspective on the market, and (3) public with less public cost and more saved time.

6. In this research, uncertainties are modeled in construction processes as random based changes in production rate of resources and crews. Future research would highly benefit from adopting more realistic productivity change patterns under 
uncertainties, such as using learning and forgetting patterns. This would result in higher reliability on outcomes since it is proved that construction crew follow certain patterns when they work on a project for a long time as well as when they start working on new projects.

7. As a continue to this study, future research would adopt advanced procedures to model risk utility of decision makers in order be able to suggest specific project managers for new acquired projects. It means that by knowing confidence level and risk tendencies of their available project managers and based on work type and situation of newly added jobs, enterprise leaders may assign PMs to job that bring more value and higher reliability to the network. 


\section{REFERENCES AND FURTHER READINGS}

\section{Resource Utilization Under Uncertainty}

Barraza, G. 2011. Probabilistic Estimation and Allocation of Project Time Contingency. Journal of Construction Engineering and Management, ASCE, 137(4): 259-265.

Chen, S., Griffis, F.H., Chen, P., and Chang, L. 2012. Simulation and analytical techniques for construction resource planning and scheduling. Automation in Construction, 21: 99113

Feng, C., Liu, L., and Burns, S. 2000. Stochastic Construction Time-Cost Trade-Off Analysis. Journal of Computing in Civil Engineering, ASCE, 14(2): 117-126.

Hong, T., Cho, K., Hyun, C., and Han, S. 2011. Simulation-Based Schedule Estimation Model for ACS-Based Core Wall Construction of High-Rise Building. Journal of Construction Engineering and Management, ASCE, 137(6): 393-402.

Isidore, L. and Back, W. 2001. Probabilistic Optimal-Cost Scheduling. Journal of Construction Engineering and Management, ASCE, 127(6): 431-437.

Isidore, L. and Back, W. 2002. Multiple Simulation Analysis for Probabilistic Cost and Schedule Integration. Journal of Construction Engineering and Management, ASCE, 128(3): 211-219.

Khamooshi, H. and Cioffi, D. (2012). Uncertainty in Task-Duration and Cost Estimates: A Fusion of Probabilistic Forecasts and Deterministic Scheduling. Journal of Construction Engineering and Management, ASCE, In press. 
Lee, D. 2005. Probability of Project Completion Using Stochastic Project Scheduling Simulation. Journal of Construction Engineering and Management, ASCE, 131(3): 310318.

Lee, D. and Arditi, D. 2006. Automated Statistical Analysis in Stochastic Project Scheduling Simulation. Journal of Construction Engineering and Management, ASCE, 132(3): 268-277.

Lee, H., Shin, J., Park, M., and Ryu, H. 2009. Probabilistic Duration Estimation Model for High-Rise Structural Work. Journal of Construction Engineering and Management, ASCE, 135(12): 1289-1298.

Lee, D., Yi, C., Lim, T., and Arditi, D. 2010. Integrated Simulation System for Construction Operation and Project Scheduling. Journal of Computing in Civil Engineering, ASCE, 24(6): 557-569.

Ökmen, Ö. and Öztaş, A. 2008. Construction Project Network Evaluation with Correlated Schedule Risk Analysis Model. Journal of Construction Engineering and Management, ASCE, 134(1): 49-63.

Peña-Mora, F., Han, S., Lee, S., and Park, M. 2008. Strategic-Operational Construction Management: Hybrid System Dynamics and Discrete Event Approach. Journal of Construction Engineering and Management, ASCE, 134(9): 701-710.

Sadeghi, N., Robinson Fayek, A. and Ingolfsson, A. 2011. Simulation-based approach for estimating project completion time of stochastic resource-constrained project networks, ASCE, Journal of Computing in Civil Engineering, 26(4): 558-560.

Taghaddos, H., AbouRizk, S., Mohamed, Y., and Hermann, U. 2012. Simulation-Based Auction Protocol for Resource Scheduling Problems. Journal of Construction Engineering and Management, ASCE, 138(1): 31-42.

Vaziri, K., Carr, P., and Nozick, L. 2007. Project Planning for Construction under Uncertainty with Limited Resources. Journal of Construction Engineering and Management, ASCE, 133(4): 268-276.

Zhang, H. and Li, H. 2004. Simulation-based optimization for dynamic resource allocation. Automation in Construction, 13(3): 409-420. 


\section{Multi-Project Resource Planning Under Uncertainty}

Barraza, G. A. (2010). "Probabilistic estimation and allocation of project time contingency." J.Constr.Eng.Manage., 137(4), 259-265.

Chen, S., Chen, P., and Chang, L. (2012). "Simulation and analytical techniques for construction resource planning and scheduling." Autom.Constr., 21 99-113.

Deb, K., Agrawal, S., Pratap, A., and Meyarivan, T. (2000). "A fast elitist non-dominated sorting genetic algorithm for multi-objective optimization: NSGA-II." Lecture Notes in Computer Science, 1917 849-858.

Feng, C., Liu, L., and Burns, S. A. (2000). "Stochastic construction time-cost trade-off analysis." J.Comput.Civ.Eng., 14(2), 117-126.

Gabriel, S. A., Ordóñez, J. F., and Faria, J. A. (2006). "Contingency planning in project selection using multiobjective optimization and chance constraints." J Infrastruct Syst, 12(2), 112-120.

Heravi, G., and Faeghi, S. (2012). "Group Decision Making for Stochastic Optimization of Time, Cost, and Quality in Construction Projects." J.Comput.Civ.Eng., 28(2), 275-283.

Hong, T., Cho, K., Hyun, C., and Han, S. (2011). "Simulation-based schedule estimation model for ACS-based core wall construction of high-rise building." J.Constr.Eng.Manage., 137(6), 393-402.

Isidore, L. J., and Back, W. E. (2002). "Multiple simulation analysis for probabilistic cost and schedule integration." J.Constr.Eng.Manage., 128(3), 211-219.

Isidore, L. J., and Back, W. E. (2001). "Probabilistic optimal-cost scheduling." J.Constr.Eng.Manage., 127(6), 431-437.

Khamooshi, H., and Cioffi, D. F. (2012). "Uncertainty in task duration and cost estimates: Fusion of probabilistic forecasts and deterministic scheduling." J.Constr.Eng.Manage., 139(5), 488-497. 
Lee, D. (2005). "Probability of project completion using stochastic project scheduling simulation." J.Constr.Eng.Manage., 131(3), 310-318.

Lee, D., and Arditi, D. (2006). "Automated statistical analysis in stochastic project scheduling simulation." J.Constr.Eng.Manage., 132(3), 268-277.

Lee, D., Yi, C., Lim, T., and Arditi, D. (2010). "Integrated simulation system for construction operation and project scheduling." J.Comput.Civ.Eng., 24(6), 557-569.

Lee, H., Shin, J., Park, M., and Ryu, H. (2009). "Probabilistic duration estimation model for high-rise structural work." J.Constr.Eng.Manage., 135(12), 1289-1298.

Ökmen, Ö, and Öztaş, A. (2008). "Construction project network evaluation with correlated schedule risk analysis model." J.Constr.Eng.Manage., 134(1), 49-63.

Orabi, W., Senouci, A. B., El-Rayes, K., and Al-Derham, H. (2010). "Optimizing resource utilization during the recovery of civil infrastructure systems." J.Manage.Eng., 26(4), 237246.

Orabi, W., Sheykhi, R., and El-Anwar, O. (2013). "Using Probabilistic Crew Production Rate to Simulate Schedule-Related Risks in Construction Projects." CSCE 4th Construction Specialty Conference, CON-048-1.

Peña-Mora, F., Han, S., Lee, S., and Park, M. (2008). "Strategic-operational construction management: Hybrid system dynamics and discrete event approach." J.Constr.Eng.Manage., 134(9), 701-710.

Puri, V., and Martinez, J. C. (2012). "Modeling of simultaneously continuous and stochastic construction activities for simulation." J.Constr.Eng.Manage., 139(8), 10371045.

Sadeghi, N., Fayek, A. R., and Ingolfsson, A. (2012). "Simulation-Based Approach for Estimating Project Completion Time of Stochastic Resource-Constrained Project Networks." J.Comput.Civ.Eng., 26(4), 558-560.

Shahin, A., AbouRizk, S., and Mohamed, Y. (2010). "Modeling weather-sensitive construction activity using simulation." J.Constr.Eng.Manage., 137(3), 238-246. 
Taghaddos, H., AbouRizk, S., Mohamed, Y., and Hermann, U. (2011). "Simulation-based auction protocol for resource scheduling problems." J.Constr.Eng.Manage., 138(1), 31-42.

Vaziri, K., Carr, P. G., and Nozick, L. K. (2007). "Project planning for construction under uncertainty with limited resources." J.Constr.Eng.Manage., 133(4), 268-276.

Zhang, H., and Li, H. (2004). "Simulation-based optimization for dynamic resource allocation." Autom.Constr., 13(3), 409-420.

\section{Corporate Level Resource and Profitability Management}

Ahn, C., Peña-Mora, F., Lee, S., and Arboleda, C. A. (2012). "Consideration of the environmental cost in construction contracting for public works: A C and A B C bidding methods." J.Manage.Eng., 29(1), 86-94.

Aziz, R. F. (2013). "Optimizing strategy for repetitive construction projects within multimode resources." Alexandria Engineering Journal, 52(1), 67-81.

Barraza, G. A. (2010). "Probabilistic estimation and allocation of project time contingency." J.Constr.Eng.Manage., 137(4), 259-265.

Castro-Lacouture, D., Süer, G. A., Gonzalez-Joaqui, J., and Yates, J. (2009). "Construction project scheduling with time, cost, and material restrictions using fuzzy mathematical models and critical path method." J.Constr.Eng.Manage., .

Chen, S., Chen, P., and Chang, L. (2012). "Simulation and analytical techniques for construction resource planning and scheduling." Autom.Constr., 21 99-113.

Construction Industry Institute (CII). (2012). "Performance Assessment 2012 Edition." CII, Austin, TX, USA.

Construction Industry Institute (CII). (2014). "Performance Assessment 2014 Edition." CII, Austin, TX, USA.

De Wit, A. (1988). "Measurement of project success." Int.J.Project Manage., 6(3), 164170. 
Elazouni, A., and Abido, M. (2014). "Enhanced Trade-Off of Construction Projects: Finance-Resource-Profit." J.Constr.Eng.Manage., 140(9), 04014043.

Feng, C., Liu, L., and Burns, S. A. (2000). "Stochastic construction time-cost trade-off analysis." J.Comput.Civ.Eng., 14(2), 117-126.

Flyvbjerg, B., Holm, M. S., and Buhl, S. (2002). "Underestimating costs in public works projects: Error or lie?" Journal of the American Planning Association, 68(3), 279-295.

Gabriel, S. A., Ordóñez, J. F., and Faria, J. A. (2006). "Contingency planning in project selection using multiobjective optimization and chance constraints." J Infrastruct Syst, 12(2), 112-120.

Han, S. H., Diekmann, J. E., and Ock, J. H. (2005). "Contractor's risk attitudes in the selection of international construction projects." J.Constr.Eng.Manage., 131(3), 283-292.

Heravi, G., and Faeghi, S. (2012). "Group Decision Making for Stochastic Optimization of Time, Cost, and Quality in Construction Projects." J.Comput.Civ.Eng., 28(2), 275-283.

Hong, T., Cho, K., Hyun, C., and Han, S. (2011). "Simulation-based schedule estimation model for ACS-based core wall construction of high-rise building." J.Constr.Eng.Manage., 137(6), 393-402.

Isidore, L. J., and Back, W. E. (2002). "Multiple simulation analysis for probabilistic cost and schedule integration." J.Constr.Eng.Manage., 128(3), 211-219.

Kim, H., and Reinschmidt, K. F. (2010). "Effects of contractors' risk attitude on competition in construction." J.Constr.Eng.Manage., 137(4), 275-283.

Lee, D. (2005). "Probability of project completion using stochastic project scheduling simulation." J.Constr.Eng.Manage., 131(3), 310-318.

Lee, D., and Arditi, D. (2006). "Automated statistical analysis in stochastic project scheduling simulation." J.Constr.Eng.Manage., 132(3), 268-277.

Lee, H., Shin, J., Park, M., and Ryu, H. (2009). "Probabilistic duration estimation model for high-rise structural work." J.Constr.Eng.Manage., 135(12), 1289-1298. 
Liu, S., and Wang, C. (2010). "Profit optimization for multiproject scheduling problems considering cash flow." J.Constr.Eng.Manage., 136(12), 1268-1278.

Lova, A., and Tormos, P. (2001). "Analysis of scheduling schemes and heuristic rules performance in resource-constrained multiproject scheduling." Annals of Operations Research, 102(1-4), 263-286.

Love, P. E., Davis, P. R., Chevis, R., and Edwards, D. J. (2010). "Risk/reward compensation model for civil engineering infrastructure alliance projects." J.Constr.Eng.Manage., 137(2), 127-136.

Ökmen, Ö, and Öztaş, A. (2008). "Construction project network evaluation with correlated schedule risk analysis model." J.Constr.Eng.Manage., 134(1), 49-63.

Orabi, W., Senouci, A. B., El-Rayes, K., and Al-Derham, H. (2010). "Optimizing resource utilization during the recovery of civil infrastructure systems." J.Manage.Eng., 26(4), 237246.

Orabi, W., Sheykhi, R., and El-Anwar, O. (2013). "Using Probabilistic Crew Production Rate to Simulate Schedule-Related Risks in Construction Projects." CSCE 4th Construction Specialty Conference, CON-048-1.

Ozcan-Deniz, G., Zhu, Y., and Ceron, V. (2011). "Time, cost, and environmental impact analysis on construction operation optimization using genetic algorithms." J.Manage.Eng., 28(3), 265-272.

Park, M., Kim, W., Yoon, Y., and Nepal, M. P. (2010). "Scheduling decisions and their dynamic consequences on construction performance." KSCE Journal of Civil Engineering, 14(3), 251-259.

Payne, J. H. (1995). "Management of multiple simultaneous projects: a state-of-the-art review." Int.J.Project Manage., 13(3), 163-168.

Peña-Mora, F., Han, S., Lee, S., and Park, M. (2008). "Strategic-operational construction management: Hybrid system dynamics and discrete event approach." J.Constr.Eng.Manage., 134(9), 701-710. 
Puri, V., and Martinez, J. C. (2012). "Modeling of simultaneously continuous and stochastic construction activities for simulation." J.Constr.Eng.Manage., 139(8), 10371045.

Senouci, A., and El-Rayes, K. (2009). "Time-profit trade-off analysis for construction projects." J.Constr.Eng.Manage., 135(8), 718-725.

Shahin, A., AbouRizk, S., and Mohamed, Y. (2010). "Modeling weather-sensitive construction activity using simulation." J.Constr.Eng.Manage., 137(3), 238-246.

Shrestha, P. P., Burns, L. A., and Shields, D. R. (2013). "Magnitude of construction cost and schedule overruns in public work projects." Journal of Construction Engineering, 2013.

Taghaddos, H., AbouRizk, S., Mohamed, Y., and Hermann, U. (2011). "Simulation-based auction protocol for resource scheduling problems." J.Constr.Eng.Manage., 138(1), 31-42.

Touran, A. (2009). "Probabilistic approach for budgeting in portfolio of projects." J.Constr.Eng.Manage., 136(3), 361-366.

Vaziri, K., Carr, P. G., and Nozick, L. K. (2007). "Project planning for construction under uncertainty with limited resources." J.Constr.Eng.Manage., 133(4), 268-276.

Zhang, H., and Li, H. (2004). "Simulation-based optimization for dynamic resource allocation." Autom.Constr., 13(3), 409-420. 


\section{Publications and Presentations based on the Current Research}

\section{Journal Papers}

R. Sheykhi and W. Orabi, "Risk Based Decision Support for Construction Corporate Resource management", Ongoing to be submitted to Journal of Construction Engineering and Management, ASCE.

R. Sheykhi and W. Orabi, "Resource Utilization Decision Making Through Modeling the Daily-Changing Nature of Uncertainties", Ongoing to be submitted to Journal of Construction Engineering and Management, ASCE.

\section{Conference Papers}

R. Sheykhi and W. Orabi, (2016), "A Framework for Investigating the Impact of Planners' Risk Tendency on Optimal Project Completion Outcomes", Proceedings of the Construction Research Congress 2016, Puerto Rico.

W. Orabi and R. Sheykhi, (2013), "Using Probabilistic Crew Production Rate to Simulate Schedule-Related Risks in Construction Projects", Proc. of the Canadian Society of Civil Engineers Conf. 2013, Montreal, Canada.

\section{Oral and Poster Presentations}

R. Sheykhi and W. Orabi, (2014), "Optimizing Resource Utilization of Construction Project Portfolios under Uncertainty", Poster Presentation at Construction Industry Institute (CII) Conference, Indianapolis, IN.

R. Sheykhi and W. Orabi, (2014), "Resource Utilization Optimization under Uncertainty", Poster Presentation at Construction Research Congress (CRC), Atlanta, GA.

R. Sheykhi and W. Orabi, (2014), "Optimum Resource Planning Solutions in Construction", Poster Presentation at FIU Annual Graduate Scholarly Forum (GSAW), Miami, FL.

R. Sheykhi and W. Orabi, (2014), "Uncertainty Modeling in Construction Projects to Obtain Optimum Resource Management Scenarios", Poster Presentation at FIU Civil Engineering Graduate Research Day, Miami, FL. 
VITA

\section{REZA SHEYKHI}

2003-2008

2008-2011

2009-2011

2009-2011

2010-2011

2012-2016

2012-2016

2016

2016

2016

2016
B.Sc., Civil Engineering

University of Tehran

Tehran, Iran

M.Sc., Construction Engineering, and Management University of Tehran

Tehran, Iran

Assistant Director of Research and Development Boland Payeh Construction Company

Tehran, Iran

Assistant to Project Manager

Boland Payeh Construction Company

Tehran, Iran

Graduate Teaching Assistant

University of Tehran

Tehran, Iran

Ph.D., Civil and Environmental Engineering Florida International University

Miami, FL, USA

Graduate Teaching Assistant

Florida International University

Miami, FL, USA

FIU Graduate Student Leader of the Year Outstanding Student Life Awards

Florida State Graduate Student of the Year ASCE FIA Section Annual Awards

Miami-Dade Graduate Student of the Year ASCE Miami Branch Awards

Miami-Dade Annual Scholarship Winner ASCE Miami Branch Scholarships 


\section{PUBLICATIONS AND PRESENTATIONS}

R. Sheykhi and W. Orabi, (2016), "A Framework for Investigating the Impact of Planners' Risk Tendency on Optimal Project Completion Outcomes", Proceedings of the Construction Research Congress 2016, Puerto Rico.

R. Sheykhi and W. Orabi, (2014), "Evaluating the Impact of Resource Utilization Decisions on Energy Consmption in Construction Projects", Proceedings of the Construction Research Congress 2014, Atlanta, GA.

W. Orabi and R. Sheykhi, (2013), "Using Probabilistic Crew Production Rate to Simulate Schedule-Related Risks in Construction Projects", Proc. Of the Canadian Society of Civil Engineers Conf. 2013, Montreal, Canada.

A. A. Najafi, M. Fereydooni, A. Sadeghi and R. Sheykhi, (2012), "Value Engineering in Design and Construction of Water Shafts in Hydropower Dams", Proceedings of the $1^{\text {st }}$ International Conference of Dams and Hydropower (ICDHP2012), Tehran, Iran.

R. Sheykhi and B. Zahraie, (2011), "Resource Leveling in Construction Projects Considering Activity Splitting", Proceedings of the Sixth National Conference of Civil Engineering (6NCCE2011), Semnan, Iran.

Book Chapter: R. Sheykhi, (2011), "Concrete Pylon Construction Methods" from the book: "Lali Cable-Stayed Bridge Construction Methods" written as a group effort in Boland Payeh Construction Co.

Book Chapter: R. Sheyki, (2011), "Metal Deck Construction and Installation Methods" from the book: "Lali Cable-Stayed Bridge Construction Methods" written as a group effort in Boland Payeh Construction Co.

R. Sheykhi and W. Orabi, (2014), "Optimizing Resource Utilization of Construction Project Portfolios under Uncertainty", Poster Presentation at Construction Industry Institute (CII) Conference, Indianapolis, IN.

R. Sheykhi and W. Orabi, (2014), "Evaluating the Impact of Resource Utilization Decisions on Energy Consumption in Construction", Oral Presentation at Construction Research Congress (CRC), Atlanta, GA.

R. Sheykhi and W. Orabi, (2014), "Research Utilization Optimization under Uncertainty", Poster Presentation at Construction Research Congress (CRC), Atlanta, GA. 